\title{
"Whatever it takes" to resolve the European sovereign debt crisis? Bond pricing regime switches and monetary policy effects
}

\author{
António Afonso ${ }^{\$}$, Michael G. Arghyrou\#, María Dolores Gadea ${ }^{+}$, \\ Alexandros Kontonikas ${ }^{ \pm}$
}

April 2018

\begin{abstract}
This paper investigates the role of unconventional monetary policy as a source of time-variation in the relationship between sovereign bond yield spreads and their fundamental determinants. We use a two-step empirical approach. First, we apply a time-varying parameter panel modelling framework to determine shifts in the pricing regime characterising sovereign bond markets in the euro area over the period January 1999 to July 2016. Second, we estimate the impact of ECB policy interventions on the time-varying risk factor sensitivities of spreads. Our results provide evidence of a new bond-pricing regime following the announcement of the Outright Monetary Transactions (OMT) programme in August 2012. This regime is characterised by a weakened link between spreads and fundamentals, but with higher spreads relative to the pre-crisis period and residual redenomination risk. We also find that unconventional monetary policy measures affect the pricing of sovereign risk not only directly, but also indirectly through changes in banking risk. Overall, the actions of the ECB have operated as catalysts for reversing the dynamics of the European sovereign debt crisis.
\end{abstract}

JEL: E43, E44, F30, G01, G12

Keywords: euro area, spreads, crisis, time-varying relationship, unconventional monetary policy

\footnotetext{
\$ISEG-UL - Universidade de Lisboa; REM - Research in Economics and Mathematics, UECE - Research Unit on Complexity and Economics. email: aafonso@iseg.utl.pt

\# Corresponding Author: Cardiff Business School, Cardiff University, Colum Drive, Cardiff, CF10 3EU, UK, email: arghyroum@cardiff.ac.uk

+ Department of Applied Economics, University of Zaragoza, Gran Via, 4, 50005 Zaragoza, Spain, email: lgadea@unizar.es

${ }^{ \pm}$Essex Business School, University of Essex, Colchester Campus, Wivenhoe Park, Colchester, CO4 3SQ, email: a.kontonikas@essex.ac.uk
}

\section{Acknowledgements}

We thankfully acknowledge financial support by FCT (Fundação para a Ciência e a Tecnologia, Portugal). FCT had no involvement in the study design, collection, analysis and interpretation of data, writing and submission of this research paper. M. Dolores Gadea acknowledges financial support from the Ministerio de Ciencia y Tecnologia, Spain, under grant ECO2011-30260-C03-02. We are grateful to two anonymous referees for their very useful comments and suggestions. We thank participants at the 6th UECE Conference on Economic and Financial Adjustments, 2017 (Lisbon) for very useful comments, and we are grateful to Mina Kazemi for valuable research assistance. The opinions expressed herein are those of the authors and do not necessarily reflect those of the authors' employers. 


\section{Introduction}

The European sovereign debt crisis has dominated the international economic debate in recent years. It has posed an existential threat for the European Economic and Monetary Union (EMU), largely monopolised the agenda of policy makers and triggered a vast academic literature on the subject. Within the latter, one may distinguish four related but distinct branches. First, theoretical models of the EMU crisis highlighting the role of changes in market expectations as a key driver of the crisis' evolution (Arghyrou and Tsoukalas, 2011; De Grauwe and Ji, 2013). Second, empirical studies investigating the fundamental determinants of EMU long-term government bond yield spreads against Germany. These document significant time-variation in the relationship, specifically a shift from a pre-crisis to a crisis-related bond pricing regime (Arghyrou and Kontonikas, 2012; Bernoth and Erdogan, 2012, Afonso et al. 2014, 2015). Third, the role of banking risk in transforming the global financial crisis of 2008/09 into the sovereign debt crisis, and the nexus between banking risk and sovereign risk (Alter and Schüler, 2012; De Bruyckere et al., 2013; Acharya et al., 2014). Finally, a fourth branch investigates the effectiveness of unconventional monetary policy actions by the European Central Bank (ECB) to stabilise sovereign bond markets. Most of these studies analyse the Security Markets Programme (SMP) and the effect of the Outright Monetary Transactions (OMT) announcement, while a few more recent papers consider the ECB's Quantitative Easing (QE) programme. ${ }^{1}$ They typically find that the ECB policy interventions are associated with lower spreads without, however, identifying the channels via which they affect spreads. ${ }^{2}$

\footnotetext{
1 The SMP commenced on May 2010 and involved the purchase of sovereign bonds from euro area periphery countries (Greece, Ireland, Italy, Portugal and Spain) during 2010-2011. For studies on the impact of SMP on spreads see, among others, Eser and Schwaab (2013), Ghysels et al. (2014) and Trebesch and Zettelmeyer (2014). The OMT was announced on 2 August 2012, following the statement by President Draghi on 26 July 2012 that the "ECB is ready to do whatever it takes to preserve the euro". The technical framework for the OMT was revealed on 6 September 2012 and on the same date the SMP was terminated. Altavilla et al. (2014) evaluate the reaction of spreads to the OMT announcement, while Krishnamurthy et al. (2015), Szczerbowicz (2015) and Gibson et al. (2016) examine both the SMP and the OMT. The QE programme was announced in January 2015 and is effective since March 2015. It involves the monthly purchase of euro area sovereign bonds, as well as other assets. The impact of QE on spreads is analysed in Altavilla et al. (2015) and De Santis (2016).

${ }^{2}$ An exception is the study of Krishnamurthy et al. (2015), who decompose the policy impact on sovereign yields into effects via default risk, market segmentation and redenomination risk. They find that default risk and market
} 
This paper brings together multiple branches of the literature on the European debt crisis by investigating the hypothesis that the relationship linking spreads with fundamentals is affected by the behaviour of the ECB. In other words, we posit that policy interventions may alter the underlying bond pricing regime. This hypothesis reflects notably the insights from the theoretical models of the European sovereign debt crisis quoted above. The key prediction of these models relates to the possibility of multiple equilibria in the relationship between spreads and fundamentals. Drawing on models of currency crises (e.g. Obstfeld, 1986, 1996), they predict that the variable determining which of the possible multiple equilibria will eventually prevail is the status of redenomination/default expectations held by the private sector. Under favourable expectations, markets impose small penalties on risk factors, determining spreads at relatively low levels. An adverse shift in expectations results into higher penalties on risk factors and relatively high spread values. The ECB, through its actions and a conditional guarantee that it is ready to operate as a lender of last resort (LLR), can improve expectations and thereby generate a shift in bond pricing behaviour.

To explore this hypothesis, we adopt a two-step empirical approach. Fist, we employ a timevarying parameter (TVP) panel econometric methodology to capture changes in the relationship between 10-year sovereign bond yield spreads against Germany and their fundamental determinants (global financial risk, liquidity risk and credit risk). We present results for a panel of ten EMU countries over the period January 1999 to July 2016, as well as its core and periphery countries constituent sub-panels. This part of our analysis extends previous research on the timevarying relationship between spreads and fundamentals, whose samples typically end in 2010/11, into the period following the announcement of the OMT and Quantitative Easing (QE) programmes. The evolution of the TVP estimates obtained for the EMU panels allows us, in combination with results obtained for a non-EMU control panel, to shed light on the validity of

\footnotetext{
segmentation are the dominant channels through which the SMP and OMT worked in Italy and Spain, while
} redenomination risk may have been a policy channel in Spain and Portugal. 
the multiple equilibria view of the European sovereign debt crisis vis-à-vis alternative explanations of the crisis, such as the wake-up call hypothesis (Goldstein, 1998; Beirne and Fratzscher, 2013; Bekaert et al., 2014); and changes in the market's assessment regarding future macroeconomic convergence/divergence (Aizenman et al., 2013). Second, we model the series of TVP coefficients estimated for each of the spreads' determinants on a dummy variable capturing the effects of the OMT announcement and empirical measures of ECB monetary policy (conventional and unconventional). Moreover, we control for the effects of bank credit risk in the euro area.

With regards the determinants of spreads, we confirm the main finding of previous studies and extend them with a significant new one. Specifically, we document a change in the EMU bond-pricing regime from risk under-pricing before the global financial crisis, where the sensitivity of spreads to fundamentals is zero or near zero, to a regime involving increasingly larger penalties on risk factors and very high spreads. ${ }^{3}$ In addition to these two regimes, however, we identify a third pricing regime, triggered by the announcement of the OMT in August 2012 and characterised by a weakening of the link between spreads and their underlying fundamentals. This regime-shift has not been reported in previous studies, except from Delatte et al. (2017) who conclude that it represents a restoration of the first (pre-crisis/non-crisis) regime, driven by a decline in bank credit risk. We argue, however, that the third regime is new and different from the first one, with the main distinguishing factors being higher spreads relative to the pre-crisis era and a residual redenomination risk in periphery countries, carried over from the second (crisis) regime.

\footnotetext{
${ }^{3}$ Earlier studies typically document the switch from a pre-crisis to a crisis-related bond pricing regime using fixedparameter models and imposing exogenous break points on the data. These include Barrios et al. (2009), Arghyrou and Kontonikas (2012), Caggiano and Greco (2012). Another strand of the literature identifies the regime shift using time-varying coefficients models and endogenously determined structural breaks. Such studies include work by Aßmann and Boysen-Hogrefe (2012), Bernoth and Erdogan (2012), Constantini et al. (2014), D'Agostino and Ehrmann (2014), Afonso et al. (2015), Paniagua et al. (2016) and Delatte et al. (2017).
} 
The second part of our analysis provides evidence that the transition from the second regime to the third is determined by factors relating to monetary policy, especially unconventional interventions. Specifically, we find that the OMT announcement reduced the responsiveness of spreads to their fundamental determinants. Expansions in the ECB balance sheet due to the SMP and QE programmes, also had a similar effect. Finally, we show that the impact of monetary policy on the relationship between spreads and fundamentals can materialise not only directly but also indirectly through reductions in bank credit risk. This is because banking risk affects the sensitivity of spreads to fundamentals, but at the same time is highly driven by unconventional monetary policy actions.

Our findings are in line with the predictions of theoretical models of the European debt crisis and are intuitively appealing. They suggest that by providing markets with a conditional guarantee that it stands ready to act as an LLR, the ECB managed to improve expectations causing a shift away from the "bad" equilibrium prevailing during the crisis. The direct effect suggests that the OMT and purchases of sovereign bonds in the secondary market reassured investors that the ECB stands ready to prevent the collapse of sovereign bond markets due to existing fiscal liabilities. The indirect effect hints that the ECB reassured markets that sovereigns will not be called upon to finance unsustainable contingent fiscal liabilities originating from extensive bank losses.

Overall, our work is related to several strands of the literature on the European debt crisis and contributes to it in numerous ways. First, it validates the predictions of multiple equilibria models of the EMU debt crisis. Second, it presents evidence of a new bond-pricing regime following the announcement of OMT, which is different both to the pre-crisis as well as the crisis pricing regimes reported in previous literature. Third, it identifies a two-fold channel, direct and indirect, via which the ECB has stabilised euro area sovereign bond markets. Our paper's main take-home message is that President Draghi's speech on 26 July 2012 announcing the 
introduction of OMT was a game-changer for the resolution of the crisis. The expansion of the ECB's balance sheet provided extra stimulus towards that direction.

The remainder of this paper is structured as follows: Sections 2 and 3 respectively discuss our econometric methodology and data. Sections 4 and 5 presents our empirical findings. Specifically, section 4 estimates and discusses TVP panel models capturing the changing relationship between spreads and fundamentals, while section 5 investigates the factors that affect the TVP coefficients. Finally, section 6 summarises and offers concluding remarks.

\section{Theoretical background and methodology}

Our empirical analysis is directly linked to the theoretical models of the European debt crisis by Arghyrou and Tsoukalas (2011) and De Grauwe and Ji (2013). In these models the decision of authorities to default and/or exit the eurozone is modelled as a rational choice, determined by comparing the costs/benefits of the two policy options. Crucially, the location of the cost/benefit function applying to non-default/euro-exit is endogenous to the state of market expectations/perceptions regarding the occurrence of such events. In line with the currency-crisis literature (see Obstfeld 1986, 1996), shifts in these probabilities result in multiple equilibria, where the same level of macro-imbalances results in different sovereign borrowing cost levels. This allows for self-fulfilling fiscal defaults and/or euro-exit, caused by exogenous changes in the latter's perceived probabilities. Hence, the models predict a time-varying relationship between borrowing costs and fundamentals, determined by the time evolution of the probabilities perceived by markets regarding default and/or euro-exits.

A TVP panel estimation framework modelling spreads on their underlying risk factors is well-suited to test this hypothesis. Specifically, in periods of increased (reduced) default/eurobreak up probabilities we should observe relatively high (low) TVP risk-factor coefficients. Importantly, the TVP framework captures the effect of shifting default/euro-exit probabilities triggered by multiple sources, including spill-over/contagion effects and banking crises (Obstfeld 
1996); increased noise trading caused by herding behavior (Jeanne and Rose, 2002), and sentiment shocks combined with the absence of a LLR (De Grauwe and Ji, 2013). These contributions predict multiple equilibria due to strategic interaction among market participants, allowing for runs on assets not only because investors assess assets to be less valuable (fundamentals-based runs), but also because they expect other investors to run on the asset (nonfundamentals-based runs). The latter raises the possibility of sunspot events (i.e., events that are irrelevant for the fundamental valuation of the asset) triggering a market overreaction and coordinating investor expectations in a different equilibrium, without a corresponding change in the levels of fundamental risk factors. ${ }^{4}$ In the context of European sovereign bond markets, changes in bonds valuations due to multiple equilibria will be reflected in changes in the estimated TVP coefficients of the spreads' underlying risk factors.

Nevertheless, such changes can also be caused by fundamental-based factors relating to the European sovereign bond markets, including the wake-up call hypothesis (Goldstein, 1998; Beirne and Fratzscher, 2013; Bekaert et al., 2014); and changes in the market's assessment regarding future macroeconomic convergence/divergence (Aizenman et al., 2013). It is empirically difficult to differentiate shifts in TVP coefficients caused by fundamentals versus non-fundamental factors. Having said that, the multiple-equilibria models mentioned above have a simple empirical prediction: the price of an asset is more prone to equilibrium indeterminacy under conditions of limited market liquidity. This allows us to differentiate the existence of multiple-equilibria from other alternative channels affecting spreads' sensitivity to risk factors via two identification strategies:

The first is time-series evidence relating to the values of the estimated risk-factor TVP coefficients for the EMU panel. Discrete major events, such as the announcement of the OMT

\footnotetext{
${ }^{4}$ This is the essence of the difference between first (Krugman, 1979) and second generation (Obstfeld, 1986) models of currency crises as well as the closely related literature on self-fulfilling bank runs (Diamond and Dybvig, 1983) and sudden stops on sovereign debt (Calvo, 1988).
} 
programme, create a quasi-experimental setting to determine whether changes in the sensitivities of spreads to risk factors are due to the processing of new fundamentals-related information (i.e., wake-up calls or changes of expectations on future fundamentals) or simply due to the amelioration of investors' strategic concerns caused by the absence of an LLR in EMU sovereign debt markets. To the extent that the OMT announcement is found to ease the overreaction problems in the market, we can infer that market behaviour up to that point could be attributed, at least partly, to the self-fulfilling strategic interactions among investors, consistent with the multiple-equilibria interpretation of the EMU crisis.

Second, cross-section evidence distinguishing between EMU and non-EMU panels. If the spreads of eurozone countries (for which an LLR was completely absent prior to 2012) are more sensitive to risk factors relative to non-euro countries, (whose independent monetary policy implies the existence of an LLR throughout the EMU crisis), the implication would be that eurozone countries issuing debt in a common currency are more prone to self-fulfilling dynamics, since they cannot control the liquidity of their sovereign bond markets. Combined with the time series evidence described above, such a finding would support the multiple-equilibria explanation of the EMU crisis relative to alternative fundamentals-based channels.

Based on the above, we adopt a two-step empirical approach, where the asset's sensitivity to risk factors, identified in the first step, is conditioned upon a set of explanatory variables in the second step. Studies employing a similar two-step approach include Manasse and Zavalloni (2013), and Bekaert et al. (2014). More specifically, in the first stage of our analysis, we model government bond yield spreads against Germany using a TVP panel specification, estimated for the euro area, as well as for a panel of European countries not participating to the euro. Given Greece's idiosyncratic characteristics, in the baseline estimates, we present results for the euro area panel excluding and including this country. ${ }^{5}$ Following Li et al. (2011) and Bernoth and

\footnotetext{
${ }^{5}$ Unlike the rest of our sample countries, Greece joined the euro in 2001 rather than 1999. Furthermore, since July 2015 Greece has in place capital controls, designed to stabilise the Greek banking system following large deposits
} 
Erdogan (2012), we estimate the following TVP specification, which forms the baseline model of our analysis:

$$
y_{i t}=x_{i t}^{\prime} \beta_{t}+\alpha_{\iota}+f_{t}+v_{i t}
$$

In equation (1), $y_{i t}$ denotes 10-year government bond yield spreads, where $i=1 \ldots N ; t$ $=1 \ldots T ; x_{i t}=\left[x_{i t, 1}, \ldots, x_{i t, k}\right]^{\prime}$ is a vector of $k$ regressors; and $\beta_{t}=\left[\beta_{t, 1}, \ldots, \beta_{t, k}\right]^{\prime}$ is a vector of $k$ time-varying coefficients. In line with previous studies (Manganelli and Wolswijk, 2009; Afonso et al., 2014), $x_{i t}$ includes variables measuring global financial risk, liquidity risk and credit risk. $\alpha_{i}$ captures country fixed effects and $v_{i t}$ a random error term. Fixed effects account for unobserved time-invariant country-specific factors that can affect spreads. ${ }^{6}$ The trend function $f_{t}$ denotes time-specific effects. These control for omitted variables that do not vary across countries but evolve over time. The model of $\mathrm{Li}$ et al. (2011) is a non-parametric time-varying coefficient panel data model based on previous contributions by Robinson (1989) and Cai (2007), estimated using the local linear dummy variable (LLDV) approach which improves the rate of convergence of $\hat{\beta}$ and outperforms the averaged local linear estimate.

As in all non-parametric estimates based on a kernel function, the estimation involves the choice of a bandwidth parameter (denoted by $h^{*}$ ), to which the results are typically sensitive. A lower value for $h^{*}$ reduces the bias involved in the TVP estimates but increases their variance. We set $h^{*}=0.15$ using the cross-validation selection method, ${ }^{7}$ which is based on the principle of selecting the bandwidth that minimizes the mean squared error of the resulting estimates. ${ }^{8}$ Our

withdraws during the period January - June 2015. In addition, Greece is the only country among our sample countries whose sovereign bonds are not part of the QE programme. Finally, as Greece has been the country at the epicentre of the EMU sovereign debt crisis, its spreads and fiscal imbalances are a clear outlier, even when compared with the figures of other EMU periphery countries (see the descriptive statistics in Table 1).

${ }^{6}$ For identification, it is assumed that $\sum_{i=1}^{N} \alpha_{j}=0$ (Su and Ullah, 2006) and the fixed effects are eliminated in the procedure.

${ }^{7}$ Instead of the conventional leave-one-out cross validation method, we use the leave-one-unit-out approach, which is proposed by Sun et al (2009) and it is more adequate for the local linear dummy approach.

8 An alternative approach, the so-called "rule-of-thumb" method, suggested $h^{*}=0.04$. This approach is computationally less demanding but can lead to non-robust results, especially when the data series present high volatility, as it is the case with our variables. The TVP coefficients that we obtain using $h^{*}=0.04$ are broadly consistent with those using $h^{*}=0.15$, but more volatile. These results are available upon request. An extensive survey of bandwidth selection methods can be found in Racine (2008). 
estimations also account for the "boundary effect" according to which the estimated coefficients are biased at the beginning and end of the estimation sample. To address this bias, we follow Dai and Sperlich (2010) who propose reducing the bandwidth value at the beginning and end of the sample. We do so using a bandwidth correction parameter value, denoted by $\varepsilon$, equal to 0.08 , satisfying the restriction $0<\varepsilon<h^{*}$. Finally, for each estimated TVP coefficient we calculate a $95 \%$ confidence interval by applying the wild bootstrap method on the estimated residuals of the non-parametric estimated regression, based on 1000 replications, using the same boundary effect correction as in the source regression.

For the first stage of our analysis, non-linear panel models constitute the main alternative to the panel TVP approach we adopt. In their analysis of euro area spreads, Delatte et al. (2017) use the panel smooth regression transition (PSRT) model of González et al. (2017). The PSRT model offers some advantages relative to other non-linear approaches, such as threshold panel model (TPM) by Hansen (1999) but has its own limitations. ${ }^{9}$ Compared to these non-linear alternatives, the TVP approach has several advantages. First, it allows the identification of multiple regimes. Second, it accounts for gradual transition among them. Third, it allows the different regimes to be non-recurrent. Fourth, by not imposing any single transition variable, it lets the data to determine freely (through observed changes in individual TVP coefficients) the driver(s) of transition between different, non-recurring regimes. Fifth, additivity of the individual predicting variables is the only assumption regarding the functional form of the model. Finally, the Li et al. (2011) TVP approach we follow allows for cross-sectional dependence. Finally, we should stress

\footnotetext{
9 The TPM approach of Hansen (1999) has two key drawbacks. First, it assumes discrete transition among regimes, which may not be suitable for the European debt crisis, where transition between regimes gradual. Second, it allows for a maximum of three regimes, when in practice the number of regimes may be higher. On the other hand, the PSRT model of González et al. (2017) allows for smooth transition among regimes and, theoretically, a higher number of regimes, fluctuating between two extreme regimes. However, it has some limitations. First, it assumes a single, fixed transition variable, when in practice the transition variables may be more than one and/or change over time. Second, the PSRT is subject to technical complications when the series exhibit high volatility (as in our dataset), affecting the smoothness of transition among regimes. In that case, the model may face serious problems of convergence, implying that in practice it may be difficult to identify more than two regimes. Finally, by construction the PSRT, as well as the Hansen (1999) model, assume that the different regimes are recurrent, which may not be the case.
} 
that the notions of non-linear threshold effects and TVP behavior are related. As Granger (2008, p.1) points out, "any non-linear model can be approximated by a time-varying parameter linear model". Hence, ultimately it may be difficult to differentiate between the two possibilities regarding the true data generating process.

In the second stage of our analysis we model each TVP coefficient on an intercept dummy variable capturing the effects of the OMT announcement in August 2012, measures of conventional and unconventional monetary policy, as well as banking risk. Our econometric specification for this part of the analysis is given by equation (2) below:

$$
\widehat{\beta_{t}^{J}}=\gamma+z^{\prime}{ }_{t} \delta+u_{t}
$$

In equation (2), the dependent variable $\widehat{\beta_{t}^{J}}$ is the time-series estimated for the TVP coefficient of each of the spreads' determinants $j=(1 \ldots k)$, and $u_{t}$ is a random error term. We estimate equation (2) using Ordinary Least Squares (OLS) and three definitions of $z_{t} \cdot{ }^{10}$ The first includes only the OMT dummy. The second extends $z_{t}$ to include the proxies for the ECB's conventional and unconventional monetary policy, while the third adds an empirical measure of aggregate credit risk for European banks.

\section{Data}

We have obtained data on euro area government bond yield spreads and the underlying fundamentals over the period January 1999 to July 2016 (monthly frequency). Our sample includes ten EMU member states, covering core (Austria, Belgium, Finland, France and the Netherlands) and periphery (Greece, Ireland, Italy, Portugal and Spain) economies (for data descriptions and sources, see Table A1 in the Appendix). ${ }^{11}$

\footnotetext{
10 The variables entering equation (2) are stationary series (see section 5 below).

${ }^{11}$ The distinction between these two groups is common in the literature. See, among others, Afonso et al. (2014), Paniagua et al. (2016) and Garcia and Werner (2016).
} 
Figure 1 plots 10-year spreads versus Germany, while Panel A of Table 1 presents the corresponding descriptive statistics. They highlight the existence of three distinct periods. The first covers 1999 to summer 2007 and is characterised by near-zero spread values. The second covers summer 2007 to the peak of the crisis in late 2011-early 2012, and involves substantial increases in spreads, particularly in Greece but also in other periphery EMU countries. Finally, following the OMT announcement, we observe a gradual reduction in spread values to levels significantly lower than those in 2012 but higher than the pre-crisis period. Furthermore, compared to the latter, mean spread values during the third period present higher variation across countries, and are clearly higher in EMU periphery countries.

\section{[Figure 1]}

We approximate global risk conditions using the logarithm of the Chicago Board Options Exchange Volatility Index (vix), a variable used by several previous studies (Beber et al., 2009; Afonso et al.,2015) to gauge the international risk factor. The vix measures the "risk-neutral" expected stock market variance for the US S\&P500 contract, computed from a panel of options prices, and is well-known as a "fear index" for financial markets (Whaley, 2000; Bekaert and Hoerova, 2014). The data is obtained from Bloomberg. An increase in vix is expected to result in higher spread values. Developments in global risk involve low pre-crisis values, followed by significant increases between 2007 and 2012 and a gradual return towards pre-crisis values thereafter (see Figure A1 in the supplementary Appendix).

$B A$ denotes the 10-year government bond bid-ask spread, sourced from Bloomberg, used to measure liquidity effects (Favero et al., 2010; Gerlach et al., 2010). ${ }^{12}$ A higher value of $B A$ indicates a fall in bond market liquidity, and is expected to lead to an increase in government bond yield spreads. The almost zero bid-ask spreads between 1999 and 2007 reflect the ample

\footnotetext{
12 This liquidity proxy captures the trading-cost aspect of liquidity. Alternative measures of financial market liquidity, such the difference between on-the-run and off-the-run spreads, turnover, trading volume and the price impact ratio, have been considered in previous papers (D'Amico et al., 2010; Florackis et al., 2014). However, these measures are not available for the full sample of countries and time-period covered by our analysis.
} 
liquidity of the pre-crisis period. A significant deterioration in liquidity conditions ensued, associated with the global financial crisis and European sovereign debt crisis, which affected more strongly the periphery group. Since mid-2012, periphery bid-ask spreads declined significantly but, on average, still exceed their pre-crisis level.

Finally, we measure credit risk using two forward-looking variables: First, the logarithm of the Economic Sentiment Index relative to Germany (esi), available from Eurostat. The sentiment index is a weighted average of five sectoral indexes, whose scores are gathered from surveys stating agents' assessment of the current economic situation and their expectations about future developments. As such, the sentiment index is used in the literature as a forward-looking variable capturing growth expectations (Monfort and Renne, 2013; Dewachter et al., 2015). Higher esi values signal lower credit risk and are therefore expected to result into lower spread levels. Second, the one-year ahead expected general government gross debt-to-GDP ratio relative to Germany $(E D)$, provided by the European Commission's Economic Forecasts. The use of expected, as opposed to historical fiscal data, is in line with previous studies on the determinants of spreads (Attinasi et al., 2009; Arghyrou and Kontonikas, 2012). Fiscal conditions are related to credit quality, with fiscal deterioration implying higher credit risk. Hence, increased values for $E D$ are expected to result in higher spread levels.

Both measures of credit risk indicate significant increases during the crisis period (see Panels $\mathrm{C}$ and D of Table 1). Unlike vix and $b a$, however, credit risk variables do not signal improvements following the summer of 2012. By contrast, economic sentiment relative to Germany deteriorates further in all core countries and Italy, while the improvement observed in the cases of Greece, Portugal and Spain falls short of restoring the average pre-crisis relative esi levels. Moreover, except from Finland and the Netherlands, average expected debt values relative to Germany increase further since summer 2012. All in all, the summary statistics reported in Table 1 suggest that the substantial reductions in spreads observed since the OMT announcement do not coincide with a similar improvement in national macro/fiscal fundamentals. This is a prima-facie evidence 
supporting the multiple equilibria theoretical models of the European sovereign debt crisis discussed in the introduction.

Moving on to the second moment of the risk factors, the picture that emerges is mixed and does not always indicate higher volatility during the crisis period. ${ }^{13}$ The correlation matrix of the risk factors is shown in Table 2. The correlations are small and do not support the presence of significant endogeneity. The strongest correlations are those between $B A$ and the two forwardlooking proxies of credit risk, i.e. esi and $E D$. The correlation of $B A$ with esi displays the largest magnitude for all three panels.

[Tables 1 and 2]

For the second part of our econometric analysis, i.e. the modelling of the spread's timevarying responses to the factors described above, we require measures of conventional and unconventional monetary policy, as well as banking risk. Conventional monetary policy is approximated using the change in the main policy rate of the ECB, namely the main refinancing operations rate $(\triangle M R O)$. Unconventional monetary policy is captured by the growth (logarithmic difference) in the amount of securities held by the ECB for monetary policy purposes $(\Delta s h m p)$, as reported in the ECB's weekly financial statements. The ECB's securities holdings, data for which is available since July 2009 only, have also been used by Gibson et al. (2016) and Delatte et al. (2017), among others, to capture the effect of non-standard monetary measures adopted by the ECB during the crisis. To construct a monthly series for securities holdings, we use the relevant figure quoted in each month's last weekly consolidated financial statement of the Eurosystem, published by the ECB (assets side, item 7.1). The resulting series is presented in Figure 2 and depicts the significant expansion of the ECB's balance sheet effected in the context

\footnotetext{
${ }^{13}$ Given the large shifts in the mean values of our series, the relative standard deviation (absolute value of the coefficient of variation) is more appropriate to examine the variability of the subsamples in Table 1. Comparing the pre-crisis and crisis periods, there are cases of higher relative volatility (6/10 sample countries for $B A ; 9 / 10$ for esi) but also cases of lower relative volatility during the crisis ( $7 / 10$ sample countries for $E D)$. Moreover, Figure 1 in the supplementary Appendix indicates that vix variability is not exclusively a crisis phenomenon. Overall, the risk factors display sufficient variation during the pre-crisis period.
} 
of the SMP and, much more so, the QE programme. At the same time, Figure 2 shows the gradual relaxation of the ECB's conventional monetary policy stance, captured by the reduction in the $M R O$ towards zero since the end of 2011. Both the change in the MRO and the growth of the ECB's securities holdings are included at lagged form (1-month lag) when estimating equation (2).

[Figure 2]

We also use an intercept dummy variable to reflect the effect of the OMT announcement on the relationship between spreads and fundamentals. The dummy variable $\left(D^{O M T}\right)$ is equal to 1 since August 2012 and 0 otherwise. Finally, we capture banking sector risk in the euro area using two banking CDS indices published by Markit. The indexes respectively cover 25 senior and junior subordination European banks. The use of CDS data to measure bank credit risk is consistent with several previous studies (Acharya et al., 2014; Acharya and Steffen, 2015; Drechsler et al., 2016). The relevant data is presented in Figure 3. It confirms the strong correlation between banking and sovereign risk, as both measures of banking risk mirror the movements of spreads reported in Figure $1 .{ }^{14}$ Specifically, both CDS indexes are close to zero before the financial crisis; increase since summer 2007, reaching a maximum at the end of 2011; and decline, albeit to a level higher than their pre-crisis mean, since summer 2012. In baseline estimates of equation (2), we use the lagged CDS senior index, while in robustness checks we employ the CDS subordinate index.

[Figure 3]

\footnotetext{
${ }^{14}$ Bank credit risk is not included as explanatory variable in the model for spreads since, given the high correlation between sovereign risk and banking risk and the existing literature on the sovereign-bank nexus, reverse feedback from the former (our dependent variable) to the latter cannot be ruled out. As De Grauwe and Ji (2013, p.23) point out, "In the existing empirical literature there has been a tendency to add a lot of other variables on the right-hand side...In fact, the addition of these variables creates a risk of false claims that the fundamental model explains the spreads well".
} 


\section{TVP estimates and bond pricing regimes}

\subsection{Empirical findings}

The TVP estimates of equation (1) for the full panel of core and periphery EMU sample countries, excluding Greece, are reported in Figure 4. The figure provides clear evidence for the existence of three pricing regimes in euro area sovereign bond markets. The first covers the period from the euro's launch in 1999 to approximately mid-2007. During this period, the estimated TVP coefficients of all risk sources (global financial risk, liquidity risk and credit risk) are zero or near-zero. The sole exception is the expected gross government debt-to-GDP ratio relative to Germany, whose coefficient has a small but statistically significant positive value throughout most of the pre-crisis period. Figures 5 and 6 present TVP estimates for the core and periphery country groups, respectively, again excluding Greece in the case of the latter. They show that the first pricing regime applied both to core and periphery EMU countries, although the role of expected debt in determining spreads is noticeably more pronounced in the periphery, signalling higher penalties on fiscal imbalances for this group of countries. On the other hand, core countries present higher statistical significance for the coefficient of expected growth.

[Figure 4]

The second pricing regime approximately extends between mid-2007 and mid-2012 and involves a rapid increase both in the absolute value as well as statistical significance of the coefficients of all risk factors. ${ }^{15}$ Again, this trend is common both for core as well as periphery countries. However, the absolute values of the estimated TVP coefficients are, overall, noticeably

\footnotetext{
${ }^{15}$ Note that for a very small number of observations in this regime, as well as in the third pricing regime discussed below, the point estimates of the estimated TVP coefficients fall outside the confidence interval (CI) calculated using the wild bootstrap methodology. These can be regarded as outliers produced by the bootstrapping exercise, with no impact on the reliability of our results: the standard calculation of a CI involves use of a parameter's point estimate as the central point of the CI estimation and calculation of the CI around the point estimate. This ensures that the point estimate always falls within the estimated CI bounds. Bootstrap methods, on the other hand, follow a different CI estimation approach, involving multiple estimates of the parameter in question (in our case 1000, one per bootstrap iteration) and the empirical setting of an upper and lower CI bound within which 95 per cent (or any other predetermined proportion) of these estimates fall. In this methodology of CI construction, it is possible for a parameter's point estimate to fall outside the empirically constructed CI. Indeed, for a 95 per cent CI calculated using our bootstrapping methodology, the a priori expectation is that the point estimate will fall outside the calculated CI in 5 per cent of observations.
} 
higher for the group of periphery countries, capturing the larger risk exposure of the periphery. The signs of the estimated TVP coefficients are in line with the theoretical expectations. The only exception is expected relative sovereign debt in core countries for which we obtain a negative sign. This finding indicates the presence of misspecification, however it persists in all robustness tests presented in section 4.2.2 below undertaken to address this possibility. Therefore, variants of debt to GDP ratio, commonly used to capture national credit risk may, in certain cases, be missing something important for the determination of sovereign debt risk. This is an important remark motivating future research on this subject. Nevertheless, we note that for the vast majority of observations the negative debt TVP coefficient is statistically insignificant.

\section{[Figures 5 and 6]}

Finally, we provide evidence for a third pricing regime, covering the period between approximately mid-2012 to the end of our sample. This period is characterised by a reduction in the absolute values and/or statistical insignificance of the estimated TVP coefficients. As far as the international risk factor is concerned, its coefficient maintains a positive, albeit declining, value until approximately mid-2014. This, however, is statistically significant only for the core panel. Thereafter, the vix coefficient takes near-zero and insignificant values in all three panels. Liquidity risk also presents a positive yet declining TVP coefficient during the third regime. This is statistically significant until mid-2014 for the full and periphery panels and until the end of 2013 for the core panel (see Figures 5 and 6). Thereafter, the coefficient of $B A$ takes a zero and insignificant value in core countries. On the other hand, starting from early 2015 the $B A$ coefficient registers a significant increase for the periphery panel. This is another unexpected finding, which, however, does not persist in the robustness checks in section 4.2.

Expected relative growth maintains a negative and significant coefficient well into the third regime, albeit with a declining absolute value. For the full panel, statistical significance is maintained until the end of 2014; for core countries until summer 2013 and for periphery countries until summer 2015. By the end of our sample, esi takes near-zero and insignificant 
values in all three panels. Finally, the TVP coefficient of expected relative debt ratio registers a sharp decline in mid-2012 in the full panel, becoming statistically insignificant in mid-2013. However, starting from early 2014 the ED coefficient resumes an upwards movement. This falls short of being statistically significant at the $95 \%$ level, although it is close to being so. The movements of the $E D$ coefficient in the full panel are mainly driven by the periphery group, although the increase towards the end of our sample is also recorded for core countries.

We end our discussion in this section with a reference to the possibility that our TVP findings capture a non-linear, time-invariant relationship between spreads and risk factors, rather than regime changes reflected into a time-varying relationship (see section 2 above). To that end, we plot the average value of each risk factor along with the estimated time-varying parameters. The results are reported in Figure A2 in the supplementary Appendix. The average values of esi and $B A$ shift significantly during the crisis period and, at the same time, the sensitivity of spreads to these risk factors changes, hinting towards the possibility of nonlinear threshold effects. However, in the case of vix, high pre-crisis values are not associated with higher TVP coefficients. Indeed, the vix coefficient is activated at a record low vix levels. The same holds true for the $E D$ coefficient which starts rising at relatively low values, and later displays a significant drop, even though average $E D$ continues to rise towards record levels. The movements of the vix and ED TVP coefficients are clearly not consistent with non-linear threshold effect. All in all, the evidence reported in Figure A2 indicates a combination of nonlinear threshold behavior and shifts from between non-recurrent pricing regimes, both of which, according to Granger (2008), can be captured by our TVP methodology.

\subsection{Robustness tests}

We tested the robustness of the findings reported in section 4.1 in numerous ways, all of which confirm their validity. The first group of robustness tests maintains the same baseline specification in terms of the risk factors on which spreads are modelled, differentiating on the 
sample of included countries, the timing of the right hand-side terms and the values of the bandwidth and correction parameters. The second group expands/modifies the set of risk factors. With one exception (the case of including Greece), to economize space we only report findings relating to the full panel. The results relating to the core and periphery countries are consistent with those reported above and are available upon request.

\subsubsection{Baseline specification tests}

\section{Including Greece}

First, we added Greece into the analysis. The results are reported in Figures 7 (full panel) and 8 (periphery panel). Our findings remain broadly robust, although the inclusion of Greece increases the absolute values of the TVP estimates in both panels, as well as the bounds of their 95\% confidence intervals towards the end of the sample period. The latter is consistent with the highly idiosyncratic circumstances faced by Greece in 2015-2016, including a major confrontation with its official lenders in the first half of 2015, which brought Greece very near to withdrawing from the EMU and led to the imposition of (still in place) capital controls; and the exclusion of Greek bonds from the ECB's QE programme announced in January 2015. Moreover, including Greece, the puzzling finding reported in Figure 6 regarding the increase in the liquidity coefficient of the periphery panel since 2015 disappears.

[Figures 7 and 8]

\section{First lag of regressors}

Second, to address any endogeneity concerns, we repeated the estimation of equation (1) using the first lag rather than the contemporaneous values of the independent variables. The results are consistent with the findings reported in section 4.1 above (see Figure A3 in the supplementary material Appendix). 


\section{Alternative bandwidth and correction parameters}

Third, we have tested the robustness of our findings to changes in the value of the bandwidth estimation parameter $h$. Specifically, we estimated equation (1) using three alternative $h$-values, namely $0.10,0.20$ and 0.30 , to assess the tradeoff between the bias of the TVP estimates and their variance. The results are consistent with those obtained by our benchmark model, where $h$ is set equal to 0.15 (see Figure A4 in the supplementary Appendix). Fourth, we have tested the robustness of our findings to alternative values of the bandwidth correction parameter $\varepsilon$. Again, the results are consistent with those obtained from the benchmark model, which sets $\varepsilon=0.08$ (see Figure A5 in the supplementary Appendix).

\section{Orthogonalized bid-ask spread}

Since $B A$ exhibits the strongest comovement with the other risk factors (see Table 2), in this robustness check we orthogonalize BA to remove its systematic comovement with the other risk factors (Bekaert et al., 2009). Specifically, we estimate a fixed effects panel regression of $B A$ on vix, esi and $E D$, and collect the residuals. These correspond to the orthogonalized version of BA capturing more appropriately the idiosyncratic variation in $B A$. Figure 9 shows the full panel TVP results which, overall, are similar to those obtained by the baseline model. The results remain unchanged for the core and periphery panels too (see Figures A6 and A7 in the supplementary Appendix, respectively). One notable difference, however, is that the puzzling finding of the increasing TVP liquidity coefficient for the full and periphery panels at the end of the sample disappears. These findings imply that the orthogonalized $B A$ series is a better measure of liquidity risk /or the unorthogonalised $B A$ series captures an unobserved risk factor for the last part of our sample.

[Figure 9] 


\section{Actual debt-to-GDP ratio}

To account for the possibility of measurement errors in the expected debt-to-GDP ratio, we replace it with the actual values of the debt-to-GDP ratio (data sourced from Eurostat). The results for the full panel are reported in Figure A8 of the supplementary Appendix. These are similar with those from the baseline specification.

\subsubsection{Expanding the set of risk factors}

\section{Decomposing VIX}

It is well-known that VIX reflects both stock market uncertainty and a volatility risk premium (Bollerslev et al., 2009; Bekaert and Hoerova, 2014; Stillwagon, 2017). The volatility premium has been shown to be a good predictor of stock returns (Bollerslev et al., 2009; Bekaert and Hoerova, 2014), while Stillwagon (2017) has used it the modelling of TIPS bonds. Motivated by this literature, we decompose the VIX in its two components: More specifically, following Bollerslev et al. (2009) we define the volatility premium as the difference between the squared VIX in monthly percentages (i.e. VIX ${ }^{2} / 12$ ) and realized volatility. ${ }^{16}$ The volatility premium reflects the wedge between the "model-free" risk-neutral expected volatility (or implied volatility) over the $[t, t+1]$ time interval and actual (or physical) stock market volatility, measured over the $[t-1, \mathrm{t}]$ time interval. The volatility premium serves as a proxy for the aggregate degree of risk aversion. ${ }^{17}$

The results in Figure 10 indicate that the effect of both components of the VIX, realized volatility and volatility premium, are statistically significant during the crisis period. Hence, both time-varying volatility risk and time-varying risk aversion appear to play a significant role in explaining variation in spreads. Nevertheless, compared to the VIX index, the effect of its

\footnotetext{
16 The dataset is obtained from the website of H. Zhou (https://sites.google.com/site/haozhouspersonalhomepage/).

17 The advantage of this approach is that both implied volatility and realized volatility, and therefore the volatility premium, are directly observable at time $t$. An alternative would entail obtaining a forecast of expected realized volatility and calculating the expected variance premium. As Bollerslev et al. (2009) point out, the two premia would coincide under the assumption that realized volatility is a martingale difference sequence.
} 
individual constituent components appears to be more short-lived in terms of statistical significance. Finally, compared to the benchmark model the decomposition of the VIX did not affect the TVP coefficients of the remaining risk factors.

[Figure 10]

\section{Adding real effective exchange rate}

Motivated by the multiple equilibria theoretical model of the European debt crisis by Arghyrou and Tsoukalas (2011) and previous empirical analyses by Arghyrou and Kontonikas (2012) and Afonso et al. (2014), among others, we extend the set of risk factors to include the logarithm of the real effective exchange rate (reer). This variable is a proxy of denomination risk, arising from real exchange rate overvaluation. If the multiple equilibria narrative of the European deb crisis is correct, we would expect to obtain time variation for the reer coefficient.

\section{[Figure 11]}

As we can see in Figure 11, including reer in the empirical model for spreads does not affect the TVP coefficients of the remaining risk factors. Crucially, the TVP coefficient of reer fluctuates in size and statistical significance over time. During the pre-crisis period, it takes nearzero values and is insignificant. This indicates no perception of redenomination risk during the early EMU years. The onset of the global financial crisis in summer 2007 is associated with a gradual increase in the reer coefficient's size and statistical significance, reaching a peak in summer 2010, indicating transition to a new regime characterized by the pricing of redenomination risk. This is additional to increased fiscal default risk, as the latter is captured by the simultaneous increase in the coefficient of $E D$ during the crisis period. In the wake of the first Greek bail-out and the introduction of the SMP, the reer coefficient's size and significance starts declining and gradually becomes insignificant. Finally, it becomes significant again between mid-2014 and end-2015. Summarising, our evidence is consistent with the predictions of the theoretical model of Arghyrou and Tsoukalas (2011), which differentiates explicitly 
between fiscal default and redenomination risk. In section 4.3 below we further analyse the issue of redenomination risk from alternative perspectives.

\subsection{Discussion}

Overall, our TVP analysis confirms the existence of the pre-crisis and crisis bond-pricing regimes identified by previous studies on the determinants of sovereign bond yield spreads in the euro area. In addition to these regimes, however, we find evidence of a third regime introduced in the second part of 2012. Apart from the studies by Saka et al. (2015) and Delatte et al. (2017), the previous literature on regime-dependent sovereign bond pricing has not analysed the implications of the OMT announcement and more generally the role of ECB policy interventions. The latter study concludes that the change in the regime following the announcement represents a restoration of the regime that was in place prior to the crisis. This inference, however, is not consistent with the movements of spreads since August 2012, which by comparison to the pre-crisis regime are on average higher; and have stabilized at levels noticeably higher, and more variable across countries, (see Figure 1 and Panel A of Table 1). These stylized facts imply that the third regime is not identical to the pre-crisis regime, but a new, distinct regime, where markets are pricing sources of risk that were: (a) either less penalized by markets, or (b) not priced at all during the pre-crisis period. ${ }^{18}$

With regards to the former argument, our analysis above confirmed that during a substantial part of the third regime, markets continued to price fundamentals in way that was less pronounced compared to the second regime but more pronounced compared to the first.

\footnotetext{
${ }^{18}$ Saka et al. (2015) find that the explanatory power of macro /fiscal fundamentals, captured by the adjusted $\mathrm{R}^{2}$ of regressions modelling CDS spreads, is stronger in the post-OMT window. They interpret this as evidence for the ECB's role in combating sentiment-driven self-fulling dynamics, helping euro area bond markets to co-ordinate on a more fundamental-based equilibrium. Their finding can be reconciled with our finding that the sensitivity of spreads to the risk factors declines during the third regime. The latter reflects lower perceived default/euro-exit probabilities and improving market sentiment, resulting into stabilization of bonds prices and lower spread's volatility (see Panel A in Table 1). Both sets of findings are consistent with the theoretical models discussed in section 2, which predict that improvements in market sentiment lowers spread's levels and volatility, increasing the predictive power of macro/fiscal fundamentals in spreads' determination.
} 
Furthermore, liquidity risk in periphery countries continues to be priced at the end of our sample and the same may hold for expected relative debt ratios, whose TVP coefficient is close to being significant at the 5\% level for the full panel. As far as the latter argument is concerned, valuable insights are provided by the time effects in equation (1). Time effects capture the net impact of country-invariant factors that may increase or decrease spreads over time beyond the level predicted by the model's explanatory variables. Hence, if non-zero, they will signal the importance of factors other than global financial risk, liquidity risk and credit risk.

The time effects for the core and periphery panels are presented in Figure 12. In both panels, during the pre-crisis regime time effects were near zero. Time effects become much more important during the crisis period. Between summer 2007 and late 2011, they take increasingly negative values. ${ }^{19}$ This implies that over that period, spreads would have been even higher in the absence of mitigating factors pushing spreads below fundamentals-consistent values. ${ }^{20}$ Such factors include the provision of programmes of financial assistance to those countries mostly affected by the crisis (Greece, Portugal and Ireland), and the introduction of institutional innovations such as the European Financial Stability Facility (EFSF), whose primary target was to set in place a previously non-existing fiscal back-stop at the union level. ${ }^{21}$

\footnotetext{
${ }^{19}$ The difference between our results and those of De Grauwe and Ji (2013) regarding the sign of the time effects during the pre-OMT period may be attributed to the different empirical frameworks utilized. De Grauwe and Ji (2013) use fixed parameter specifications to test the multiple-equilibria theory of the European debt crisis. They argue that their positive time effects during the crisis capture movements in spreads caused by negative sentiment shifts, which provides the link with the multiple equilibria narrative of the crisis. By contrast, we use a TVP specification with time effects, which as explained in section 2, provides a more suitable framework to test the underlying theory. Our findings agree with De Grauwe and Ji's (2013) conclusions regarding the shift to a "bad" equilibrium during the crisis, therefore the two sets of findings are consistent. However, as we capture regime shifts through the movements of the model's TVP individual coefficients, our empirical framework corresponds better to the underlying theoretical models and is more informative regarding the drivers of regime changes.

${ }^{20}$ For core countries, the maximum difference is estimated in the range of 120 basis points, observed in early 2012. In the periphery panel excluding Greece, the maximum difference (approximately 150 basis points) is recorded in early 2009 and early 2012. When Greece is included in the periphery panel, the difference records its maximum level between late 2011 and the first half 2012, taking values ranging between 600 and 700 basis points.

${ }^{21}$ While financial support programmes occurred at the country-level, it is possible that they reduced the upward pressure on spreads of other countries through "benign" spillover effects. See Arghyrou and Kontonikas (2012), De Santis (2014), Saka et al. (2015) and Ehrmann and Fratzcher (2017) among others, for analyses of spillover effects in the context of the European debt crisis. It can also be argued that bailouts and the creation of the EFSF improved market sentiment (or helped to avoid further deterioration) and reduced overall uncertainty, since they demonstrated the willingness of policymakers to fight the crisis. The idea that time effects may capture market sentiment is consistent with De Grauwe and Ji (2013) and Gibson et al. (2016).
} 
[Figure 12]

These mitigating influences started to disappear in early 2012, especially in periphery countries, as suggested by the sharply increasing time effects in Figure 12. Greece, Italy and Spain recorded significant spread increases in spring 2012. These tensions may reflect a negative view by market participants about the adequacy of measures taken up to that point to fully and successfully resolve the crisis. Crucially, the EMU had not set in place a mechanism endowed with enough resources to fund rescue programmes in case they were needed to stabilize notably the Italian and Spanish bond markets and banking systems. With Italian and Spanish spreads already in the range of 500 basis points, this dynamic, if left unchecked, could result into a collapse of Italian and Spanish bond markets, representing an imminent threat to the existence of the euro. ${ }^{22}$

It is precisely this threat the ECB sought to address by announcing the OMT programme. ${ }^{23}$ The OMT allows the ECB to intervene in secondary sovereign bond markets, provided that the country requesting its activation agrees a programme of economic adjustment or a precautionary Enhanced Conditions Credit Line (ECCL) with the European Stability Mechanism (ESM). Therefore, by involving conditionality, the OMT cannot be interpreted as a blanket monetary guarantee of fiscal liabilities; and by introducing it the ECB has not assumed the role of lender of last resort (LLR) in the classic sense, as under the latter the central bank can unilaterally intervene in secondary bond markets without reference to any external prerequisites. If the ECB had provided a blanket guarantee, spreads would have completely stopped responding to

\footnotetext{
${ }^{22}$ As Di Cesare et al. (2012) point out, concerns about a possible break-up of the euro area became widespread by late spring/early summer 2012. The volume of Google searches of "euro break-up" or similar keywords using peaked, while a survey of central bank reserve managers by the UBS bank revealed that about three quarters of them expected at least one country to leave the euro area within five years. Finally, the Sentix index discussed below, suggests a high perceived euro-break probability just before and after the announcement of OMT.

${ }^{23} \mathrm{ECB}$ officials have publicly stated that one of the targets of the unconventional policy interventions was to reduce redenomination risk (Krishnamurthy et al., 2015). Apart from President Draghi's "whatever it takes to preserve the euro" speech of 26 July 2012, other examples include the speech by ECB Executive Board Member Benoît Cœuré on 3 September 2013 (http://www.ecb.europa.eu/press/key/date/2013/html/sp130902.en.html), where he discussed redenomination risk in the context of the OMT.
} 
country-specific credit risk factors; and the relationship between spreads and risk factors would be similar to the first regime.

Having said that, average spread values in the third regime are significantly lower than in the second. According to our findings, this is the result of a substantial reduction in their responsiveness to the underlying risk factors triggered by the OMT's announcement. As mentioned in section 2 above, the time-series evolution of the risk-factor TVP coefficients following the introduction of OMT suggests that the mere announcement of conditional liquidity provision by the ECB eased the strategic concerns of investors in the absence of an LLR in the EMU sovereign bond markets. This implies that OMT triggered a regime shift in European sovereign bonds prices, because Mr. Draghi's famous “whatever it takes” speech succeeded in lowering substantially (though not eliminating) the perceived probability of sovereign defaults and/or exits from the euro area.

Further evidence in favour of this conclusion is obtained by estimating our benchmark TVP model for a control group of non-EMU countries, including Denmark, Sweden and the UK. These are all European Union countries with independent monetary policies, whose national central banks can undertake the role of LLR in the event of a sovereign debt crisis. This provides investors a guarantee that the sovereign bonds of these countries face limited default risk compared to individual EMU countries with no control over the single monetary policy, implying no ability to inject liquidity in their sovereign bond markets during a crisis (De Grauwe and Ji, 2013; Saka et al., 2015). The reduced default probability should be reflected in smaller and less time-variant TVP risk factor coefficients. The corollary of potential monetary financing of fiscal liabilities is the existence of inflation and exchange rate risk, the combination of which can be captured by the movements of the real exchange rate. Therefore, when estimating the benchmark model for the non-EMU panel we add reer as an extra risk variable.

The results are presented in Figure 13. Consistent with the LLR stabilization effect, our the TVP estimates for the majority of risk factors (vix, BA and esi) are statistically insignificant. The 
only risk factors that are significant for relatively short periods of time, mainly during the precrisis period, are the expected debt to GDP ratio differential against Germany and real effective exchange rate risk. ${ }^{24}$ We have tested the robustness of these findings by extending the non-EMU panel to include two European countries that are not part of the European Union, namely Switzerland and Norway. Our inference remains unchanged, as the majority of the TVP coefficients remain statistically insignificant in explaining spreads; indeed, incidences of significance are further restricted compared to the findings reported in Figure 13 (see Figures A9 and A10 in the supplementary Appendix, respectively, adding Switzerland and then Norway to the panel). ${ }^{25}$

Overall, the combination of the two sets of findings discussed above, respectively referring to EMU and non-EMU countries, support the multiple equilibria view of the eurozone sovereign debt crisis vis-à-vis alternative fundamentals-based explanations of the evolution of the crisis. By undertaking the LLR role (even under conditionality), the ECB introduced a new bonds' pricing regime, abolishing the "bad" equilibrium of the crisis period with one involving lower spread values. $^{26}$

\footnotetext{
${ }^{24}$ Specifically, $E D$ is positive and significant during the period mid-2001 and mid-2005; and then again for the relatively short period covering November 2011 to December 2013. These are periods during which the value of expected debt to GDP ratio against Germany increased for the majority of observations in the panel. The increase observed in the TVP coefficient of $E D$ is consistent with the argument by Obstfeld (1996) according to which increased public debt can be a source of more aggressive pricing of fundamentals. On the other hand, reer is priced with the expected positive sign between mid-2003 and mid-2009, which covers a large part of the pre-crisis period as well as the period of the global financial crisis. However, reer is not priced during the European debt crisis.

${ }^{25}$ When the non-EMU panel is extended to include Switzerland, the significance of the debt to GDP differential against Germany is restricted to the period November 2011 to August 2013; while the real effective exchange rate is significant only between February 2007 and May 2009 (see Figure A9 in the supplementary Appendix). Adding Norway as a fifth panel member fully eliminates the statistical significance of the debt to GDP differential against Germany, leaving the real effective exchange rate as the sole statistically significant determinant of spreads, for the period April 2006 to April 2009 only (see Figure A10 in the supplementary Appendix). Note that the European Commission data sets for Economic Sentiment Indicator and debt forecasts do not include Norway and Switzerland. As a result, the TVP models underlying Figures A9 and A10 have been estimated using, for all five countries involved in the estimations, the Business Confidence Indicator published by the Organization for Economic Cooperation and Development (OECD) and the quarterly actual debt series published by the Bank of International Settlements.

${ }^{26}$ Our findings are consistent with those by Saka et al. (2015) who find increased commonality in the movements of spreads post-OMT in euro area, as they imply a gradual phasing-out of negative market sentiment and countryspecific redenomination risk. This results into a more homogenous, and more favourable bonds pricing model, replacing the "bad equilibrium" pricing model of the crisis period.
} 
[Figure 13]

Nevertheless, the reduction in spreads triggered by the OMT announcement did not happen immediately. Although spreads entered a downward path immediately after the OMT announcement, Figure 12 suggests that time effects in the periphery panel kept on rising until mid-2013. Thereafter, they declined only gradually. We interpret this as evidence of residual redenomination risk carried over from the crisis period. This interpretation is consistent with De Santis (2015) who finds that following the OMT announcement redenomination risk declined but remained at positive levels.

In addition, the time effects of the periphery panel including Greece provide further evidence in favour of the redenomination risk interpretation. Unlike time effects excluding Greece, the series depicts an upward movement since mid-2014, reaching a maximum in June 2015, at the peak of Greece's confrontation with its official lenders. Thereafter, the series stabilizes but at significantly positive values. ${ }^{27}$ As the possibility of Greece exiting the EMU increased in 2015, the argument that the time effects reported for the post-OMT period mainly capture redenomination risk gains further credibility. This is an important differentiating factor between the first (pre-crisis) and third (post-OMT) pricing regimes. Redenomination risk did not exist in the former but existed for the best part of the latter. This helps to explain the difference in average spread values observed between the two regimes.

Further evidence in support of residual redenomination risk is provided by the Sentix eurobreak up index, depicted in Figure 14. Sentix is being published since June 2012 and measures the proportion of surveyed investors (private and institutional) predicting at least one country leaving the euro area within the next twelve months. The June, July and August 2012 Sentix's values reveal that, just before and after the announcement of the OMT programme, markets perceived very significant redenomination risk, with $55 \%, 73 \%$ and $62 \%$ of the surveyed

\footnotetext{
${ }^{27}$ Overall, Figure 12 provides strong evidence to support Greece's significant idiosyncratic features relative to the rest of the periphery countries, justifying our choice to exclude it from our baseline periphery panel.
} 
investors, respectively. This percentage gradually declined but remained positive, maintaining mainly double-digit values, throughout the period August 2012 - August 2014. Sentix resumed an increasing trend, returning to values close to 50\%, between September 2014 and June 2015, a period coinciding with the escalating confrontation between Greece and its EMU partners. Finally, following agreement on the third Greek financial adjustment programme in July 2015, Sentix gradually returned to lower values, close to $10 \%$. Overall, the movements of Sentix are similar to those of the time effects presented in Figure 12, especially when including Greece into the analysis, supporting our argument that the time effects capture declining but non-zero redenomination risk during the third regime. ${ }^{28}$

\section{[Figure 14]}

\section{ECB policy, banking risk and bond pricing regimes}

\subsection{Empirical findings}

In this section we investigate the link between monetary policy, banking risk and bond pricing regimes. We start by modelling the point estimates of the TVP coefficients obtained in the first stage of our analysis on an intercept dummy variable capturing the effect of the OMT announcement, as well as ECB policy measures and bank credit risk. ${ }^{29}$ The sample period for this analysis is August 2009 - July 2016, covering the third and second (partially) bond pricing regimes identified in the first stage, and is dictated by non-availability of data on the ECB's securities holdings prior to July 2009. Table 3 presents OLS estimates of equation (2) with

\footnotetext{
${ }^{28}$ The TVP reer coefficients reported in Figure 11 are broadly consistent with the inference obtained from the time effects estimated for our benchmark model: Both indicate lack of redenomination risk during the pre-crisis period and non-zero redenomination risk during the post-OMT period. However, for the first part of 2012, the reer coefficients reported in Figure 11 are not significant, whereas the estimated time effects reported in Figure 12 indicate increasing redenomination risk, confirmed by the Sentix index values reported in Figure 13. This implies that although the movements of the reer coefficient contain significant information regarding the evolution of redenomination risk in the euro area, they are not a perfectly accurate measure for the latter.

${ }^{29}$ All the TVP coefficients are stationary according to the Lee and Strazicich (2003) unit root test, which allows for structural breaks in the series' deterministic components. The regressors included in the right-hand side of equation (2) are also stationary series. The results of these tests are available upon request.
} 
Newey and West (1987) standard errors. Panel A refers to the full set of countries, while Panels $\mathrm{B}$ and $\mathrm{C}$ present the results for the core and periphery groups, respectively. ${ }^{30}$

[Table 3]

The findings in column 1 of Table 3 - Panel A correspond to the specification where only the OMT dummy variable is used to explain the TVP coefficients of the full panel group (the dummy variable is equal to 1 since August 2012 and 0 otherwise). They show that in most instances the OMT effect is statistically significant at the $5 \%$ level, or lower, and its sign consistent with lower sensitivity of spreads to fundamentals. Evidence for the core and periphery groups in Panels B and $\mathrm{C}$, respectively, is also consistent with a weaker response of spreads to the risk factors since summer 2012. An exception is the reaction of spreads to liquidity conditions in the periphery panel, which becomes stronger, with the point estimate of the TVP coefficient of $B A$ more than doubling. The OMT dummy has a positive sign in the case of the core group's expected relative debt, which we interpret as evidence for correction of the unexpected negative sign that occurred during the second regime, while consistently depicting a negative sign for the periphery group.

We then add in equation (2) the lagged growth of securities held by the ECB for monetary policy purposes, a proxy for unconventional interventions, and the lagged change in the MRO, a measure of conventional monetary policy shifts. ${ }^{31}$ The results in column 2 of Table 3 show that including these variables does not alter the findings pertaining to the OMT effects. The evidence highlights the important role of unconventional monetary policy actions since the growth of the ECB's security holdings is statistically significant in many instances. The sign of the estimated coefficients indicates that the expansion of the ECB's security holdings is typically associated with lower sensitivity of spreads to liquidity risk and credit risk, when the latter is proxied by expected relative growth. This result holds for the full panel, as well as the core and periphery

\footnotetext{
${ }^{30}$ Note that Greece is excluded from both the full panel and the panel of periphery countries.

31 The motivation for differencing is related to the non-stationarity of the log level of securities held for monetary policy purposes. Since we use $\Delta s h m p$ for our estimations, we cannot take an explicit position in the "stock" vs. "flow" argument of the central bank balance sheet. There is a nascent debate at policy level on this issue with the views being divided (BIS, 2017). Our results can only provide evidence for the potential importance of flows.
} 
groups. On the other hand, the effect of conventional monetary policy actions is statistically insignificant at the $5 \%$ level in all cases.

Finally, motivated by the evidence in Delatte et al. (2017) about the importance of bank credit risk as a source of time variation in the relationship between spreads and fundamentals, we add the lagged European banking sector senior subordination CDS index to the set of explanatory variables in equation (2). The results are presented in column 3 of Table 3 . They show that bank credit risk is an important driver of the TVP coefficients, with the adjusted $\mathrm{R}^{2}$ rising by $25 \%$ on average, across the various specifications. An increase in bank credit risk is typically associated with larger (in absolute magnitude) point estimates, indicating heightened sensitivity of spreads to fundamentals, and the effect is statistically significant at the $1 \%$ level. The only consistent exception to this general rule involves the impact of bank risk on the coefficient of the expected relative debt ratio. As far as the other coefficients are concerned, the results in columns 1 and 2, which do not account for developments in the banking sector, remain broadly robust to the inclusion of the bank credit risk measure in column 3. Similar findings are obtained when the European banking sector junior subordination CDS index is used as a proxy for banking risk (results available upon request).

Overall, the evidence in Table 3 suggests that ECB interventions and banking risk are both important in explaining the time-varying relationship between spreads and fundamentals between 2009 and 2016. However, it is plausible that bank credit risk is itself affected by ECB policy interventions. This implies that an indirect effect of policy interventions on the sensitivity of spreads to fundamentals, working through changes in banking risk, can co-exist with a direct one. In fact, Chodorow-Reich (2014) uses a high-frequency event study and shows that during 2008-2009 banking risk in the U.S. declined following unconventional monetary policy announcements. Fratzscher et al. (2014) take a similar approach, producing consistent findings, 
when analysing the impact of ECB policy announcements in the period 2007-2012. ${ }^{32}$ Hence, we proceed by modelling our empirical measures of bank credit risk on the OMT announcement dummy, the two variables that capture conventional and unconventional monetary policy developments and several control variables. The set of controls includes the first lag of vix, growth expectations, and bank credit risk.

The results in columns 1, 2 and 3 of Table 4 show the OMT effect is negative and statistically significant, capturing a decline in bank credit risk associated with the OMT announcement. This finding is consistent with the results of Fratzscher et al. (2014). The lagged growth of ECB security holdings is strongly significant too. It displays a negative coefficient, indicating that unconventional monetary policy interventions led to lower banking risk. These effects are more pronounced in the equations modelling the subordinate CDS. The impact of lagged MRO changes on bank credit risk, however, is statistically insignificant. Thus, our evidence stresses the significance of unconventional monetary policy as a determinant of aggregate euro area banking risk.

ECB policies, however, may affect banking risk not only directly, but also indirectly, through changes in sovereign spreads. As Acharya et al. (2017) explain, the decrease in the spreads (and corresponding increase in the value) of periphery sovereign bonds caused by the announcement of OMT resulted into substantial windfall gains and an indirect recapitalization of European banks with significant holdings of such bonds. To account for this indirect effect, we expand our empirical specification modelling banking risk by incorporating the lagged first principal component of euro area spreads, calculated using the full set of countries. In line with Arghyrou and Kontonikas (2012) and Saka et al. (2015), among others, we interpret the first principal component of spreads, depicted in Figure A11 in the supplementary Appendix, as a euro area

\footnotetext{
${ }^{32}$ Delatte et al. (2017) interpret the gradual reversion to the non-crisis regime since summer 2012, suggested by their estimates, in the light of the OMT announcement by arguing that the ECB was successful in taming aggregate banking risk and severing the sovereign-bank nexus. Nevertheless, they do not formally test these conjectures.
} 
sovereign risk factor. The estimates of the extended model are shown in column 4 of Table 4 . The OMT dummy and the lagged growth in security holdings remain important determinants of banking risk, thereby supporting the existence of a direct effect of OMT on banking risk. At the same time, however, the lagged sovereign risk factor is also highly significant with a positive sign. This indicates that a reduction in sovereign risk, which occurred in the post-OMT period, results into lower banking risk. Overall, our findings suggest that ECB policies have both direct and indirect effects on banking risk.

[Table 4]

Summarising, this section presents strong evidence that the announcement of the OMT programme influenced the mechanism linking spreads to global financial risk, liquidity risk and credit risk. The expansion of the ECB's balance sheet provided extra stimulus and further weakened the link between spreads and fundamentals. Importantly, the impact of policy interventions on the risk factors' sensitivities is both direct and indirect, the latter materialising through reductions in bank credit risk. The direct effect suggests that the OMT and purchases of sovereign bonds in the secondary market improved expectations by signalling that the ECB stands ready to prevent the collapse of sovereign bond markets due to existing fiscal liabilities. The indirect effect hints that the ECB reassured investors that sovereigns will not be called upon to finance unsustainable contingent fiscal liabilities originating from extensive bank losses, and at the same time (indirectly) recapitalised the European banking system.

\subsection{Robustness checks}

In this section we provide two robustness checks for the second-stage of our analysis which examines the factors affecting the TVP coefficients. First, we use an alternative proxy for unconventional monetary policy in the euro area, namely the size of the ECB's balance sheet, 
which allows us to expand the time-dimension of the sample. ${ }^{33}$ Specifically, we re-estimate the most extended version of equation (2) reported in column 3 of Table 3 by replacing the first lag of the log-difference of securities held for monetary policy purposes $(\Delta s h m p)$ with that of the log-difference of the ECB's balance sheet ( $\triangle e c b b s)$. The results in column 1 of Table 5 are based upon the same sample used in the baseline analysis (August 2009 - July 2016). Column 2 uses a longer sample (July 2004 - July 2016), the starting point of which is dictated by bank CDS data availability.

The results show that over the shorter common period, replacing $\Delta s h m p$ with $\Delta e c b b s$ does not affect the findings pertaining to the significant effect of the OMT and banking risk on the TVP coefficients of risk factors underlying spreads. Also, in most instances, the insignificant effect of conventional monetary policy actions is not overturned. In the full panel, the sign of the estimated coefficients indicates that the expansion of the ECB's balance sheet is typically associated with lower sensitivity of spreads to global financial risk and liquidity risk. In the core and periphery panels we also identify a significant effect on credit risk, when the latter is proxied by expected relative growth.

When the sample period is expanded, however, the results deteriorate substantially in terms of the magnitude and statistical significance of the unconventional monetary policy proxy. This finding is not surprising since the longer sample incorporates a substantial period from the first (pre-crisis) regime during which unconventional monetary was not present. The statistical significance of the OMT dummy in the longer sample verifies that the Draghi announcement was instrumental in driving the transition from the second to the third regime. Finally, the effect of conventional monetary policy actions becomes significant in the longer sample for $B A$ and

\footnotetext{
${ }^{33}$ For a plot of the level of the ECB's balance sheet along with the security holdings, see Figure A12 in the supplementary Appendix. Both series trend strongly upwards since early 2015 reflecting the ECB's QE programme.
} 
esi. Its sign indicates that expansionary conventional monetary policy (fall in MRO rate) is associated with weaker sensitivity of spreads to liquidity risk and credit risk. ${ }^{34}$

[Table 5]

Second, we re-estimate the most extended version of equation (2) using the TVP parameters obtained from the full panel including Greece. The results in Table A1 of the supplementary Appendix results are in line with the baseline findings since they confirm the important role of the OMT announcement and the ECB's unconventional monetary policy in affecting the sensitivity of bond spreads to the risk factors.

We conduct a final robustness check estimating equation (2) using as dependent variables the TVP coefficients obtained by employing the orthogonalized BA series in the first stage estimations, which capture more appropriately idiosyncratic variation in liquidity conditions. This analysis is motivated by the puzzling finding of a stronger $B A$ TVP coefficient following the OMT announcement in the periphery group (see Panel $\mathrm{C}$ in Tables 3, 5 and $\mathrm{A} 1$ in the supplementary Appendix), while at the same time the orthogonalized $B A$ coefficient decreases at the end of the sample (see Figure A7 in the supplementary Appendix). The results reported in Table A2 of the supplementary Appendix indicate that, overall, our baseline findings remain largely unchanged. Focusing on the effect of OMT on the sensitivity of spreads to liquidity conditions in the periphery group, the impact of OMT is quantitatively substantially weaker. It maintains a significantly positive sign only in column 3 . Hence, the improvement in the periphery group's results referring to the TVP coefficient of the orthogonalized BA series depicted in Figure A7 relative to Figure 6 is not sufficient to overturn the positive sign of the OMT dummy in the most extended specification of Table A2. ${ }^{35}$

\footnotetext{
${ }^{34}$ Again, this finding is not surprising since the extended sample includes a substantial part of the pre-crisis period, when European financial markets were less fragmentated and the transmission mechanism of conventional monetary policy, with the MRO rate being one of the key policy instruments, was largely intact.

${ }^{35}$ As we highlight in footnote 12 above, the bid-ask spread captures a specific dimension of liquidity (trading cost). It is possible that using other dimensions of liquidity (e.g. trading volume) the finding of a positive sign for the OMT dummy on the $B A$ TVP coefficient in the periphery group could be overturned. However, data for these
} 


\section{Summary and concluding remarks}

In this paper, we investigate the hypothesis that ECB policy interventions can affect the model used by markets to price EMU sovereign bonds. Our empirical strategy consists of two steps. First, we use a TVP panel methodology to model the ten-year government bond yield spread against Germany of ten EMU countries on proxies of international financial risk, liquidity risk and credit risk over the period January 1999 to July 2016. Second, we estimate the impact of ECB interventions on the time-varying sensitivity of spreads to each risk factor, controlling for the effects of bank credit risk.

Our work brings together multiple branches of the literature on the European sovereign debt crisis. Our main findings are as follows. First, we present evidence consistent with the predictions of theoretical models regarding multiple equilibria and the role of shifts in expectations. Second, we find that the announcement of OMT in August 2012 was a game changer for the evolution of the European debt crisis, as it led to a new bond-pricing regime. This regime is characterised by a weakened link between spreads and fundamentals, but with higher spreads relative to the precrisis era and a residual redenomination risk, carried over from the crisis regime, in the periphery countries. Third, we show that ECB policy interventions affect the relationship between spreads and fundamentals not only directly, but also indirectly, working through the bank credit risk channel. The OMT announcement and the expansion of the ECB's balance sheet through purchases of sovereign bonds expressed the commitment of the ECB to preserve the single currency and enabled markets to exit the crisis regime.

This assessment, however, comes with three important caveats. The first relates to the design of the OMT and the conditionality it involves. The markets' response to the OMT's introduction indicates that the activation of the OMT, if needed in the future, will occur smoothly. There can be no guarantee, however, that this expectation will certainly be validated. For example, there

alternative measures of liquidity are not available for the full sample of countries and time-period covered by our analysis. 
may be disagreements among the ESM members, whose unanimous agreement is necessary for the OMT's activation, or there may be difficulties in agreeing the terms of the necessary EMS programme with the crisis-hit country. If the activation of the OMT programme is not smooth, the unavoidable update of market expectations regarding its role may result in increased perceived default/denomination risk. In that case, the stabilizing effects caused by the OMT announcement may be moderated, or even fully offset, making a resurgence of the European debt crisis possible.

The second and third caveats relate to unconventional monetary policy. As unconventional monetary policy measures have played a significant role in supporting euro area sovereign bonds, their reversal in the future may cause renewed market turbulence. Furthermore, the downward pressure they exercise on sovereign borrowing costs could be a source of moral hazard in fiscal and structural reforms. On this important question, opinions are divided: some authors, including Claeys and Leandro (2016) arrive at reassuring conclusions, whereas other contributions, including Sinn (2014) and Deutche Bundesbank (2016), strike a much more sceptical tone. Given its far-reaching implications, the question merits considerable attention on behalf of academic authors. Meanwhile, and as long as the jury is still out, the prudent policy approach would be not to discount the risks of financial instability and moral hazard.

\section{References}

Acharya, V., Drechsler, I. and Schnabl, P. (2014). A pyrrhic victory? Bank bailouts and sovereign credit risk. Journal of Finance, 69, 2689-2739.

Acharya, V. and Steffen, S. (2015). The "greatest" carry trade ever? Understanding eurozone bank risks. Journal of Financial Economics, 115, 215-236. 
Acharya, V., Eisert, T., Eufinger, C. and Hirsch, C. (2017). Whatever it takes: The real effects of unconventional monetary policy. CEPR Discussion Paper No DP12005.

Afonso, A., Arghyrou, M.G. and Kontonikas, A. (2014). Pricing sovereign bond risk in the European Monetary Union area: an empirical investigation. International Journal of Finance and Economics, 19, 49-56.

Afonso, A., Arghyrou, M.G., Bagdatoglou, G. and Kontonikas, A. (2015). On the time-varying relationship between EMU sovereign spreads and their determinants. Economic Modelling, 44, 363-371.

Aizenman, J., Hutchison, M. and Jinjarak, Y. (2013). What is the risk of European sovereign debt defaults? Fiscal space, CDS spreads and market pricing of risk. Journal of International Money and Finance, 34, 37-59.

Altavilla, C., Giannone, D. and Lenza, M. (2014). The financial and macroeconomic effects of OMT announcements. European Central Bank, Working Paper No 1707.

Altavilla C., Carboni G. and Motto R. (2015). Asset purchases programmes and financial markets: Lessons from the euro area. European Central Bank, Working Paper No 1864.

Alter, A. and Schüler, Y.S. (2012). Credit spread interdependencies of European states and banks during the financial crisis. Journal of Banking and Finance, 36, 3444-3468.

Arghyrou, M.G. and Tsoukalas, J. (2011). The Greek debt crisis: Likely causes, mechanics and outcomes. World Economy, 34, 173-191.

Arghyrou, M.G. and Kontonikas, A. (2012). The EMU sovereign debt crisis: Fundamentals, expectations and contagion. Journal of International Financial Markets, Institutions and Money, 22, 658-677.

Aßmann, C. and Boysen-Hogrefe, J. (2012). Determinants of government bond spreads in the euro area: In good times as in bad". Empirica, 39, 341-356. 
Attinasi, M-G., Checherita, C. and Nickel, C. (2009). What explains the surge in euro area sovereign spreads during the financial crisis of 2007-09? European Central Bank, Working Paper No 1131.

Bank of International Settlements (2017). Monetary policy: Inching towards normalization. BIS 87th Annual Report, 59-78.

Barrios, S., Iversen, P., Lewandowska, M. and Setzer, R. (2009). Determinants of intra-euro-area government bond spreads during the financial crisis. European Commission, Economic Papers No 388.

Beber, A., Brandt, M. and Kavajecz, K. (2009). Flight-to-quality or flight-to-liquidity? Evidence from the euro-area bond market. Review of Financial Studies, 22, 925-957.

Bekaert, G., Hodrick, R. and Zhang, X. (2009). International stock return comovements. Journal of Finance, 64, 2591-2626.

Bekaert, G., Ehrmann, M., Fratzscher, M. and Mehl, A. (2014). The global crisis and equity market contagion. Journal of Finance, 69, 2597-2649.

Bekaert, G. and Hoerova, M. (2014). The VIX, the variance premium and stock market volatility. Journal of Econometrics, 183, 181-192.

Beirne, J. and Fratzscher, M. (2013). The pricing of sovereign risk and contagion during the European sovereign debt crisis. Journal of International Money and Finance, 34, 60-82.

Bernoth, K. and Erdogan, B. (2012). Sovereign bond yield spreads: A time-varying coefficient approach. Journal of International Money and Finance, 31, 639-656.

Bollerslev, T., Tauchen, G. and Zhou, H. (2009). Expected stock returns and variance risk premia. Review of Financial Studies, 22, 4463-4492.

Cai, Z. (2007). Trending time-varying coefficient time series models with serially correlated errors. Journal of Econometrics, 136, 163-188.

Caggiano, G. and Greco, L. (2012). Fiscal and financial determinants of Eurozone sovereign spreads. Economics Letters, 117, 774-776. 
Calvo, G. A. (1988). Servicing the public debt: The role of expectations. The American Economic Review, 78, 647-661.

Chodorow-Reich, G., 2014. Effects of unconventional monetary policy on financial institutions. Brookings Papers on Economic Activity, Spring 2014, 155-204.

Claeys, G. and Leandro, A. (2016). The European Central Bank's quantitative easing programme: Limits and risks. Bruegel Policy Contribution No 4.

Constantini, M., Fragetta, M. and Melina, G. (2014). Determinants of sovereign bond yield spreads in the EMU: An optimal currency area perspective. European Economic Review, 70, 337-349.

D'Amico, S., Kim, D. and Wei, M. (2010). Tips from TIPS: The informational content of Treasury inflation-protected security prices. Federal Reserve Board of Governors, Finance and Economics Discussion Series Paper 19.

D'Agostino, A. and Ehrmann, M. (2014). The pricing of G7 sovereign bond spreads - The times, they are a-changin. Journal of Banking and Finance, 47, 155-176.

Dai, J. and Sperlich, J. (2010). Simple and effective boundary correction for kernel densities and regression with an application to the world income and Engel curve estimation. Computational Statistics and Data Analysis, 54, 2487-2497.

De Bruyckere, V., Gerhardt, M., Schepens, G. and Vander Vennet, R. (2013). Journal of Banking and Finance, 37, 4793-4809.

De Grauwe, P. and Ji, Y. (2013). Self-fulfilling crises in the Eurozone: An empirical test. Journal of International Money and Finance, 34, 15-36.

De Santis, R. A. (2014). The euro area sovereign debt crisis: Identifying flight-to-liquidity and the spillover mechanisms. Journal of Empirical Finance, 26, 150-170.

De Santis, R.A. (2015). A measure of redenomination risk. European Central Bank, Working Paper No 1785. 
De Santis, R.A. (2016). Impact of the asset purchase programme on euro area government bond yields using market news. European Central Bank, Working Paper No 1939.

Delatte, A.L., Fouquau, J. and Portes, R. (2017). Regime-dependent sovereign risk pricing during the euro crisis. Review of Finance, 21, 363-385.

Deutsche Bundesbank (2016). The macroeconomic impact of quantitative easing in the euro area. Monthly Report 06/2016.

Dewachter, H., Iania, L., Lyrio, M. and de Sola Perea, M. (2015). A macro-financial analysis of the euro area sovereign bond market. Journal of Banking and Finance, 50, 308-325.

Diamond, D. W. and Dybvig, P. H. (1983). Bank runs, deposit insurance, and liquidity. Journal of Political Economy, 91, 401-419.

Di Cesare, A., Grande, G., Manna, M. and Marco, T. (2012), Recent estimates of sovereign risk premia for euro-area countries. Banca d'Italia, Occasional Paper No 128.

Drechsler, I., Drechsel, T., Marques-Ibanez, D. and Schnabl, P. (2016). Who borrows from the lender of last resort? Journal of Finance, 71, 1933-1974.

Ehrmann, M. and Fratzscher, M. (2017). Euro area government bonds - Fragmentation and contagion during the sovereign debt crisis. Journal of International Money and Finance, $70,26-44$.

Eser, F. and Schwaab, B. (2013). Assessing asset purchases within the ECB's securities markets programme. European Central Bank, Working Paper No 1587.

Favero, C., Pagano, M. and von Thadden, E.L. (2010). How does liquidity affect government bond yields? Journal of Financial and Quantitative Analysis, 45, 107-134.

Florackis, C., Kontonikas, A. and Kostakis, A. (2014). Stock market liquidity and macroliquidity shocks: Evidence from the 2007-2009 financial crisis. Journal of International Money and Finance, 44, 97-117.

Fratzscher, M., Lo Duca, M. and Straub, R. (2014). ECB Unconventional monetary policy actions: Market impact, international spillovers and transmission channels. Paper 
presented at the 15th Jacques Polak Annual Research Conference, International Monetary Fund, November 13-14, 2014.

Garcia, J.A. and Werner, S.E.V. (2016). Bond risk premia, macroeconomic factors and financial crisis in the euro area. European Central Bank Working Paper No 1938.

Gerlach, S., Schulz, A. and Wolff, G. (2010). Banking and sovereign risk in the euro-area. Centre for Economic Policy Research Discussion Paper No. 7833.

Gibson, H.D., Hall, S.G. and Tavlas, G.S. (2016). The effectiveness of the ECB's asset purchase programs of 2009 to 2012. Journal of Macroeconomics, 47, 45-57.

Ghysels, E., Idier, J., Manganelli, S. and Vergote, O. (2014). A high frequency assessment of the ECB's securities markets programme. European Central Bank, Working Paper No 1642.

Goldstein, M. (1998). The Asian financial crisis: Causes, cures, and systemic implications. Peterson Institute for International Economics.

Gonzalez, A., Teräsvirta, T., Van Dijk, D. and Yang, Y. (2017.) Panel smooth transition regression models. Department of Statistics, Uppsala University, Working paper No 2017:3.

Granger, C.W.J. (2008). Non-linear models: Where do we go next - Time varying parameters? Studies in Nonlinear Dynamics and Econometrics, 12, 1-9.

Hansen, B. (1999). Threshold effects in non-dynamic panels: Estimation, testing and inference. Journal of Econometrics, 93, 345-368.

Jeanne, O. and Rose, A. K. (2002). Noise trading and exchange rate regimes. Quarterly Journal of Economics, 117, 537-569.

Koijen, R.S., Koulischer, F., Nguyen, B. and Yogo, M. (2016). Quantitative easing in the euro area: The dynamics of risk exposures and the impact on asset prices. Bank De France, Document de Travail No 601.

Krishnamurthy, A., Nagel, S. and Vissing-Jorgensen, A. (2015). ECB policies involving government bond purchases: Impact and channels. Unpublished Working Paper. 
Krugman, P. (1979). A model of balance-of-payments crises. Journal of Money, Credit and Banking, 11, 311-325.

Lee, J. and Strazicich, M.C. (2003). Minimum Lagrange multiplier unit root test with two structural breaks. Review of Economics and Statistics, 85, 1082-1089.

Li, D., Chen, J. and Gao, J. (2011). Non-parametric time-varying coefficient panel data models with fixed effects. Econometrics Journal, 14, 387-408.

Manasse, P. and Zavalloni, L. (2013). Sovereign contagion in Europe: Evidence from the CDS market. Department of Economics, University of Bologna, DSE Working Paper No 863.

Manganelli, S. and Wolswijk, G. (2009). What drives spreads in the euro-area government bond market? Economic Policy, 24, 191-240.

Monfort, A. and Renne, J.P. (2013). Decomposing euro-area sovereign spreads: credit and liquidity risks. Review of Finance, 18, 2103-2151.

Paniagua, J., Sapena, J. and Tamarit, C. (2016). Sovereign debt spreads in EMU: The timevarying role of fundamentals and market distrust. Journal of Financial Stability, in press.

Racine, J.S. (2008). Nonparametric econometrics: A primer. Foundations and Trends in Econometrics, 3, 1-88.

Robinson, P.M. (1989). Nonparametric estimation of time-varying parameters. Statistical analysis and forecasting of economic structural change. Springer: Berlin.

Obstfeld, M., (1986). Rational and self-fulfilling balance-of-payments crises. American Economic Review, 76, 72-81.

Obstfeld, M. (1996). Models of currency crises with self-fulfilling features. European Economic Review, 40, 1037-48.

Saka, O., Fuertes, A.M. and Kalotychou, E. (2015). ECB policy and Eurozone fragility: Was De Grauwe right? Journal of International Money and Finance, 54, 168-185.

Sinn, H.W. (2014). The Euro trap: On bursting bubbles, budgets, and beliefs. Oxford University Press: Oxford. 
Stillwagon, J. (2017). TIPS and the VIX: Spillovers from financial panic to breakeven inflation in an automated, nonlinear modeling framework. Oxford Bulletin of Economics and Statistics (available as online early view).

Su, L., and Ullah, A., (2006). Profile likelihood estimation of partially linear panel data models with fixed effects. Economics Letters, 92, 75-81.

Sun, Y., R. J. Carroll and Li, D., (2009). Semiparametric Estimation of Fixed Effects Panel Data Varying Coefficient Models. Advances in Econometrics, 25, 101-29.

Szczerbowicz, U. (2015). The ECB unconventional monetary policies: Have they lowered market borrowing costs for banks and governments. International Journal of Central Banking, 11, 91-127.

Trebesch, C. and Zettelmeyer, J. (2014). ECB interventions in distressed sovereign debt markets: The case of Greek bonds. CESifo Working Paper No 4731.

Whaley, R.E. (2000). The investor fear gauge. Journal of Portfolio Management, 26, 12-17. 
Figure 1: 10-year government bond yield spreads
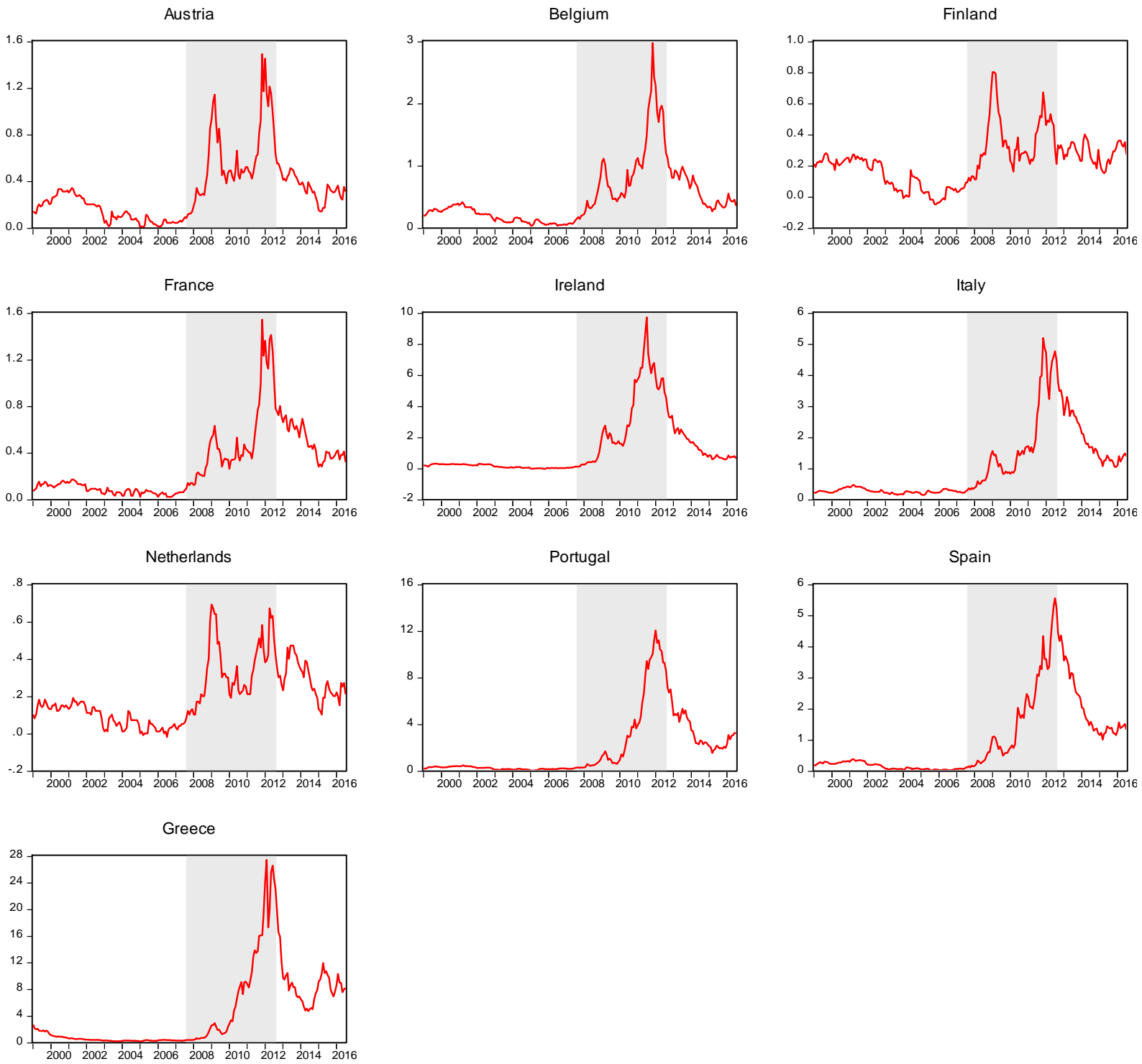

Note: This figure plots the 10-year government bond yield spreads versus Germany over the period January 1999 July 2016 (211 observations) for ten-euro area countries. Vertical axis: percentage points. The shaded area denotes the period July 2007 - July 2012. Source: European Central Bank. 
Figure 2: ECB monetary policy indicators

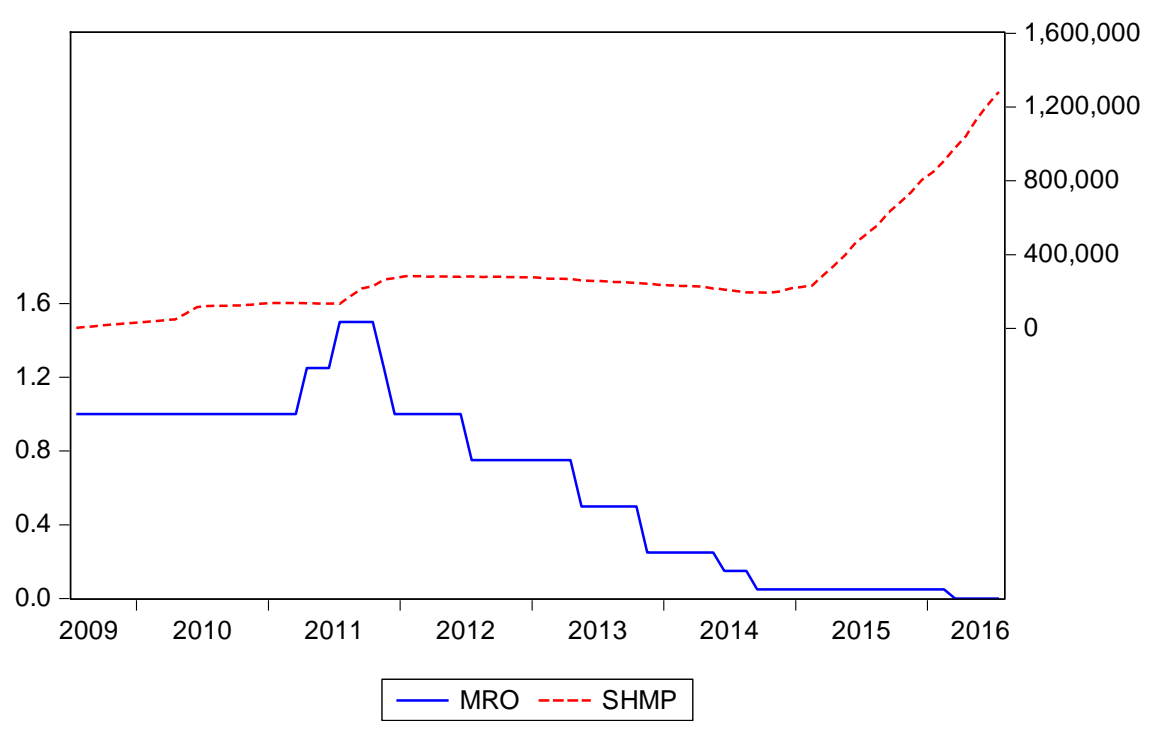

Note: This figure plots the ECB main refinancing operations rate (MRO) and the amount (in millions of euros) of securities held by the ECB for monetary policy purposes (SHMP) over the period July 2009 - July 2016 (85 observations). Left vertical axis: / - percentage points; Right vertical axis: - euro millions. Source: European Central Bank.

\section{Figure 3: European banking sector CDS}

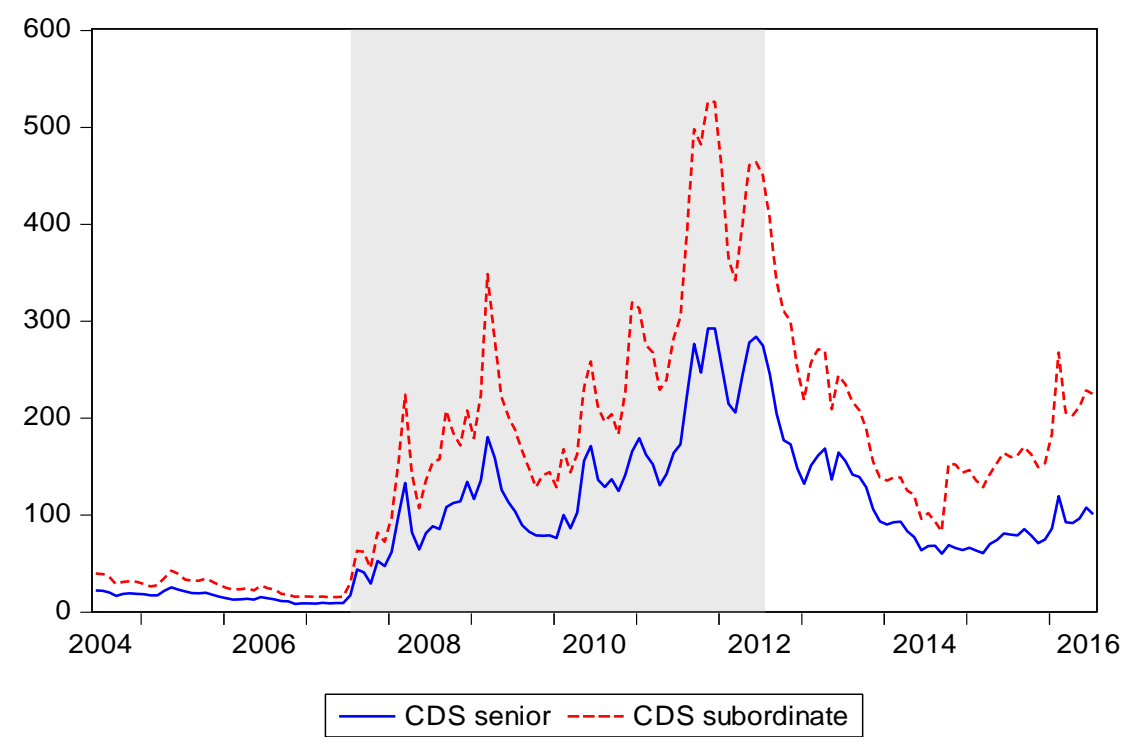

Note: This figure plots the Markit CDS indices covering 25 senior (CDS senior) and junior subordination (CDS subordinate) European banks over the period June 2004 - July 2016 (146 observations), measured in basis points. The shaded area denotes the period July 2007 - July 2012. Source: Markit 


\section{Figure 4: TVP coefficients - Full panel excluding Greece}
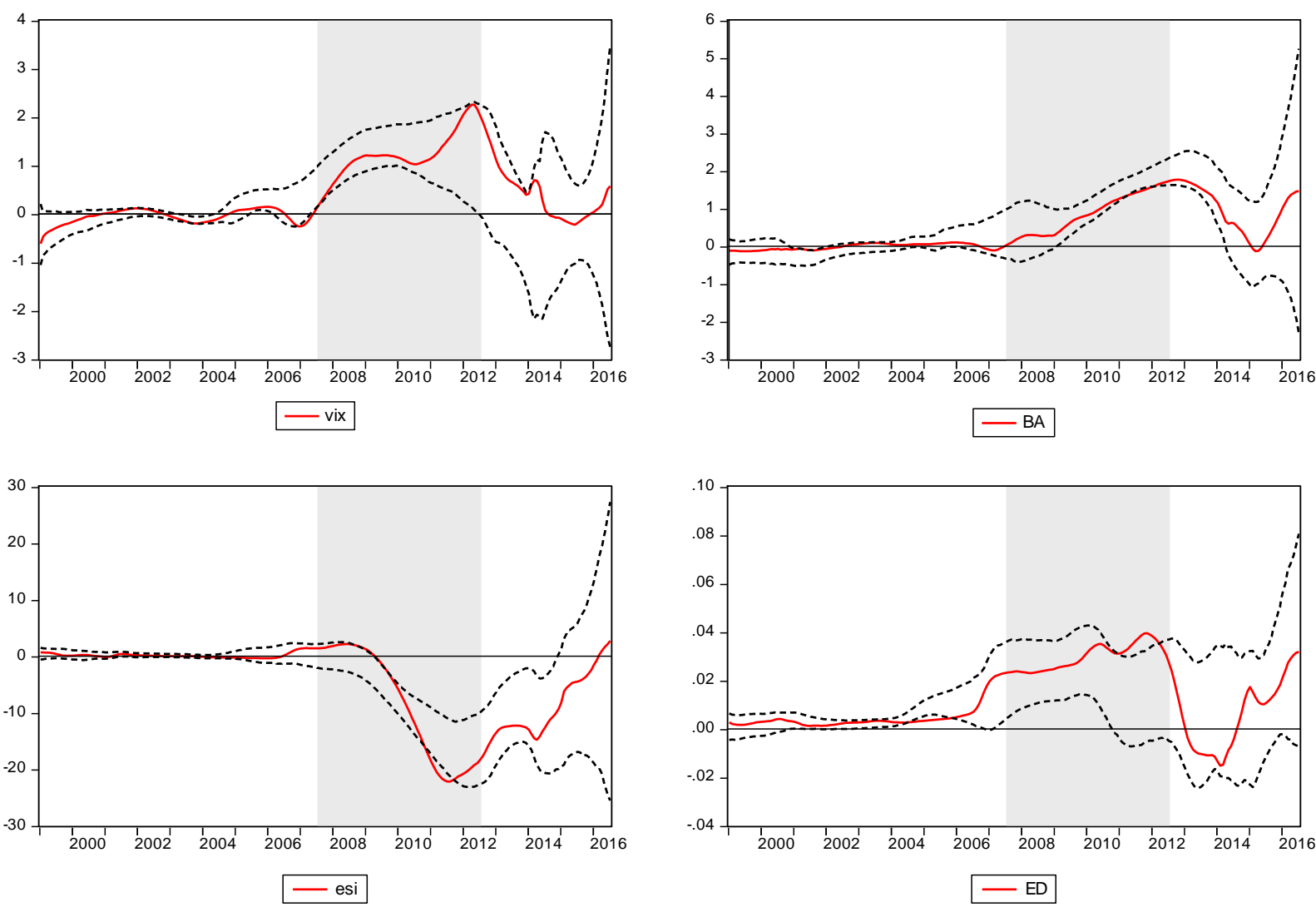

Note: This figure plots non-parametric estimates of Equation (1) over the period January 1999 - July 2016 (211 observations). Time-varying panel (TVP) coefficients and 95\% confidence intervals (dotted lines), calculated using the wild bootstrap method (1000 iterations), are shown. The estimation bandwidth parameter $(h)$ is set to 0.15 and the bandwidth correction parameter $(\varepsilon)$ to 0.08 . The panel includes Austria, Belgium, Finland, France, Ireland, Italy, the Netherlands, Portugal and Spain. The dependent variable is the 10 -year government bond yield spread versus Germany. The set of explanatory variables includes the logarithm of the Chicago Board Options Exchange Volatility Index (vix), the bid-ask spread of 10-year government bonds (BA), the logarithm of the Economic Sentiment Index relative to Germany (esi), and the 1-year ahead expected gross government debt to GDP ratio relative to Germany (ED). The shaded area denotes the period July 2007 - July 2012. 
Figure 5: TVP coefficients - Core countries
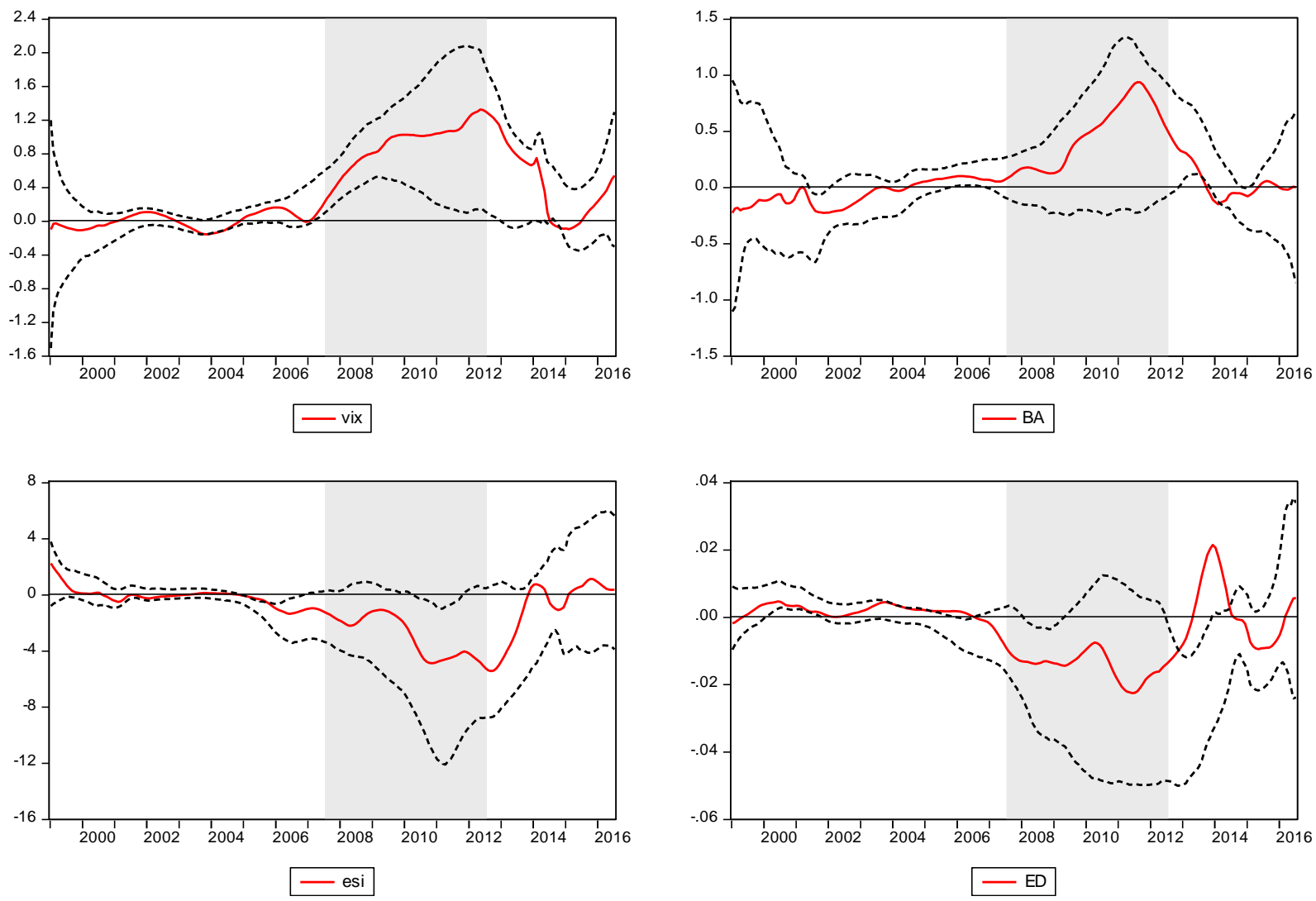

Note: This figure plots non-parametric estimates of Equation (1) over the period January 1999 - July 2016 (211 observations). Time-varying panel (TVP) coefficients and 95\% confidence intervals (dotted lines), calculated using the wild bootstrap method (1000 iterations), are shown. The estimation bandwidth parameter $(h)$ is set to 0.15 and the bandwidth correction parameter $(\varepsilon)$ to 0.08 . The panel includes Austria, Belgium, Finland, France and the Netherlands. The dependent variable is the 10-year government bond yield spread versus Germany. The set of explanatory variables includes the logarithm of the Chicago Board Options Exchange Volatility Index (vix), the bidask spread of 10-year government bonds (BA), the logarithm of the Economic Sentiment Index relative to Germany (esi), and the 1-year ahead expected gross government debt to GDP ratio relative to Germany (ED). The shaded area denotes the period July 2007 - July 2012. 
Figure 6: TVP coefficients - Periphery countries excluding Greece
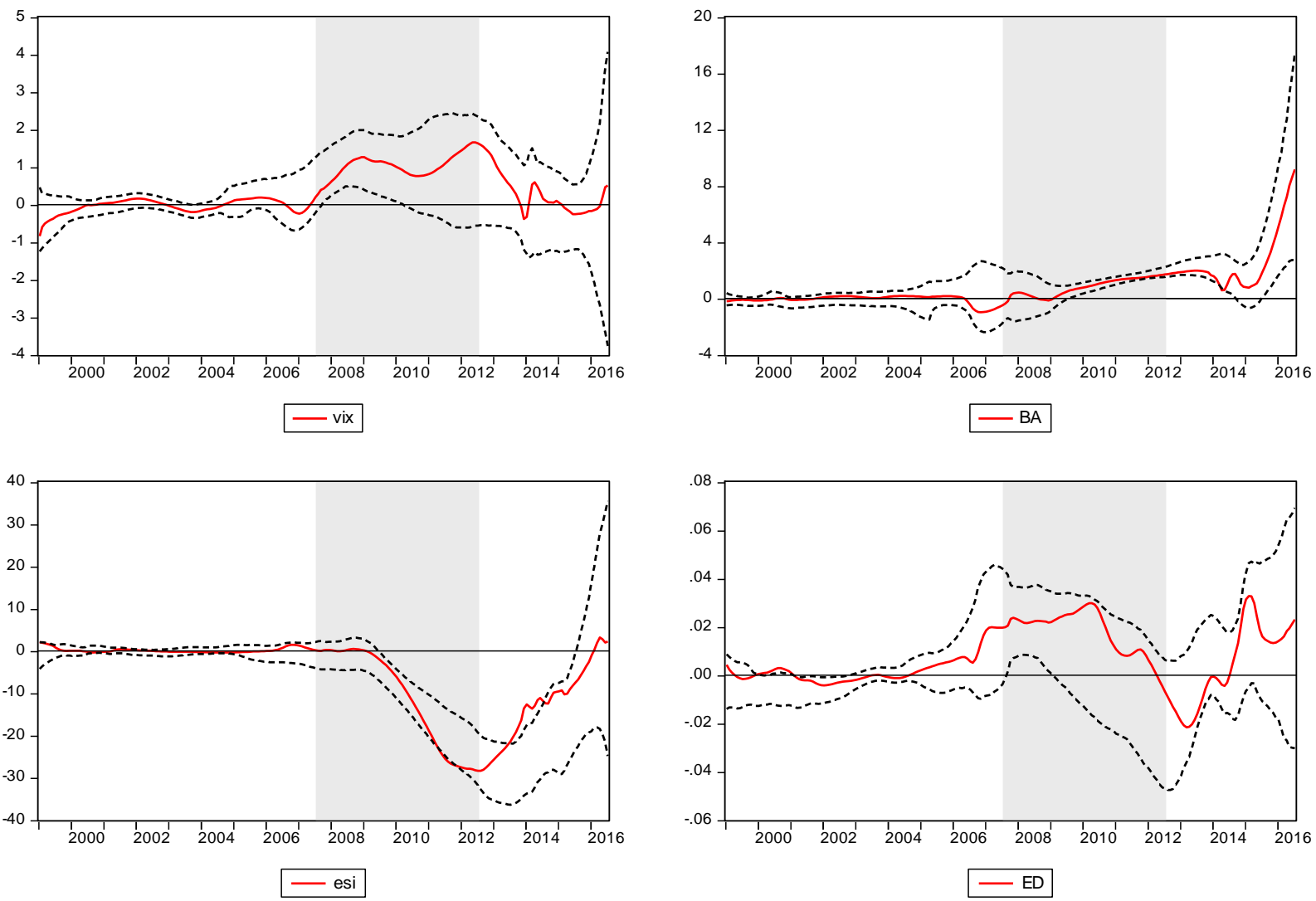

Note: This figure plots non-parametric estimates of Equation (1) over the period January 1999 - July 2016 (211 observations). Time-varying panel (TVP) coefficients and 95\% confidence intervals (dotted lines), calculated using the wild bootstrap method (1000 iterations), are shown. The estimation bandwidth parameter $(h)$ is set to 0.15 and the bandwidth correction parameter $(\varepsilon)$ to 0.08 . The panel includes Ireland, Italy, Portugal and Spain. The dependent variable is the 10-year government bond yield spread versus Germany. The set of explanatory variables includes the logarithm of the Chicago Board Options Exchange Volatility Index (vix), the bid-ask spread of 10-year government bonds (BA), the logarithm of the Economic Sentiment Index relative to Germany (esi), and the 1-year ahead expected gross government debt to GDP ratio relative to Germany (ED). The shaded area denotes the period July 2007 - July 2012. 
Figure 7: TVP coefficients - Full panel including Greece
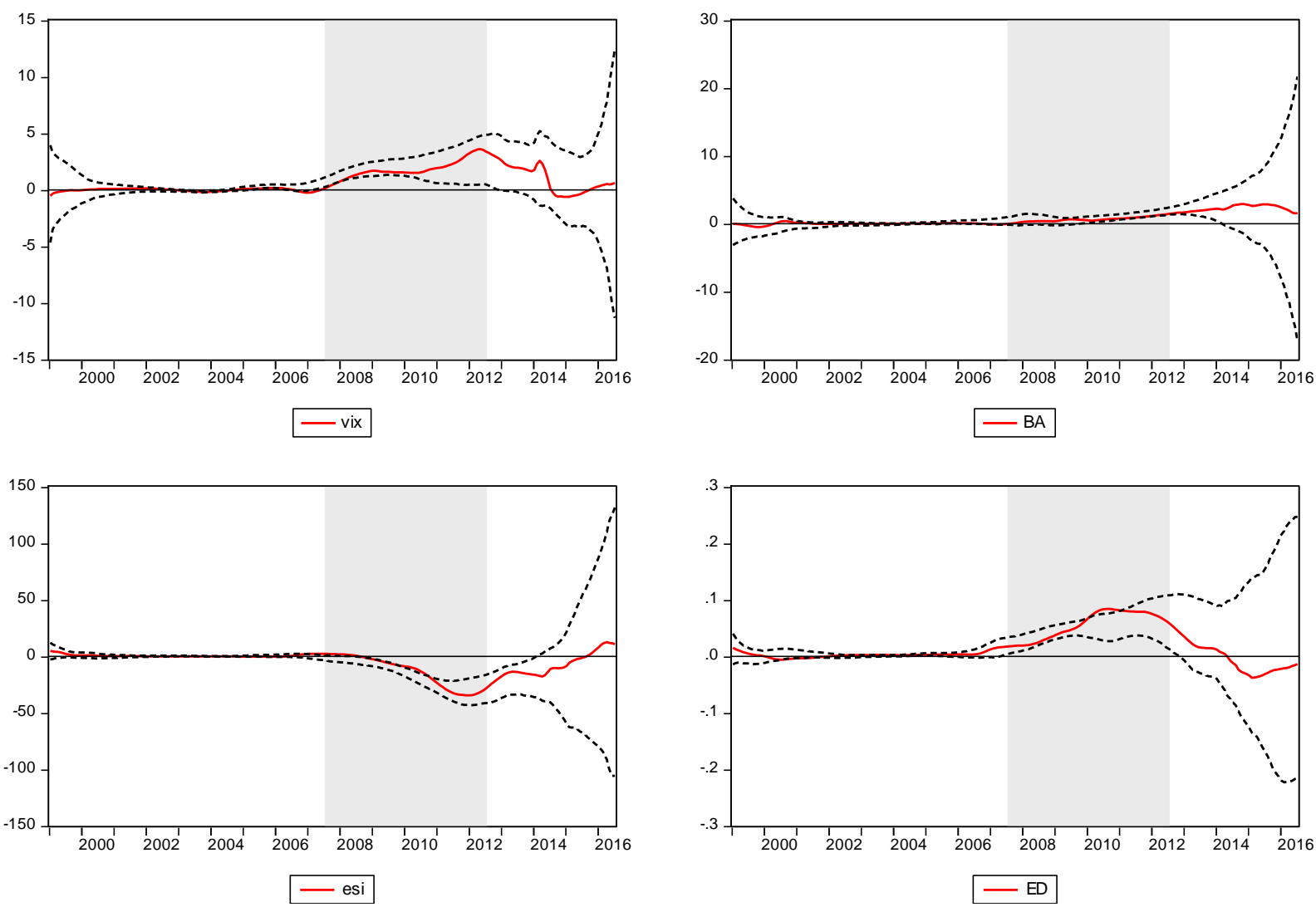

Note: This figure plots non-parametric estimates of Equation (1) over the period January 1999 - July 2016 (211 observations). Time-varying panel (TVP) coefficients and 95\% confidence intervals (dotted lines), calculated using the wild bootstrap method (1000 iterations), are shown. The estimation bandwidth parameter $(h)$ is set to 0.15 and the bandwidth correction parameter $(\varepsilon)$ to 0.08. The panel includes Austria, Belgium, Finland, France, Greece, Ireland, Italy, the Netherlands, Portugal and Spain. The dependent variable is the 10-year government bond yield spread versus Germany. The set of explanatory variables includes the logarithm of the Chicago Board Options Exchange Volatility Index (vix), the bid-ask spread of 10-year government bonds (BA), the logarithm of the Economic Sentiment Index relative to Germany (esi), and the 1-year ahead expected debt-to-GDP ratio relative to Germany (ED). The shaded area denotes the period July 2007 - July 2012. 
Figure 8: TVP coefficients - Periphery countries including Greece
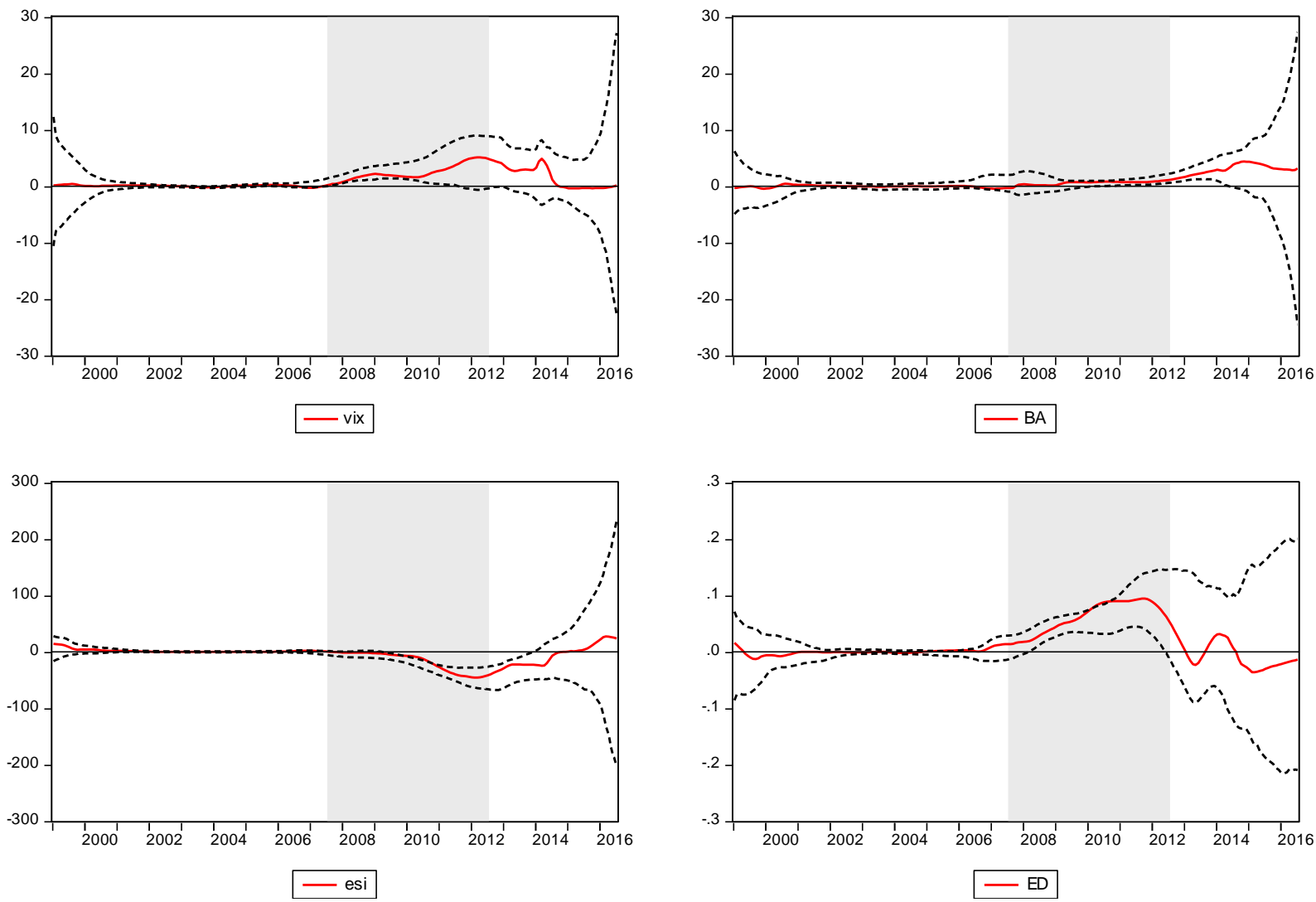

Note: This figure plots non-parametric estimates of Equation (1) over the period January 1999 - July 2016 (211 observations). Time-varying panel (TVP) coefficients and 95\% confidence intervals (dotted lines), calculated using the wild bootstrap method (1000 iterations), are shown. The estimation bandwidth parameter $(h)$ is set to 0.15 and the bandwidth correction parameter $(\varepsilon)$ to 0.08 . The panel includes Ireland, Italy, Greece, Portugal and Spain. The dependent variable is the 10-year government bond yield spread versus Germany. The set of explanatory variables includes the logarithm of the Chicago Board Options Exchange Volatility Index (vix), the bid-ask spread of 10-year government bonds (BA), the logarithm of the Economic Sentiment Index relative to Germany (esi), and the 1-year ahead expected gross government debt to GDP ratio relative to Germany (ED). The shaded area denotes the period July 2007 - July 2012. 


\section{Figure 9: TVP coefficients - Full panel - Using orthogonalized bid-ask spread}
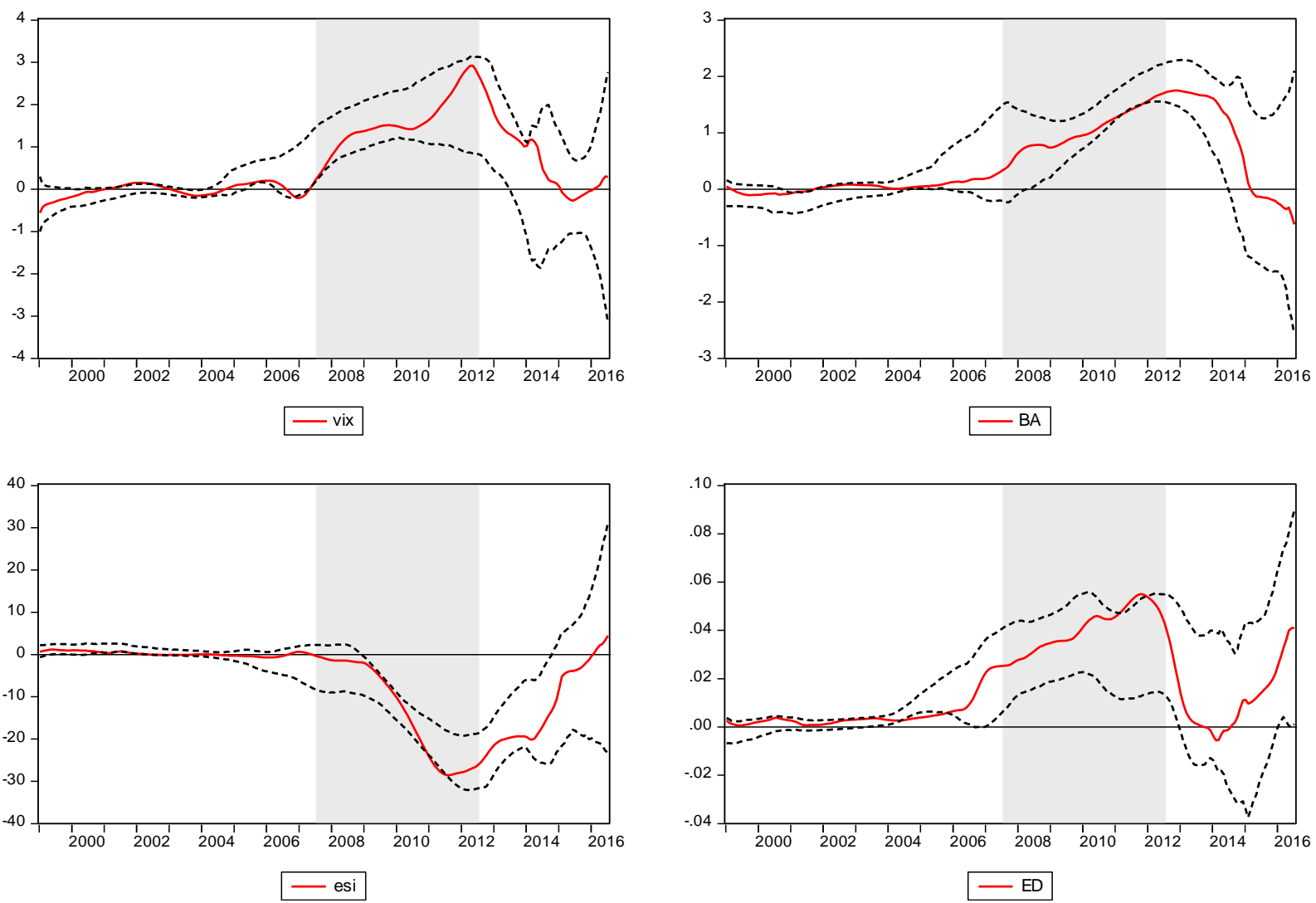

Note: This figure plots non-parametric estimates of Equation (1) over the period January 1999 - July 2016 (211 observations). Time-varying panel (TVP) coefficients and 95\% confidence intervals (dotted lines), calculated using the wild bootstrap method (1000 iterations), are shown. The estimation bandwidth parameter $(h)$ is set to 0.15 and the bandwidth correction parameter $(\varepsilon)$ to 0.08 . The panel includes Austria, Belgium, Finland, France, Ireland, Italy, the Netherlands, Portugal and Spain. The dependent variable is the 10 -year government bond yield spread versus Germany. The set of explanatory variables includes the logarithm of the Chicago Board Options Exchange Volatility Index (vix), the orthogonalized bid-ask spread of 10-year government bonds (BA), the logarithm of the Economic Sentiment Index relative to Germany (esi), and the 1-year ahead expected gross government debt to GDP ratio relative to Germany (ED). The orthogonalized BA series correspond to the residuals from a fixed effects panel regression of BA on vix, esi and ED. The shaded area denotes the period July 2007 - July 2012. 


\section{Figure 10: TVP coefficients - Full panel - Replacing VIX with realised volatility and volatility premium}
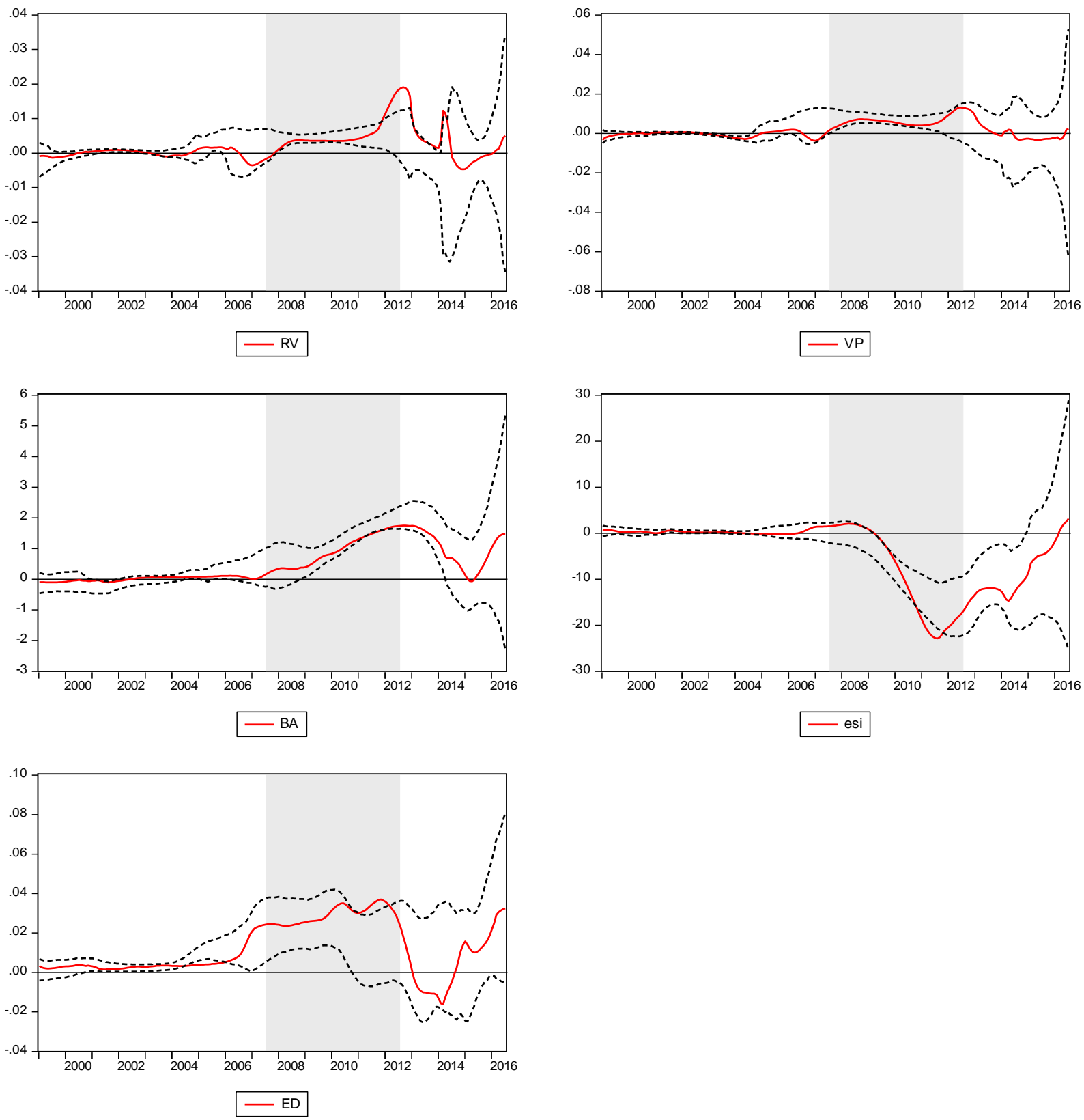

Note: This figure plots non-parametric estimates of Equation (1) over the period January 1999 - July 2016 (211 observations). Time-varying panel (TVP) coefficients and 95\% confidence intervals (dotted lines), calculated using the wild bootstrap method (1000 iterations), are shown. The estimation bandwidth parameter $(h)$ is set to 0.15 and the bandwidth correction parameter $(\varepsilon)$ to 0.08. The panel includes Austria, Belgium, Finland, France, Ireland, Italy, the Netherlands, Portugal and Spain. The dependent variable is the 10-year government bond yield spread versus Germany. The set of explanatory variables includes the realised volatility (RV), the volatility premium (VP), the bid-ask spread of 10-year government bonds (BA), the logarithm of the Economic Sentiment Index relative to Germany (esi), and the 1-year ahead expected gross government debt to GDP ratio relative to Germany (ED). The shaded area denotes the period July 2007 - July 2012. 


\section{Figure 11: TVP coefficients - Full panel - Adding real effective exchange rate}
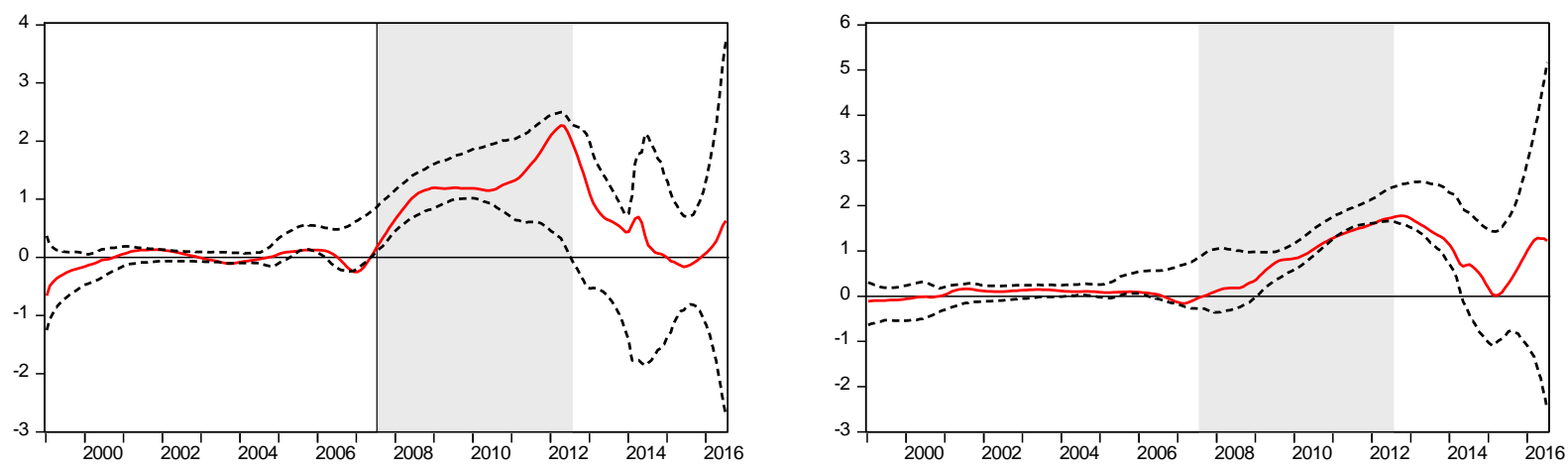

- vix
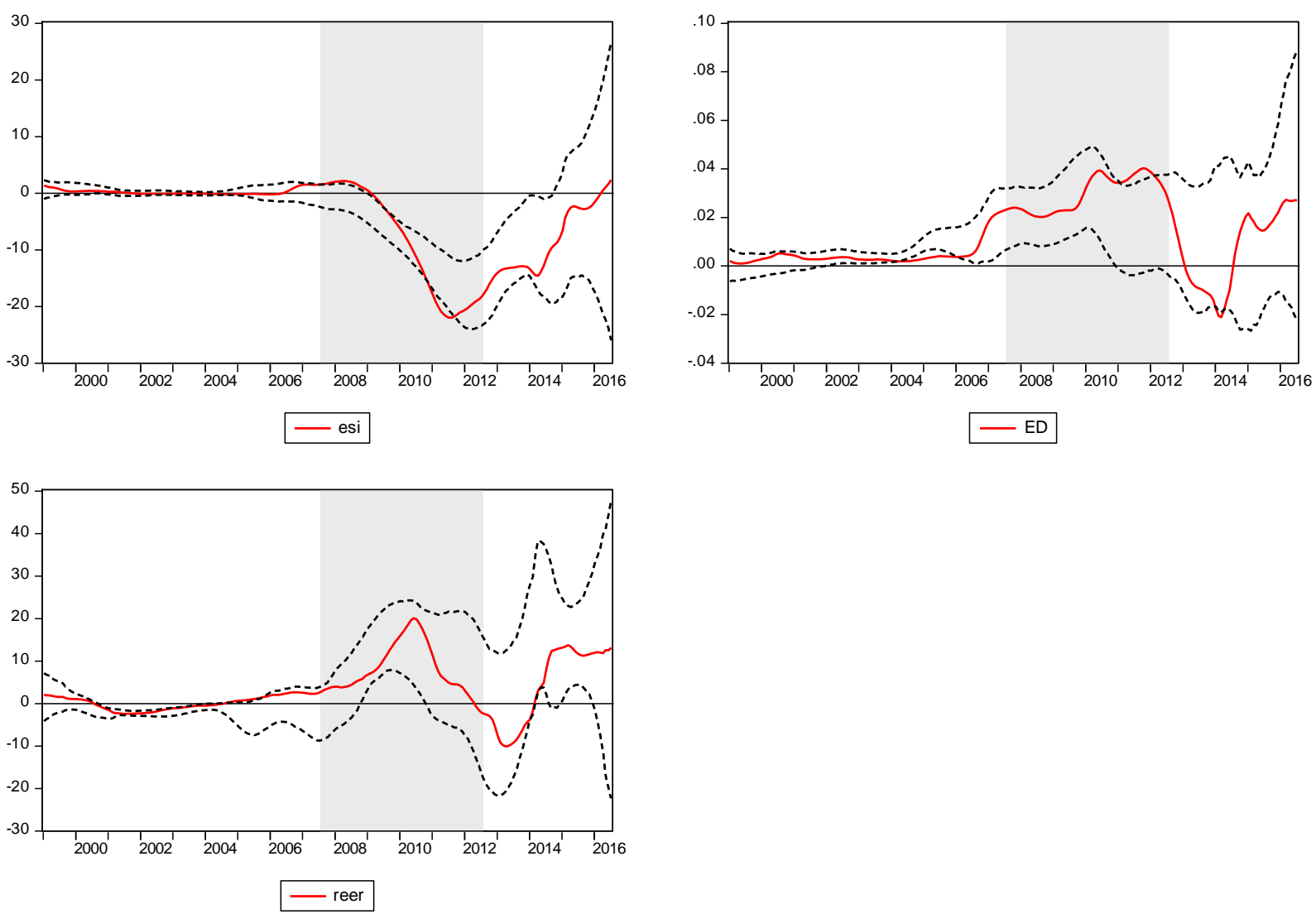

Note: This figure plots non-parametric estimates of Equation (1) over the period January 1999 - July 2016 (211 observations). Time-varying panel (TVP) coefficients and 95\% confidence intervals (dotted lines), calculated using the wild bootstrap method (1000 iterations), are shown. The estimation bandwidth parameter $(h)$ is set to 0.15 and the bandwidth correction parameter $(\varepsilon)$ to 0.08 . The panel includes Austria, Belgium, Finland, France, Ireland, Italy, the Netherlands, Portugal and Spain. The dependent variable is the 10-year government bond yield spread versus Germany. The set of explanatory variables includes the logarithm of the Chicago Board Options Exchange Volatility Index (vix), the bid-ask spread of 10-year government bonds (BA), the logarithm of the Economic Sentiment Index relative to Germany (esi), the 1-year ahead expected gross government debt to GDP ratio relative to Germany (ED), and the logarithm of the real effective exchange rate (reer). The shaded area denotes the period July 2007 - July 2012. 
Figure 12: Time effects - Core and periphery countries

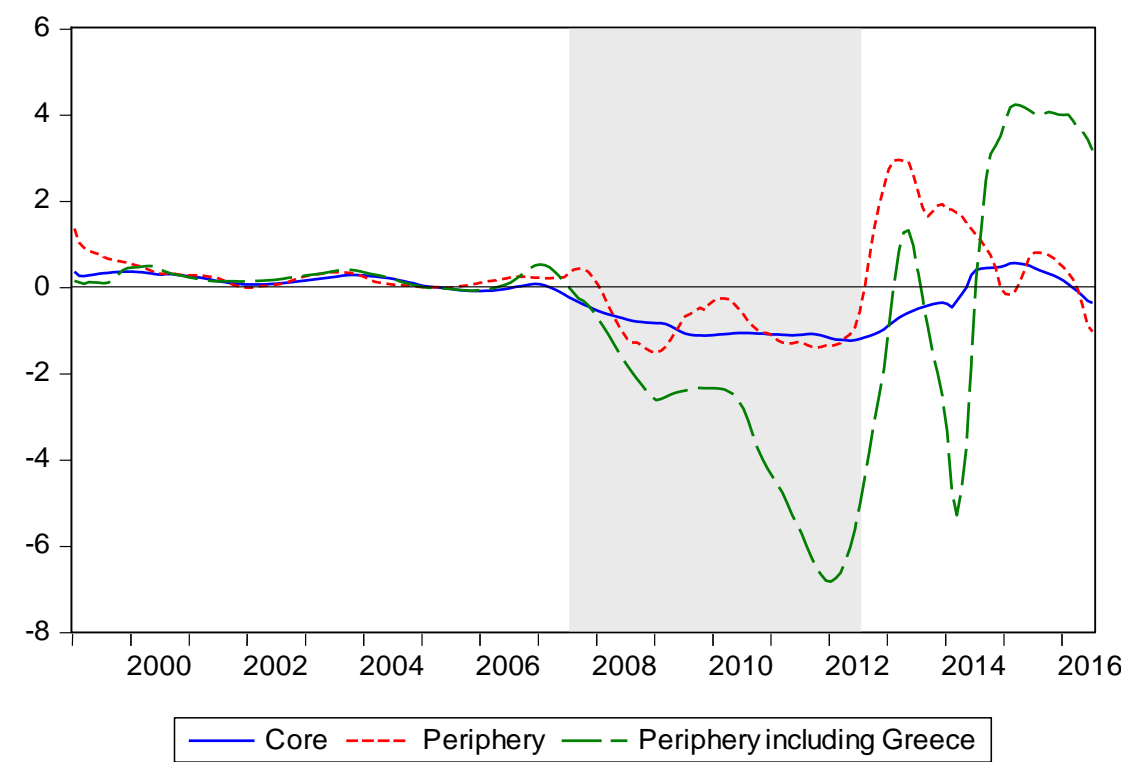

Note: This figure plots the estimated time effects from Equation (1) over the period January 1999 - July 2016 (211 observations). The panel of core countries includes Austria, Belgium, Finland, France and the Netherlands. The panel of periphery countries (excluding Greece) includes Ireland, Italy, Portugal and Spain. The dependent variable is the 10-year government bond yield spread versus Germany. The set of explanatory variables includes the logarithm of the Chicago Board Options Exchange Volatility Index (vix), the bid-ask spread of 10-year government bonds (BA), the logarithm of the Economic Sentiment Index relative to Germany (esi), and the 1-year ahead expected gross government debt to GDP ratio relative to Germany (ED). The shaded area denotes the period July 2007 - July 2012. 


\section{Figure 13: TVP coefficients - Non-EMU countries}
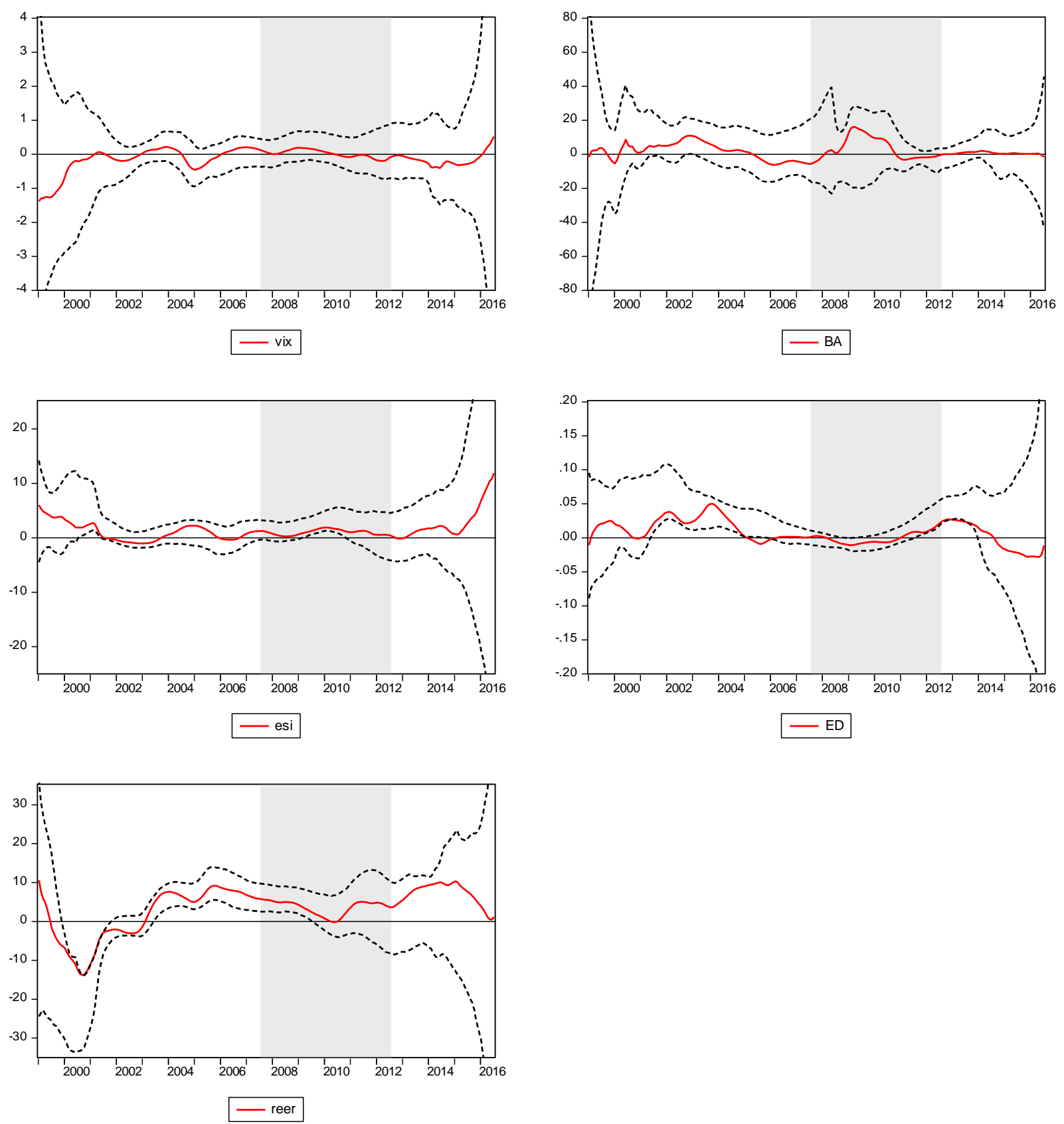

Note: This figure plots non-parametric estimates of Equation (1) over the period January 1999 - July 2016 (211 observations). Time-varying panel (TVP) coefficients and 95\% confidence intervals (dotted lines), calculated using the wild bootstrap method (1000 iterations), are shown. The estimation bandwidth parameter $(h)$ is set to 0.15 and the bandwidth correction parameter $(\varepsilon)$ to 0.08 . The panel includes Denmark, Sweden and the United Kingdom. The dependent variable is the 10-year government bond yield spread versus Germany. The set of explanatory variables includes the logarithm of the Chicago Board Options Exchange Volatility Index (vix), the bid-ask spread of 10-year government bonds (BA), the logarithm of the Economic Sentiment Index relative to Germany (esi), the 1-year ahead expected gross government debt to GDP ratio relative to Germany (ED), and the logarithm of the real effective exchange rate (reer). The shaded area denotes the period July 2007 - July 2012. 
Figure 14: Sentix euro breakup index

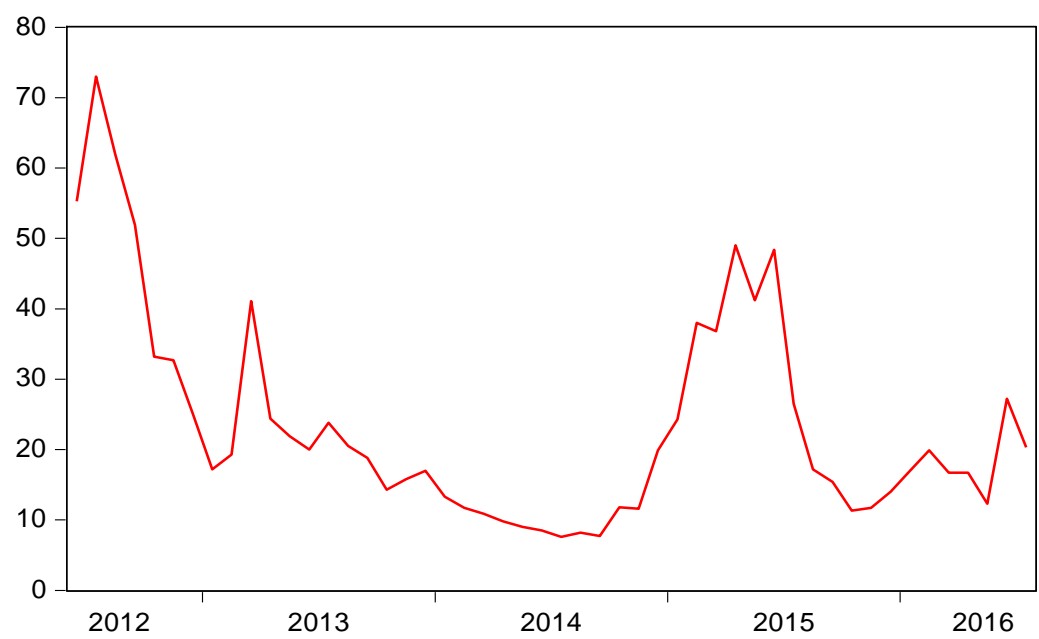

Note: This figure plots the Sentix euro breakup index over the period June 2012 - July 2016 (50 observations). The index measures the proportion (\%) of investors (private and institutional) predicting at least one country leaving the euro area within the next twelve months. Source: http://www.sentix.de/. 
Table 1: Descriptive statistics

Panel A: 10-year government bond yield spreads versus Germany

\begin{tabular}{|c|c|c|c|c|c|c|c|c|c|c|c|c|c|c|c|}
\hline & $\mathrm{AT}$ & $\mathrm{BE}$ & FI & FR & IE & IT & NL & PT & ES & EL & All+EL & All & Core & Per+EL & Per \\
\hline \multicolumn{16}{|c|}{ 1999.01-2016.07 } \\
\hline Mean & 0.320 & 0.486 & 0.228 & 0.300 & 1.297 & 1.064 & 0.202 & 1.915 & 1.007 & 4.353 & 1.117 & 0.758 & 0.307 & 1.927 & 1.321 \\
\hline StDev & 0.279 & 0.498 & 0.160 & 0.300 & 1.949 & 1.158 & 0.160 & 2.761 & 1.270 & 5.896 & 1.443 & 0.948 & 0.279 & 2.607 & 1.784 \\
\hline RStDev & 0.872 & 1.025 & 0.703 & 1.000 & 1.503 & 1.088 & 0.790 & 1.442 & 1.261 & 1.354 & 1.104 & 1.076 & 0.878 & 1.329 & 1.323 \\
\hline \multicolumn{16}{|c|}{$1999.01-2007.07$} \\
\hline Mean & 0.142 & 0.177 & 0.126 & 0.083 & 0.118 & 0.258 & 0.084 & 0.204 & 0.141 & 0.535 & 0.187 & 0.148 & 0.123 & 0.251 & 0.180 \\
\hline StDev & 0.102 & 0.111 & 0.101 & 0.041 & 0.110 & 0.073 & 0.058 & 0.109 & 0.111 & 0.518 & 0.133 & 0.091 & 0.083 & 0.184 & 0.101 \\
\hline RStDev & 0.715 & 0.628 & 0.804 & 0.491 & 0.930 & 0.282 & 0.690 & 0.533 & 0.788 & 0.968 & 0.683 & 0.651 & 0.665 & 0.700 & 0.633 \\
\hline \multicolumn{16}{|c|}{$2007.08-2012.07$} \\
\hline Mean & 0.596 & 0.922 & 0.360 & 0.509 & 3.150 & 1.698 & 0.337 & 3.606 & 1.606 & 7.233 & 2.002 & 1.421 & 0.545 & 3.459 & 2.515 \\
\hline StDev & 0.339 & 0.661 & 0.179 & 0.372 & 2.601 & 1.382 & 0.170 & 3.860 & 1.439 & 7.869 & 1.887 & 1.223 & 0.344 & 3.430 & 2.320 \\
\hline RStDev & 0.569 & 0.717 & 0.498 & 0.731 & 0.826 & 0.814 & 0.503 & 1.071 & 0.896 & 1.088 & 0.771 & 0.736 & 0.604 & 0.939 & 0.901 \\
\hline \multicolumn{16}{|c|}{$2012.08-2016.07$} \\
\hline Mean & 0.355 & 0.603 & 0.280 & 0.505 & 1.512 & 2.001 & 0.286 & 3.473 & 2.116 & 8.945 & 2.008 & 1.237 & 0.406 & 3.609 & 2.276 \\
\hline StDev & 0.112 & 0.257 & 0.064 & 0.154 & 0.994 & 0.863 & 0.097 & 1.672 & 1.104 & 3.595 & 0.891 & 0.591 & 0.137 & 1.645 & 1.158 \\
\hline RStDev & 0.315 & 0.427 & 0.228 & 0.305 & 0.658 & 0.431 & 0.340 & 0.481 & 0.521 & 0.402 & 0.411 & 0.412 & 0.323 & 0.499 & 0.523 \\
\hline
\end{tabular}


Panel B: Bid-ask spread of 10-year government bonds

\begin{tabular}{|c|c|c|c|c|c|c|c|c|c|c|c|c|c|c|c|}
\hline & AT & $\mathrm{BE}$ & FI & FR & $\mathrm{IE}$ & IT & NL & PT & $\mathrm{ES}$ & EL & All+EL & All & Core & Per+EL & Per \\
\hline \multicolumn{16}{|c|}{$1999.01-2016.07$} \\
\hline Mean & 0.204 & 0.199 & 0.092 & 0.110 & 0.412 & 0.113 & 0.083 & 0.474 & 0.188 & 0.567 & 0.244 & 0.208 & 0.138 & 0.351 & 0.297 \\
\hline StDev & 0.183 & 0.218 & 0.122 & 0.092 & 0.837 & 0.157 & 0.070 & 0.908 & 0.251 & 1.064 & 0.390 & 0.315 & 0.137 & 0.643 & 0.538 \\
\hline RStDev & 0.896 & 1.096 & 1.324 & 0.838 & 2.032 & 1.386 & 0.842 & 1.918 & 1.335 & 1.875 & 1.354 & 1.296 & 0.999 & 1.709 & 1.668 \\
\hline \multicolumn{16}{|c|}{$1999.01-2007.07$} \\
\hline Mean & 0.076 & 0.062 & 0.009 & 0.057 & 0.019 & 0.052 & 0.058 & 0.064 & 0.054 & 0.068 & 0.048 & 0.046 & 0.053 & 0.044 & 0.038 \\
\hline StDev & 0.036 & 0.023 & 0.083 & 0.043 & 0.098 & 0.022 & 0.055 & 0.032 & 0.029 & 0.046 & 0.047 & 0.047 & 0.048 & 0.045 & 0.045 \\
\hline RStDev & 0.473 & 0.365 & 9.066 & 0.749 & 5.212 & 0.415 & 0.946 & 0.507 & 0.539 & 0.682 & 1.895 & 2.030 & 2.320 & 1.471 & 1.668 \\
\hline \multicolumn{16}{|c|}{$2007.08-2012.07$} \\
\hline Mean & 0.306 & 0.237 & 0.142 & 0.173 & 1.182 & 0.238 & 0.143 & 1.205 & 0.359 & 1.262 & 0.525 & 0.443 & 0.200 & 0.849 & 0.746 \\
\hline StDev & 0.197 & 0.214 & 0.107 & 0.106 & 1.157 & 0.244 & 0.080 & 1.386 & 0.348 & 1.731 & 0.557 & 0.427 & 0.141 & 0.973 & 0.784 \\
\hline RStDev & 0.645 & 0.905 & 0.755 & 0.613 & 0.979 & 1.026 & 0.556 & 1.150 & 0.971 & 1.372 & 0.897 & 0.844 & 0.695 & 1.100 & 1.031 \\
\hline \multicolumn{16}{|c|}{$2012.08-2016.07$} \\
\hline Mean & 0.353 & 0.445 & 0.208 & 0.144 & 0.374 & 0.089 & 0.060 & 0.439 & 0.263 & 0.771 & 0.315 & 0.264 & 0.242 & 0.387 & 0.291 \\
\hline StDev & 0.163 & 0.219 & 0.072 & 0.086 & 0.513 & 0.075 & 0.025 & 0.470 & 0.214 & 0.294 & 0.213 & 0.204 & 0.113 & 0.313 & 0.318 \\
\hline RStDev & 0.460 & 0.492 & 0.347 & 0.602 & 1.374 & 0.840 & 0.419 & 1.071 & 0.816 & 0.381 & 0.680 & 0.714 & 0.464 & 0.897 & 1.025 \\
\hline
\end{tabular}


Panel C: Log of economic sentiment index relative to Germany

\begin{tabular}{|c|c|c|c|c|c|c|c|c|c|c|c|c|c|c|c|}
\hline & AT & $\mathrm{BE}$ & FI & FR & $\mathrm{IE}$ & IT & NL & PT & ES & EL & All+EL & All & Core & Per+EL & Per \\
\hline \multicolumn{16}{|c|}{$1999.01-2016.07$} \\
\hline Mean & 0.003 & 0.006 & 0.005 & 0.009 & 0.000 & 0.004 & -0.001 & -0.005 & 0.005 & -0.009 & 0.002 & 0.003 & 0.005 & -0.001 & 0.001 \\
\hline StDev & 0.029 & 0.026 & 0.034 & 0.034 & 0.012 & 0.040 & 0.031 & 0.044 & 0.046 & 0.063 & 0.036 & 0.033 & 0.031 & 0.041 & 0.036 \\
\hline RStDev & 8.645 & 4.091 & 6.266 & 3.645 & 32.657 & 9.700 & 43.620 & 9.256 & 9.705 & 6.704 & 13.429 & 14.176 & 13.253 & 13.604 & 15.329 \\
\hline \multicolumn{16}{|c|}{$1999.01-2007.07$} \\
\hline Mean & 0.025 & 0.025 & 0.026 & 0.036 & 0.006 & 0.030 & 0.020 & 0.018 & 0.039 & 0.036 & 0.026 & 0.025 & 0.026 & 0.026 & 0.023 \\
\hline StDev & 0.022 & 0.019 & 0.028 & 0.021 & 0.008 & 0.028 & 0.020 & 0.024 & 0.032 & 0.028 & 0.023 & 0.022 & 0.022 & 0.024 & 0.023 \\
\hline RStDev & 0.865 & 0.761 & 1.044 & 0.585 & 1.331 & 0.921 & 1.002 & 1.356 & 0.827 & 0.774 & 0.947 & 0.966 & 0.852 & 1.042 & 1.109 \\
\hline \multicolumn{16}{|c|}{$2007.08-2012.07$} \\
\hline Mean & -0.008 & -0.006 & 0.004 & -0.003 & -0.014 & -0.017 & -0.019 & -0.029 & -0.040 & -0.053 & -0.019 & -0.015 & -0.007 & -0.031 & -0.025 \\
\hline StDev & 0.019 & 0.020 & 0.022 & 0.023 & 0.007 & 0.040 & 0.030 & 0.057 & 0.035 & 0.072 & 0.033 & 0.028 & 0.023 & 0.042 & 0.035 \\
\hline RStDev & 2.277 & 3.360 & 6.087 & 7.045 & 0.508 & 2.320 & 1.594 & 1.992 & 0.880 & 1.356 & 2.742 & 2.896 & 4.073 & 1.411 & 1.425 \\
\hline \multicolumn{16}{|c|}{$2012.08-2016.07$} \\
\hline Mean & -0.028 & -0.018 & -0.037 & -0.031 & 0.006 & -0.024 & -0.022 & -0.023 & -0.013 & -0.051 & -0.024 & -0.021 & -0.027 & -0.021 & -0.014 \\
\hline StDev & 0.011 & 0.012 & 0.015 & 0.013 & 0.009 & 0.029 & 0.021 & 0.034 & 0.024 & 0.030 & 0.020 & 0.019 & 0.014 & 0.025 & 0.024 \\
\hline RStDev & 0.399 & 0.660 & 0.393 & 0.421 & 1.614 & 1.169 & 0.931 & 1.482 & 1.942 & 0.579 & 0.959 & 1.001 & 0.561 & 1.357 & 1.552 \\
\hline
\end{tabular}


Panel D: 1-year ahead expected gross government debt to GDP ratio relative to Germany

\begin{tabular}{|c|c|c|c|c|c|c|c|c|c|c|c|c|c|c|c|}
\hline & AT & $\mathrm{BE}$ & FI & $\mathrm{FR}$ & $\mathrm{IE}$ & IT & NL & PT & ES & EL & All+EL & All & Core & Per+EL & Per \\
\hline \multicolumn{16}{|c|}{$1999.01-2016.07$} \\
\hline Mean & -0.529 & 29.700 & -22.161 & 5.945 & -6.035 & 45.668 & -9.361 & 13.320 & -4.493 & 57.609 & 10.966 & 5.784 & 0.719 & 21.214 & 12.115 \\
\hline StDev & 6.842 & 10.694 & 8.231 & 10.393 & 32.506 & 8.285 & 6.975 & 22.404 & 19.720 & 30.327 & 15.638 & 14.006 & 8.627 & 22.649 & 20.729 \\
\hline RStDev & 12.924 & 0.360 & 0.371 & 1.748 & 5.386 & 0.181 & 0.745 & 1.682 & 4.389 & 0.526 & 2.831 & 3.087 & 3.230 & 2.433 & 2.910 \\
\hline \multicolumn{16}{|c|}{$1999.01-2007.07$} \\
\hline Mean & -0.824 & 34.903 & -22.351 & -1.983 & -31.850 & 43.451 & -9.523 & -3.149 & -12.969 & 38.023 & 3.373 & -0.477 & 0.044 & 6.701 & -1.129 \\
\hline StDev & 3.864 & 11.339 & 4.565 & 1.043 & 7.245 & 5.100 & 6.441 & 2.970 & 12.129 & 3.872 & 5.857 & 6.077 & 5.450 & 6.263 & 6.861 \\
\hline RStDev & 4.688 & 0.325 & 0.204 & 0.526 & 0.227 & 0.117 & 0.676 & 0.943 & 0.935 & 0.102 & 0.874 & 0.960 & 1.284 & 0.465 & 0.556 \\
\hline \multicolumn{16}{|c|}{$2007.08-2012.07$} \\
\hline Mean & -5.372 & 20.490 & -29.622 & 6.070 & 3.133 & 39.933 & -14.975 & 11.652 & -14.413 & 55.600 & 7.250 & 1.877 & -4.682 & 19.181 & 10.076 \\
\hline StDev & 1.881 & 2.740 & 2.591 & 3.129 & 28.362 & 1.988 & 4.043 & 11.247 & 9.358 & 29.546 & 9.489 & 7.260 & 2.877 & 16.100 & 12.739 \\
\hline RStDev & 0.350 & 0.134 & 0.087 & 0.516 & 9.052 & 0.050 & 0.270 & 0.965 & 0.649 & 0.531 & 1.260 & 1.341 & 0.271 & 2.249 & 2.679 \\
\hline \multicolumn{16}{|c|}{$2012.08-2016.07$} \\
\hline Mean & 6.156 & 30.050 & -12.425 & 22.800 & 37.900 & 57.594 & -1.994 & 50.744 & 26.094 & 102.150 & 31.907 & 24.102 & 8.918 & 54.896 & 43.083 \\
\hline StDev & 9.825 & 7.404 & 9.008 & 6.328 & 7.635 & 6.878 & 3.325 & 6.045 & 8.359 & 10.446 & 7.525 & 7.201 & 7.178 & 7.873 & 7.229 \\
\hline RStDev & 1.596 & 0.246 & 0.725 & 0.278 & 0.201 & 0.119 & 1.668 & 0.119 & 0.320 & 0.102 & 0.538 & 0.586 & 0.903 & 0.173 & 0.190 \\
\hline
\end{tabular}

Note: This table presents descriptive statistics, i.e. mean, standard deviation (StDev) and relative standard deviation (RstDev) calculated as the absolute value of the coefficient of variation (StDev/Mean), across countries, country-groups and time periods. The sample countries include Austria (AT), Belgium (BE), Finland (FI), France (FR), Ireland (IE), Italy (IT), the Netherlands (NL), Portugal (PT), Spain (ES) and Greece (EL). The following country-groups are considered: All countries including Greece (All+EL). All countries excluding Greece (All). Core countries: Austria, Belgium, Finland, France and the Netherlands. Periphery countries including Greece: Greece, Ireland, Italy, Portugal and Spain (Per+EL). Periphery excluding Greece (Per). The following time periods are considered: January 1999 - July 2016 (211 observations); January 1999 - July 2007 (103 observations); August 2008 - July 2012 (60 observations); August 2012 - July 2016 (48 observations). 
Table 2: Correlation matrix of risk factors

\section{Panel A: Full panel}

\begin{tabular}{c|c|c|c|c}
\hline \hline & $v i x$ & $B A$ & $e s i$ & $E D$ \\
\hline$v i x$ & 1 & & & \\
\hline$B A$ & 0.054 & 1 & & \\
\hline esi & 0.097 & -0.432 & 1 & \\
\hline$E D$ & -0.075 & 0.205 & -0.126 & 1 \\
\hline \hline
\end{tabular}

\section{Panel B: Core countries}

\begin{tabular}{c|c|c|c|c}
\hline \hline & vix & $B A$ & esi & $E D$ \\
\hline vix & 1 & & & \\
\hline$B A$ & -0.013 & 1 & & \\
\hline esi & 0.081 & -0.407 & 1 & \\
\hline$E D$ & -0.030 & 0.182 & -0.102 & 1 \\
\hline \hline
\end{tabular}

\section{Panel C: Periphery countries}

\begin{tabular}{c|c|c|c|c}
\hline \hline & vix & $B A$ & esi & $E D$ \\
\hline vix & 1 & & & \\
\hline$B A$ & 0.086 & 1 & & \\
\hline esi & 0.108 & -0.502 & 1 & \\
\hline$E D$ & -0.112 & 0.185 & -0.127 & 1 \\
\hline \hline
\end{tabular}

Note: This table presents the correlation coefficients for the risk factors, i.e. the logarithm of the Chicago Board Options Exchange Volatility Index (vix), the bid-ask spread of 10-year government bonds (BA), the logarithm of the Economic Sentiment Index relative to Germany (esi), and the 1-year ahead expected gross government debt to GDP ratio relative to Germany (ED). The sample period is January 1999 - July 2017 (211 observations). The full panel (Panel A) includes Austria, Belgium, Finland, France, Ireland, Italy, the Netherlands, Portugal and Spain. The panel of core countries (Panel B) includes Austria, Belgium, Finland, France and the Netherlands. The panel of periphery countries (Panel C) includes Ireland, Italy, Portugal and Spain. 
Table 3: Modelling TVP parameters on ECB policy and bank credit risk

\section{Panel A: Full panel}

\begin{tabular}{|c|c|c|c|c|c|c|c|c|c|c|c|c|}
\hline & \multicolumn{3}{|c|}{$\beta_{\mathrm{t}}^{\mathrm{vix}}$} & \multicolumn{3}{|c|}{$\beta_{\mathrm{t}}^{\mathrm{BA}}$} & \multicolumn{3}{|c|}{$\beta_{\mathrm{t}}^{\mathrm{esi}}$} & \multicolumn{3}{|c|}{$\beta_{\mathrm{t}}^{\mathrm{ED}}$} \\
\hline & (1) & (2) & $(3)$ & (1) & $(2)$ & (3) & $(1)$ & (2) & (3) & (1) & $(2)$ & (3) \\
\hline Constant & $\begin{array}{c}1.451^{* * *} \\
(0.137)\end{array}$ & $\begin{array}{c}1.471^{* * *} \\
(0.138)\end{array}$ & $\begin{array}{c}0.231 \\
(0.201) \\
\end{array}$ & $\begin{array}{l}1.242^{\text {*** }} \\
(0.102)\end{array}$ & $\begin{array}{l}1.279^{* * * *} \\
(0.098)\end{array}$ & $\begin{array}{c}0.145 \\
(0.158) \\
\end{array}$ & $\begin{array}{c}-15.230^{* * *} \\
(2.133)\end{array}$ & $\begin{array}{c}-16.052^{* * *} \\
(2.016) \\
\end{array}$ & $\begin{array}{l}-4.907^{*} \\
(2.566) \\
\end{array}$ & $\begin{array}{c}0.033^{* * *} \\
(0.001)\end{array}$ & $\begin{array}{c}0.034^{* * *} \\
(0.001)\end{array}$ & $\begin{array}{c}0.033^{* * *} \\
(0.004)\end{array}$ \\
\hline $\mathrm{D}_{\mathrm{t}}^{\mathrm{OMT}}$ & $\begin{array}{c}-1.037^{* * * *} \\
(0.195)\end{array}$ & $\begin{array}{c}-1.084^{* * * *} \\
(0.197)\end{array}$ & $\begin{array}{c}-0.611^{* * * *} \\
(0.139)\end{array}$ & $\begin{array}{c}-0.273 \\
(0.201)\end{array}$ & $\begin{array}{l}-0.326 \\
(0.202)\end{array}$ & $\begin{array}{c}0.106 \\
(0.117)\end{array}$ & $\begin{array}{l}6.259^{* *} \\
(2.626)\end{array}$ & $\begin{array}{c}7.174^{* * *} \\
(2.494)\end{array}$ & $\begin{array}{c}2.926 \\
(1.849)\end{array}$ & $\begin{array}{c}-0.027^{* * * *} \\
(0.004)\end{array}$ & $\begin{array}{c}-0.027^{* * * *} \\
(0.004)\end{array}$ & $\begin{array}{c}-0.027^{* * * * *} \\
(0.004)\end{array}$ \\
\hline$\Delta \operatorname{shmp}_{\mathrm{t}-1}$ & - & $\begin{array}{l}-0.059^{*} \\
(0.034)\end{array}$ & $\begin{array}{c}0.026^{*} \\
(0.015) \\
\end{array}$ & - & $\begin{array}{c}-0.107^{* * * *} \\
(0.033)\end{array}$ & $\begin{array}{l}-0.029^{*} \\
(0.016)\end{array}$ & - & $\begin{array}{c}2.357^{* * * *} \\
(0.576)\end{array}$ & $\begin{array}{l}1.596^{* * *} \\
(0.443)\end{array}$ & - & $\begin{array}{c}-0.0006 \\
(0.0004)\end{array}$ & $\begin{array}{c}-0.0005 \\
(0.0005) \\
\end{array}$ \\
\hline$\Delta \mathrm{MRO}_{\mathrm{t}-1}$ & - & $\begin{array}{l}-1.389^{*} \\
(0.763) \\
\end{array}$ & $\begin{array}{c}0.401 \\
(0.408) \\
\end{array}$ & - & $\begin{array}{l}-0.951^{*} \\
(0.562) \\
\end{array}$ & $\begin{array}{c}0.686 \\
(0.536) \\
\end{array}$ & - & $\begin{array}{c}7.910 \\
(8.959) \\
\end{array}$ & $\begin{array}{c}-8.170 \\
(6.694) \\
\end{array}$ & - & $\begin{array}{c}0.005 \\
(0.016) \\
\end{array}$ & $\begin{array}{c}0.007 \\
(0.013) \\
\end{array}$ \\
\hline $\mathrm{CDS}_{\mathrm{t}-1}$ & - & - & $\begin{array}{c}0.735^{* * * *} \\
(0.103) \\
\end{array}$ & - & - & $\begin{array}{c}0.672^{* * * *} \\
(0.100)\end{array}$ & - & - & $\begin{array}{c}-6.605^{* * * *} \\
(1.131)\end{array}$ & - & - & $\begin{array}{c}0.001 \\
(0.003) \\
\end{array}$ \\
\hline Adj $R^{2}$ & 0.513 & 0.526 & 0.853 & 0.053 & 0.078 & 0.567 & 0.197 & 0.276 & 0.561 & 0.597 & 0.588 & 0.583 \\
\hline
\end{tabular}

\section{Panel B: Core countries}

\begin{tabular}{|c|c|c|c|c|c|c|c|c|c|c|c|c|}
\hline & \multicolumn{3}{|c|}{$\beta_{\mathrm{t}}^{\text {vix }}$} & \multicolumn{3}{|c|}{$\beta_{\mathrm{t}}^{\mathrm{BA}}$} & \multicolumn{3}{|c|}{$\beta_{t}{ }^{e s i}$} & \multicolumn{3}{|c|}{$\beta_{\mathrm{t}}^{\mathrm{ED}}$} \\
\hline & (1) & $(2)$ & (3) & (1) & $(2)$ & (3) & (1) & (2) & (3) & $(1)$ & (2) & (3) \\
\hline Constant & $\begin{array}{c}1.087^{* * *} \\
(0.034)\end{array}$ & $\begin{array}{c}1.097^{* * *} \\
(0.033)\end{array}$ & $\begin{array}{l}0.403^{* *} \\
(0.177)\end{array}$ & $\begin{array}{c}0.663^{* * *} \\
(0.054)\end{array}$ & $\begin{array}{c}0.680^{* * *} \\
(0.053)\end{array}$ & $\begin{array}{c}0.341^{\text {*** }} \\
(0.059)\end{array}$ & $\begin{array}{c}-3.936^{* * * *} \\
(0.360)\end{array}$ & $\begin{array}{c}-4.098^{* * * *} \\
(0.330)\end{array}$ & $\begin{array}{l}-0.567 \\
(0.810)\end{array}$ & $\begin{array}{c}-0.015^{* * *} \\
(0.002)\end{array}$ & $\begin{array}{c}-0.016^{* * *} \\
(0.002)\end{array}$ & $\begin{array}{c}-0.010^{* *} \\
(0.004)\end{array}$ \\
\hline $\mathrm{D}_{\mathrm{t}}^{\mathrm{OMT}}$ & $\begin{array}{c}-0.647^{* * * *} \\
(0.125) \\
\end{array}$ & $\begin{array}{c}-0.671^{* * * *} \\
(0.125)\end{array}$ & $\begin{array}{c}-0.406^{* * * *} \\
(0.120) \\
\end{array}$ & $\begin{array}{c}-0.615^{* * * *} \\
(0.071)\end{array}$ & $\begin{array}{c}-0.632^{* * * *} \\
(0.068)\end{array}$ & $\begin{array}{c}-0.503^{* * * *} \\
(0.049)\end{array}$ & $\begin{array}{c}2.937^{* * *} \\
(0.674)\end{array}$ & $\begin{array}{c}3.130^{* * *} \\
(0.659)\end{array}$ & $\begin{array}{c}1.784^{* * *} \\
(0.661)\end{array}$ & $\begin{array}{c}0.016^{* * *} \\
(0.003)\end{array}$ & $\begin{array}{c}0.015^{* * *} \\
(0.003)\end{array}$ & $\begin{array}{c}0.013^{* * * *} \\
(0.003)\end{array}$ \\
\hline$\Delta \mathrm{shmp}_{\mathrm{t}-1}$ & - & $\begin{array}{l}-0.027^{*} \\
(0.015) \\
\end{array}$ & $\begin{array}{c}0.020^{*} \\
(0.012) \\
\end{array}$ & - & $\begin{array}{c}-0.048^{* * *} \\
(0.010) \\
\end{array}$ & $\begin{array}{c}-0.025^{* * * *} \\
(0.007)\end{array}$ & - & $\begin{array}{c}0.463^{* * * *} \\
(0.112)\end{array}$ & $\begin{array}{c}0.222^{* * * *} \\
(0.083)\end{array}$ & - & $\begin{array}{c}0.0003 \\
(0.0002) \\
\end{array}$ & $\begin{array}{l}-0.0001 \\
(0.0003) \\
\end{array}$ \\
\hline$\Delta \mathrm{MRO}_{\mathrm{t}-1}$ & - & $\begin{array}{l}-0.738^{*} \\
(0.414) \\
\end{array}$ & $\begin{array}{c}0.263 \\
(0.454) \\
\end{array}$ & - & $\begin{array}{c}-0.073 \\
(0.338) \\
\end{array}$ & $\begin{array}{c}0.415^{*} \\
(0.237) \\
\end{array}$ & - & $\begin{array}{c}2.170 \\
(2.521) \\
\end{array}$ & $\begin{array}{c}-2.924 \\
(2.421) \\
\end{array}$ & - & $\begin{array}{c}-0.013 \\
(0.013) \\
\end{array}$ & $\begin{array}{l}-0.021^{*} \\
(0.011) \\
\end{array}$ \\
\hline $\mathrm{CDS}_{\mathrm{t}-1}$ & - & - & $\begin{array}{c}0.411^{* * * *} \\
(0.098) \\
\end{array}$ & - & - & $\begin{array}{c}0.201^{* * * *} \\
(0.041)\end{array}$ & - & - & $\begin{array}{c}-2.092^{* * * *} \\
(0.480) \\
\end{array}$ & - & - & $\begin{array}{l}-0.003^{*} \\
(0.002) \\
\end{array}$ \\
\hline Adj $R^{2}$ & 0.472 & 0.475 & 0.715 & 0.770 & 0.779 & 0.882 & 0.400 & 0.422 & 0.678 & 0.470 & 0.464 & 0.486 \\
\hline
\end{tabular}




\section{Panel C: Periphery countries}

\begin{tabular}{|c|c|c|c|c|c|c|c|c|c|c|c|c|}
\hline & \multicolumn{3}{|c|}{$\beta_{\mathrm{t}}{ }^{\text {vix }}$} & \multicolumn{3}{|c|}{$\beta_{\mathrm{t}}^{\mathrm{BA}}$} & \multicolumn{3}{|c|}{$\beta_{\mathrm{t}}^{\mathrm{esi}}$} & \multicolumn{3}{|c|}{$\beta_{\mathrm{t}}^{\mathrm{ED}}$} \\
\hline & (1) & $(2)$ & (3) & (1) & (2) & (3) & (1) & $(2)$ & (3) & (1) & (2) & (3) \\
\hline Constant & $\begin{array}{l}1.103^{* * *} \\
(0.094)\end{array}$ & $\begin{array}{l}1.107^{* * *} \\
(0.097)\end{array}$ & $\begin{array}{c}0.117 \\
(0.252)\end{array}$ & $\begin{array}{l}1.227^{* * *} \\
(0.105)\end{array}$ & $\begin{array}{l}1.253^{* * *} \\
(0.105)\end{array}$ & $\begin{array}{l}0.911^{* *} \\
(0.454)\end{array}$ & $\begin{array}{c}-18.025^{* * * *} \\
(2.884)\end{array}$ & $\begin{array}{c}-19.004^{* * *} \\
(2.786)\end{array}$ & $\begin{array}{c}2.083 \\
(2.086)\end{array}$ & $\begin{array}{c}0.015^{* * *} \\
(0.003)\end{array}$ & $\begin{array}{c}0.014^{* * *} \\
(0.004)\end{array}$ & $\begin{array}{c}0.044^{* * * *} \\
(0.005)\end{array}$ \\
\hline $\mathrm{D}_{\mathrm{t}}^{\mathrm{OMT}}$ & $\begin{array}{c}-0.804^{* * * *} \\
(0.168)\end{array}$ & $\begin{array}{c}-0.824^{* * *} \\
(0.170)\end{array}$ & $\begin{array}{c}-0.447^{* *} \\
(0.177)\end{array}$ & $\begin{array}{l}1.300^{* *} \\
(0.587)\end{array}$ & $\begin{array}{l}1.298^{* *} \\
(0.614)\end{array}$ & $\begin{array}{l}1.429^{* *} \\
(0.559)\end{array}$ & $\begin{array}{c}5.338 \\
(3.785)\end{array}$ & $\begin{array}{c}6.552^{*} \\
(3.701)\end{array}$ & $\begin{array}{l}-1.486 \\
(2.026)\end{array}$ & $\begin{array}{l}-0.010^{*} \\
(0.006)\end{array}$ & $\begin{array}{l}-0.009 \\
(0.006)\end{array}$ & $\begin{array}{c}-0.021^{* * * *} \\
(0.004)\end{array}$ \\
\hline$\Delta \mathrm{shmp}_{\mathrm{t}-1}$ & - & $\begin{array}{l}-0.011 \\
(0.024)\end{array}$ & $\begin{array}{c}0.056^{* * *} \\
(0.016)\end{array}$ & - & $\begin{array}{l}-0.077^{* *} \\
(0.029)\end{array}$ & $\begin{array}{l}-0.053 \\
(0.034)\end{array}$ & - & $\begin{array}{c}2.810^{* * *} \\
(0.760)\end{array}$ & $\begin{array}{l}1.370^{* * *} \\
(0.407)\end{array}$ & - & $\begin{array}{l}0.003^{* *} \\
(0.001)\end{array}$ & $\begin{array}{c}0.001 \\
(0.001)\end{array}$ \\
\hline$\Delta \mathrm{MRO}_{\mathrm{t}-1}$ & - & $\begin{array}{c}-0.788 \\
(0.749)\end{array}$ & $\begin{array}{c}0.641 \\
(0.546)\end{array}$ & - & $\begin{array}{c}1.101 \\
(1.190)\end{array}$ & $\begin{array}{c}1.595 \\
(1.029) \\
\end{array}$ & - & $\begin{array}{c}15.410 \\
(12.888)\end{array}$ & $\begin{array}{c}-15.016^{*} \\
(8.317)\end{array}$ & - & $\begin{array}{c}0.023 \\
(0.015)\end{array}$ & $\begin{array}{l}-0.021 \\
(0.017)\end{array}$ \\
\hline $\mathrm{CDS}_{\mathrm{t}-1}$ & - & - & $\begin{array}{c}0.587^{* * * *} \\
(0.128)\end{array}$ & - & - & $\begin{array}{c}0.203 \\
(0.265)\end{array}$ & - & - & $\begin{array}{c}-12.497^{* * *} \\
(1.078)\end{array}$ & - & - & $\begin{array}{c}-0.018^{* * * *} \\
(0.003)\end{array}$ \\
\hline Adj $R^{2}$ & 0.432 & 0.428 & 0.719 & 0.124 & 0.106 & 0.099 & 0.068 & 0.127 & 0.667 & 0.102 & 0.113 & 0.543 \\
\hline
\end{tabular}

Note: This table presents OLS estimates with heteroscedasticity and autocorrelation consistent standard errors (in parentheses) of Equation (2) over the period August 2009 July 2016 (84 observations). The dependent variable is, respectively, the time-varying panel coefficient of Equation (1) associated with the logarithm of the Chicago Board Options Exchange Volatility Index $\left(\beta_{\mathrm{t}}^{\mathrm{vix}}\right)$, the bid-ask spread of 10 -year government bonds $\left(\beta_{\mathrm{t}}^{\mathrm{BA}}\right)$, the logarithm of the Economic Sentiment Index relative to Germany $\left(\beta_{\mathrm{t}}{ }^{\text {esi }}\right)$, and the 1-year ahead expected gross government debt to GDP ratio relative to Germany $\left(\beta_{\mathrm{t}}^{\mathrm{ED}}\right)$. The set of explanatory variables includes a dummy variable that is equal to 1 since August 2012 and 0 otherwise $\left(D_{t}^{\text {OMT }}\right)$, the lagged first difference of the logarithm of securities held for monetary policy purposes by the ECB $\left(\Delta\right.$ shmp $\left.\mathrm{t}_{\mathrm{t}-1}\right)$, the first difference of the ECB main refinancing operations rate $\left(\triangle \mathrm{MRO}_{\mathrm{t}-1}\right)$, and the lagged European banking sector senior subordination $\mathrm{CDS}$ index $\left(\mathrm{CDS} \mathrm{S}_{\mathrm{t}-1}\right)$. The full panel (Panel $\left.\mathrm{A}\right)$ includes Austria, Belgium, Finland, France, Ireland, Italy, the Netherlands, Portugal and Spain. The panel of core countries (Panel B) includes Austria, Belgium, Finland, France and the Netherlands. The panel of periphery countries (Panel C) includes Ireland, Italy, Portugal and Spain. *, **, *** indicate statistical significance at the $10 \%, 5 \%$ and $1 \%$ level, respectively. 
Table 4: The impact of ECB policy on bank credit risk

\begin{tabular}{c|c|c|c|c|c|c|c|c}
\hline \hline & \multicolumn{9}{|c}{ CDS senior } & \multicolumn{4}{c}{ CDS subordinate } \\
\hline & $(1)$ & $(2)$ & $(3)$ & $(4)$ & $(1)$ & $(2)$ & $(3)$ & $(4)$ \\
\hline Constant & $1.695^{* * *}$ & $1.744^{* * *}$ & 0.277 & 0.217 & $2.892^{* * *}$ & $2.967^{* * *}$ & 0.154 & -0.025 \\
& $(0.217)$ & $(0.211)$ & $(0.313)$ & $(0.263)$ & $(0.393)$ & $(0.387)$ & $(0.561)$ & $(0.532)$ \\
\hline $\mathrm{D}_{\mathrm{t}}^{\mathrm{OMT}}$ & $-0.640^{* * *}$ & $-0.724^{* * *}$ & $-0.163^{* *}$ & $-0.163^{* * *}$ & $-1.014^{* *}$ & $-1.144^{* * *}$ & $-0.237^{* *}$ & $-0.207^{* *}$ \\
& $(0.237)$ & $(0.232)$ & $(0.062)$ & $(0.054)$ & $(0.419)$ & $(0.419)$ & $(0.105)$ & $(0.089)$ \\
\hline$\Delta \mathrm{shmp}_{\mathrm{t}-1}$ & - & $-0.141^{* * *}$ & $-0.028^{* * *}$ & $-0.029^{* * *}$ & - & $-0.213^{* * *}$ & $-0.036^{* *}$ & $-0.032^{* *}$ \\
& & $(0.039)$ & $(0.009)$ & $(0.008)$ & & $(0.063)$ & $(0.016)$ & $(0.015)$ \\
\hline$\Delta \mathrm{MRO}_{\mathrm{t}-1}$ & - & $-1.875^{*}$ & 0.271 & 0.242 & - & -3.002 & 0.305 & 0.368 \\
& & $(1.010)$ & $(0.331)$ & $(0.291)$ & & $(1.947)$ & $(0.498)$ & $(0.432)$ \\
\hline vix $\mathrm{x}_{\mathrm{t}-1}$ & - & - & 0.001 & 0.216 & - & - & 0.317 & 0.615 \\
& & & $(0.226)$ & $(0.209)$ & & & $(0.424)$ & $(0.425)$ \\
\hline$\Delta \mathrm{eesi}_{\mathrm{t}-1}$ & - & - & -2.265 & -2.555 & - & - & $-7.683^{* *}$ & $-7.722^{* *}$ \\
& & & $(1.660)$ & $(1.649)$ & & & $(3.277)$ & $(3.200)$ \\
\hline $\mathrm{CDS}_{\mathrm{t}-1}$ & - & - & $0.873^{* * *}$ & $0.582^{* * *}$ & - & - & $0.837^{* * *}$ & $0.663^{* * *}$ \\
& & & $(0.038)$ & $(0.118)$ & & & $(0.044)$ & $(0.103)$ \\
\hline $\mathrm{pc}_{\mathrm{t}-1}$ & - & - & - & $0.069^{* *}$ & - & - & - & $0.072^{* *}$ \\
& & & & $(0.028)$ & & & & $(0.036)$ \\
\hline \hline Adj $\mathrm{R}^{2}$ & 0.233 & 0.296 & 0.917 & 0.922 & 0.212 & 0.252 & 0.907 & 0.910 \\
\hline \hline
\end{tabular}

Note: This table presents OLS estimates with heteroscedasticity and autocorrelation consistent standard errors (in parentheses) of Equation (3) over the period August 2009 - July 2016 (84 observations). The dependent variable is, respectively, the European banking sector senior (CDS senior) and junior subordination (CDS subordinate) CDS index. The set of explanatory variables includes a dummy variable that is equal to 1 since August 2012 and 0 otherwise $\left(\mathrm{D}_{\mathrm{t}}{ }^{\mathrm{OMT}}\right)$, the lagged first difference of the logarithm of securities held for monetary policy purposes by the ECB $\left(\Delta \mathrm{shmp}_{\mathrm{t}-1}\right)$, the first difference of the ECB main refinancing operations rate $\left(\Delta \mathrm{MRO}_{\mathrm{t}-1}\right)$, the lagged logarithm of the Chicago Board Options Exchange Volatility Index (vix $\left.\mathrm{t}_{\mathrm{t}-1}\right)$, the lagged first difference of the logarithm of the euro area Economic Sentiment Index $\left(\Delta \mathrm{eesi}_{\mathrm{t}-1}\right)$, the lagged respective $\mathrm{CDS}$ index $\left(\mathrm{CDS}_{\mathrm{t}-1}\right)$, and the lagged first principal component of spreads $\left(\mathrm{pc}_{\mathrm{t}-1}\right)$. The latter is calculated using the full set of countries (including Greece) over the period January 1999 - July 2016. *, **,*** indicate statistical significance at the 10\%, 5\% and 1\% level, respectively. 
Table 5: Modelling TVP parameters on ECB policy and bank credit risk - Using ECB balance sheet

\section{Panel A: Full panel}

\begin{tabular}{c|c|c|c|c|c|c|c|c}
\hline \hline & \multicolumn{2}{|c|}{$\beta_{\mathrm{t}}^{\text {vix }}$} & \multicolumn{2}{c|}{$\beta_{\mathrm{t}}^{\mathrm{BA}}$} & \multicolumn{2}{c}{$\beta_{\mathrm{t}}^{\text {esi }}$} & \multicolumn{2}{c}{$\beta_{\mathrm{t}}^{\mathrm{ED}}$} \\
\hline & $(1)$ & $(2)$ & $(1)$ & $(2)$ & $(1)$ & $(2)$ & $(1)$ & $(2)$ \\
\hline Constant & 0.249 & 0.016 & 0.117 & $-0.107^{* *}$ & -3.592 & $-2.634^{* * *}$ & $0.032^{* * *}$ & $0.013^{* * *}$ \\
& $(0.188)$ & $(0.062)$ & $(0.148)$ & $(0.044)$ & $(2.735)$ & $(0.776)$ & $(0.004)$ & $(0.003)$ \\
\hline $\mathrm{D}_{\mathrm{t}}{ }^{\text {OMT }}$ & $-0.640^{* * *}$ & $-0.530^{* * *}$ & 0.097 & $0.263^{* *}$ & 2.376 & -1.893 & $-0.026^{* * *}$ & $-0.017^{* * *}$ \\
& $(0.131)$ & $(0.079)$ & $(0.109)$ & $(0.131)$ & $(2.012)$ & $(1.874)$ & $(0.004)$ & $(0.005)$ \\
\hline$\Delta$ ecbbs $_{\mathrm{t}-1}$ & $-2.264^{* *}$ & -0.663 & $-3.211^{* *}$ & -1.229 & 30.737 & 14.480 & $0.141^{* * *}$ & $0.052^{*}$ \\
& $(1.069)$ & $(0.592)$ & $(1.530)$ & $(0.791)$ & $(19.297)$ & $(9.839)$ & $(0.043)$ & $(0.027)$ \\
\hline$\Delta \mathrm{MRO}_{\mathrm{t}-1}$ & 0.334 & -0.067 & 0.635 & $0.730^{* * *}$ & -8.582 & $-14.26^{* * *}$ & 0.010 & 0.007 \\
& $(0.323)$ & $(0.152)$ & $(0.430)$ & $(0.190)$ & $(7.530)$ & $(3.930)$ & $(0.012)$ & $(0.005)$ \\
\hline $\mathrm{CDS}_{\mathrm{t}-1}$ & $0.747^{* * * *}$ & $0.850^{* * *}$ & $0.706^{* * *}$ & $0.759^{* * *}$ & $-7.294^{* * *}$ & $-9.183^{* * *}$ & 0.000 & $0.010^{* * *}$ \\
& $(0.094)$ & $(0.049)$ & $(0.096)$ & $(0.049)$ & $(1.171)$ & $(0.835)$ & $(0.002)$ & $(0.002)$ \\
\hline Adj R $^{2}$ & 0.864 & 0.863 & 0.610 & 0.785 & 0.545 & 0.652 & 0.662 & 0.466 \\
\hline \hline
\end{tabular}

\section{Panel B: Core countries}

\begin{tabular}{c|c|c|c|c|c|c|c|c}
\hline \hline & \multicolumn{2}{|c|}{$\beta_{\mathrm{t}}^{\text {vix }}$} & \multicolumn{2}{|c|}{$\beta_{\mathrm{t}}^{\mathrm{BA}}$} & \multicolumn{2}{c}{$\beta_{\mathrm{t}}^{\text {esi }}$} & \multicolumn{2}{c}{$\beta_{\mathrm{t}}^{\mathrm{ED}}$} \\
\hline & $(1)$ & $(2)$ & $(1)$ & $(2)$ & $(1)$ & $(2)$ & $(1)$ & $(2)$ \\
\hline Constant & $0.415^{* *}$ & $0.105^{*}$ & $0.321^{* * *}$ & 0.026 & -0.372 & -0.337 & $-0.010^{* * *}$ & $-0.003^{*}$ \\
& $(0.159)$ & $(0.057)$ & $(0.060)$ & $(0.024)$ & $(0.750)$ & $(0.209)$ & $(0.004)$ & $(0.002)$ \\
\hline $\mathrm{D}_{\mathrm{t}}^{\text {OMT }}$ & $-0.438^{* * *}$ & $-0.276^{* * * *}$ & $-0.493^{* * *}$ & $-0.322^{* * *}$ & $1.779^{* * *}$ & $1.588^{* * *}$ & $0.013^{* * *}$ & $0.010^{* * *}$ \\
& $(0.102)$ & $(0.077)$ & $(0.047)$ & $(0.042)$ & $(0.582)$ & $(0.436)$ & $(0.003)$ & $(0.003)$ \\
\hline$\Delta$ ecbbs $_{\mathrm{t}-1}$ & $-2.999^{* * *}$ & $1.059^{*}$ & -0.271 & -0.145 & $14.053^{* * *}$ & 4.739 & -0.038 & -0.016 \\
& $(0.872)$ & $(0.602)$ & $(0.394)$ & $(0.230)$ & $(4.924)$ & $(3.106)$ & $(0.029)$ & $(0.014)$ \\
\hline$\Delta \mathrm{MRO}_{\mathrm{t}-1}$ & 0.184 & 0.041 & $0.426^{*}$ & $0.470^{* * *}$ & -2.767 & $-3.051^{* * *}$ & $-0.022^{* *}$ & -0.002 \\
& $(0.336)$ & $(0.111)$ & $(0.243)$ & $(0.121)$ & $(1.848)$ & $(0.734)$ & $(0.011)$ & $(0.004)$ \\
\hline $\mathrm{CDS}_{\mathrm{t}-1}$ & $0.430^{* * *}$ & $0.561^{* * *}$ & $0.210^{* * *}$ & $0.324^{* * *}$ & $-2.268^{* * *}$ & $-2.123^{* * *}$ & -0.003 & $-0.007^{* * *}$ \\
& $(0.087)$ & $(0.055)$ & $(0.041)$ & $(0.036)$ & $(0.431)$ & $(0.241)$ & $(0.002)$ & $(0.001)$ \\
\hline $\mathrm{Adj} \mathrm{R}^{2}$ & 0.765 & 0.774 & 0.878 & 0.776 & 0.717 & 0.677 & 0.500 & 0.444 \\
\hline
\end{tabular}


Panel C: Periphery countries

\begin{tabular}{c|c|c|c|c|c|c|c|c}
\hline \hline & \multicolumn{2}{|c|}{$\beta_{\mathrm{t}}^{\text {vix }}$} & \multicolumn{2}{c|}{$\beta_{\mathrm{t}}^{\mathrm{BA}}$} & \multicolumn{2}{c|}{$\beta_{\mathrm{t}}^{\text {esi }}$} & \multicolumn{2}{c}{$\beta_{\mathrm{t}}^{\mathrm{ED}}$} \\
\hline & $(1)$ & $(2)$ & $(1)$ & $(2)$ & $(1)$ & $(2)$ & $(1)$ & $(2)$ \\
\hline Constant & 0.159 & 0.104 & $0.882^{* *}$ & -0.196 & -3.242 & $-4.165^{* * *}$ & $0.045^{* * *}$ & $0.018^{* * *}$ \\
& $(0.237)$ & $(0.070)$ & $(0.433)$ & $(0.165)$ & $(2.311)$ & $(0.773)$ & $(0.004)$ & $(0.003)$ \\
\hline $\mathrm{D}_{\mathrm{t}}^{\text {OMT }}$ & $-0.493^{* * *}$ & $-0.496^{* * *}$ & $1.541^{* * *}$ & $2.049^{* * *}$ & -1.778 & $-3.540^{*}$ & $-0.020^{* * *}$ & $-0.008^{*}$ \\
& $(0.166)$ & $(0.104)$ & $(0.562)$ & $(0.673)$ & $(2.035)$ & $(2.092)$ & $(0.003)$ & $(0.005)$ \\
\hline$\Delta$ ecbbs $_{\mathrm{t}-1}$ & $-2.209^{* *}$ & -0.711 & 11.775 & 4.307 & $50.966^{* *}$ & 19.541 & $0.153^{* * *}$ & $0.054^{*}$ \\
& $(1.201)$ & $(0.701)$ & $(7.795)$ & $(3.509)$ & $(24.793)$ & $(13.078)$ & $(0.040)$ & $(0.031)$ \\
\hline$\Delta \mathrm{MRO}_{\mathrm{t}-1}$ & 0.546 & $-0.345^{*}$ & $1.890^{*}$ & $1.001^{* *}$ & $-14.830^{*}$ & $-17.28^{* * *}$ & -0.018 & $-0.013^{* *}$ \\
& $(0.485)$ & $(0.190)$ & $(1.031)$ & $(0.413)$ & $(8.052)$ & $(4.225)$ & $(0.013)$ & $(0.006)$ \\
\hline $\mathrm{CDS}_{\mathrm{t}-1}$ & $0.593^{* * *}$ & $0.627^{* * *}$ & 0.121 & $0.633^{* * *}$ & $-13.29^{* * *}$ & $-12.54^{* * *}$ & $-0.019^{* * *}$ & $-0.005^{* *}$ \\
& $(0.120)$ & $(0.061)$ & $(0.288)$ & $(0.150)$ & $(1.121)$ & $(0.704)$ & $(0.002)$ & $(0.002)$ \\
\hline $\mathrm{Adj} \mathrm{R}^{2}$ & 0.736 & 0.737 & 0.153 & 0.408 & 0.687 & 0.756 & 0.664 & 0.199 \\
\hline \hline
\end{tabular}

Note: This table presents OLS estimates with heteroscedasticity and autocorrelation consistent standard errors (in parentheses) of Equation (2) over the periods August 2009 July 2016 (Column 1; 84 observations) and July 2004 - July 2016 (Column 2, 145 observations). The dependent variable is, respectively, the time-varying panel coefficient of Equation (1) associated with the logarithm of the Chicago Board Options Exchange Volatility Index $\left(\beta_{\mathrm{t}}^{\text {vix }}\right)$, the bid-ask spread of 10 -year government bonds $\left(\beta_{\mathrm{t}}^{\mathrm{BA}}\right)$, the logarithm of the Economic Sentiment Index relative to Germany $\left(\beta_{t}{ }^{\text {esi }}\right)$, and the 1-year ahead expected gross government debt to GDP ratio relative to Germany ( $\left.\beta_{t}{ }^{\text {ED }}\right)$. The set of explanatory variables includes a dummy variable that is equal to 1 since August 2012 and 0 otherwise $\left(D_{t}{ }^{\text {OMT }}\right)$, the lagged first difference of the logarithm of the ECB balance sheet $\left(\Delta e \operatorname{cbbs}_{t-1}\right)$, the first difference of the ECB main refinancing operations rate $\left(\triangle \mathrm{MRO}_{\mathrm{t}-1}\right)$, and the lagged European banking sector senior subordination $\mathrm{CDS}$ index $(\mathrm{CDS}$. 1). The full panel (Panel A) includes Austria, Belgium, Finland, France, Ireland, Italy, the Netherlands, Portugal and Spain. The panel of core countries (Panel B) includes Austria, Belgium, Finland, France and the Netherlands. The panel of periphery countries (Panel C) includes Ireland, Italy, Portugal and Spain. *, **, *** indicate statistical significance at the $10 \%, 5 \%$ and $1 \%$ level, respectively. 
Appendix: Table A1 - Data Description and Sources

\begin{tabular}{|c|c|c|}
\hline Variable & Description & Source \\
\hline Spread & 10-year bond yield spread against German bund & ECB \\
\hline vix & $\begin{array}{l}\text { Logarithm of Chicago board options exchange volatility } \\
\text { index }\end{array}$ & Bloomberg \\
\hline RV & Realised volatility of S\&P 500 & https://sites.google.com/site/haozhouspersonalhomepage/ \\
\hline VRP & Volatility premium of S\&P 500 & https://sites.google.com/site/haozhouspersonalhomepage/ \\
\hline BA & 10-year bond bid-ask spread & Bloomberg \\
\hline esi & $\begin{array}{l}\text { Logarithm of Economic Sentiment Index relative to } \\
\text { Germany }\end{array}$ & Eurostat \\
\hline ED & $\begin{array}{l}\text { Expected general government gross debt differential } \\
\text { against Germany (\% of GDP) }\end{array}$ & European Commission Economic Forecasts \\
\hline reer & Logarithm of real effective exchange rate & IMF International Financial Statistics \\
\hline MRO & Main refinancing operations rate (\% per annum) & ECB \\
\hline shmp & $\begin{array}{l}\text { Logarithm of securities held by the ECB for monetary } \\
\text { policy purposes, weekly financial statements }\end{array}$ & ECB \\
\hline ecb & Logarithm of ECB balance sheet & ECB \\
\hline Sentix & $\begin{array}{l}\text { euro breakup index measures the proportion of investors } \\
\text { (private and institutional) predicting at least one country } \\
\text { leaving the euro area within the next twelve months. }\end{array}$ & http://www.sentix.de/. \\
\hline $\mathrm{D}^{\mathrm{OMT}}$ & $\begin{array}{l}\text { Dummy variable equal to } 1 \text { since August } 2012 \text { and } 0 \\
\text { otherwise }\end{array}$ & Own calculations \\
\hline CDS senior & $\begin{array}{l}\text { CDS index covering } 25 \text { senior subordination European } \\
\text { Banks }\end{array}$ & Markit \\
\hline CDS junior & $\begin{array}{l}\text { CDS index covering } 25 \text { senior junior subordination } \\
\text { European Banks }\end{array}$ & Markit \\
\hline
\end{tabular}

Note: All variables are observed in monthly frequency, except for expected and actual debt differentials, which are observed in semi-annual and quarterly frequency, respectively. To transform the semi-annual and quarterly figures into monthly we keep the observations constant for the in-between months 


\section{SUPPLEMENTARY APPENDIX}

Figure A1: Log of VIX

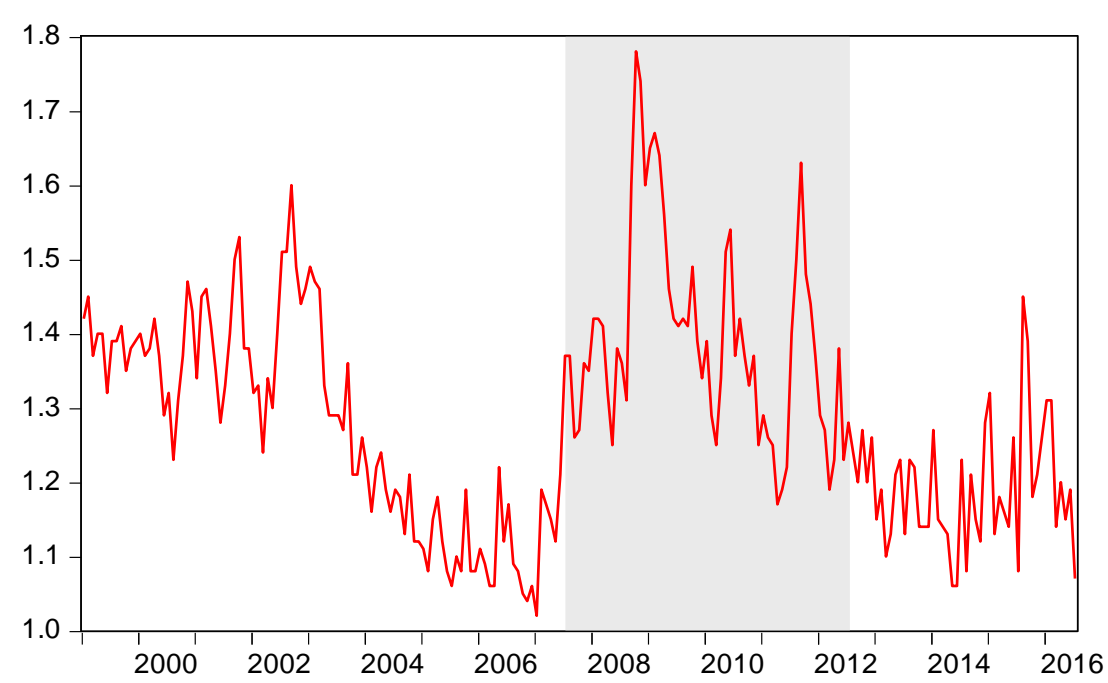

Note: This figure plots the logarithm of the Chicago Board Options Exchange Volatility Index (VIX) over the period January 1999 - July 2016 (211 observations). The shaded area denotes the period July 2007 - July 2012. Source: Chicago Board of Exchange. 


\section{Figure A2: TVP coefficients and risk factors - Full panel}
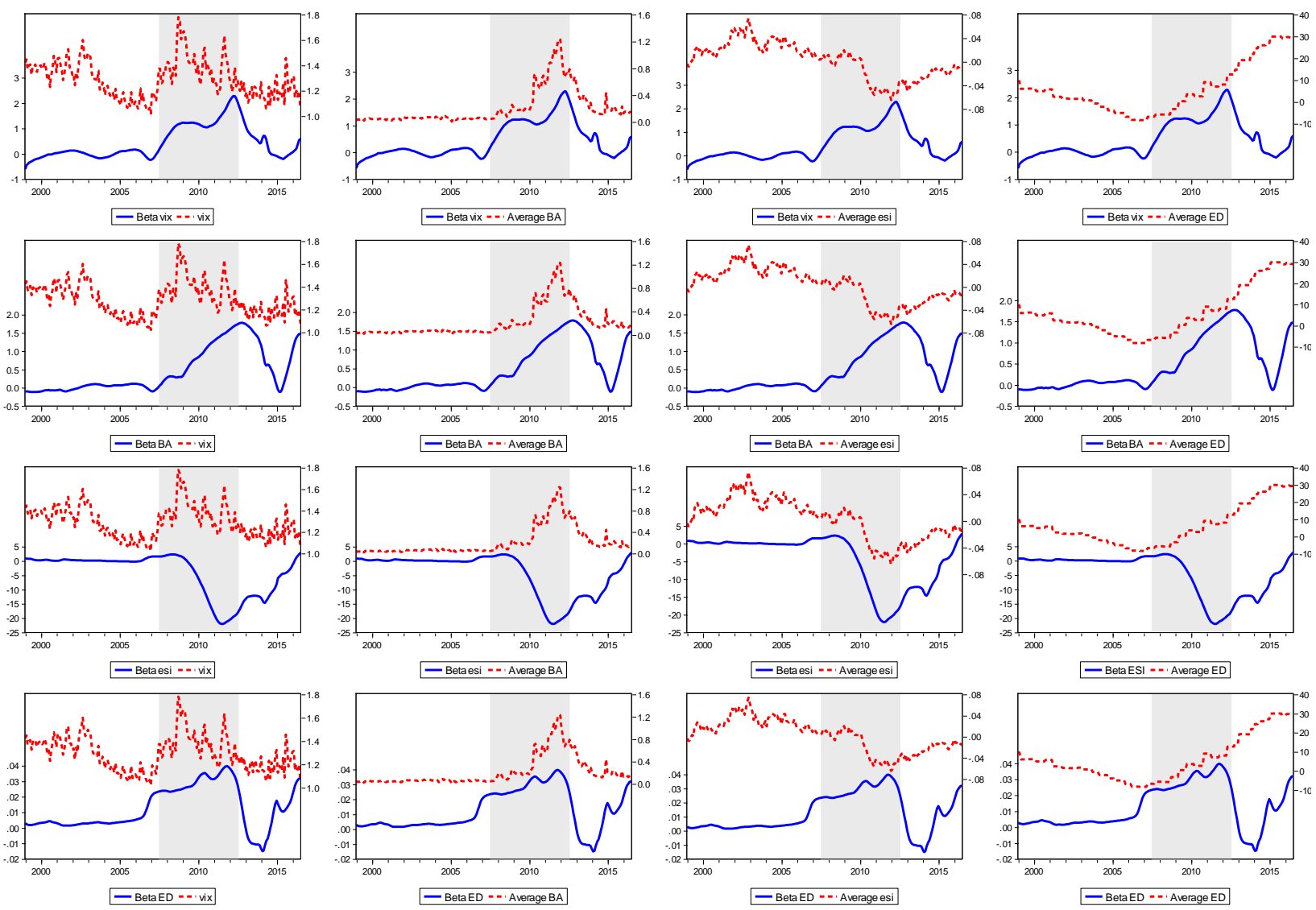

Note: This figure plots time-varying panel (TVP) beta coefficients against vix and the average value of the remaining three risk factors (BA, esi and ED) calculated across countries for each time period. The former correspond to non-parametric estimates of Equation (1) over the period January 1999 - July 2016 (211 observations). The estimation bandwidth parameter $(h)$ is set to 0.15 and the bandwidth correction parameter $(\varepsilon)$ to 0.08. The panel includes Austria, Belgium, Finland, France, Ireland, Italy, the Netherlands, Portugal and Spain. The dependent variable is the 10-year government bond yield spread versus Germany. The set of explanatory variables includes the logarithm of the Chicago Board Options Exchange Volatility Index (vix), the bid-ask spread of 10-year government bonds (BA), the logarithm of the Economic Sentiment Index relative to Germany (esi), and the 1-year ahead expected gross government debt to GDP ratio relative to Germany (ED). The shaded area denotes the period July 2007 - July 2012. 


\section{Figure A3: TVP coefficients - Full panel - Using first lag of regressors}
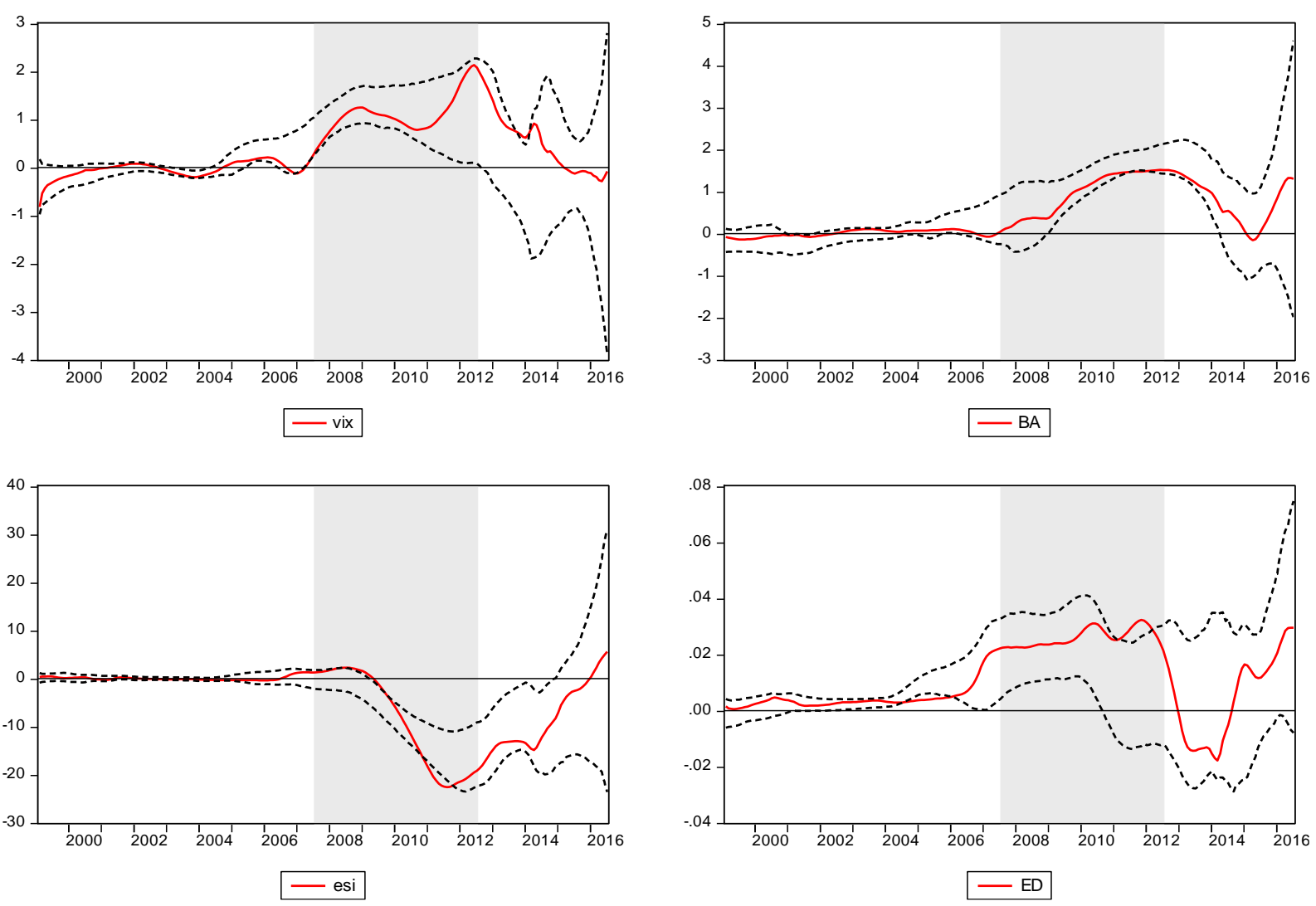

Note: This figure plots non-parametric estimates of Equation (1) over the period January 1999 - July 2016 (211 observations). Time-varying panel (TVP) coefficients and 95\% confidence intervals (dotted lines), calculated using the wild bootstrap method (1000 iterations), are shown. The estimation bandwidth parameter $(h)$ is set to 0.15 and the bandwidth correction parameter $(\varepsilon)$ to 0.08. The panel includes Austria, Belgium, Finland, France, Ireland, Italy, the Netherlands, Portugal and Spain. The dependent variable is the 10-year government bond yield spread versus Germany. The set of explanatory variables includes the lagged logarithm of the Chicago Board Options Exchange Volatility Index (vix), the lagged bid-ask spread of 10-year government bonds (BA), the lagged logarithm of the Economic Sentiment Index relative to Germany (esi), and the lagged 1-year ahead expected gross government debt to GDP ratio relative to Germany (ED). The shaded area denotes the period July 2007 - July 2012. 
Figure A4: TVP coefficients - Full panel - Alternative bandwidth parameters
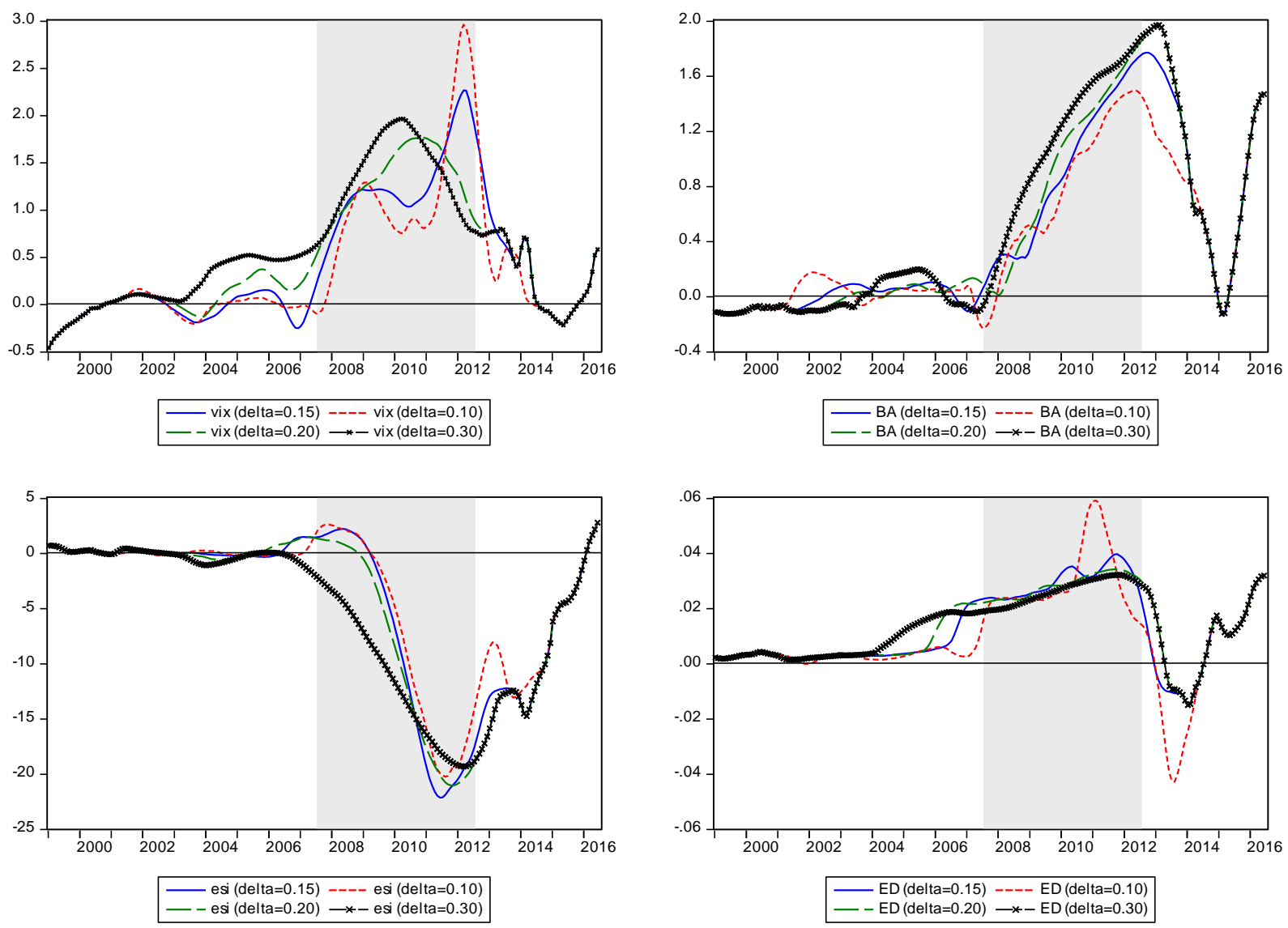

Note: This figure plots non-parametric estimates of Equation (1) over the period January 1999 - July 2016 (211 observations), using four alternative values for the bandwidth parameter: $h=0.15,0.10,0.20$ and 0.30 . In all cases, the bandwidth correction parameter $(\varepsilon)$ is set to 0.08 . Time-varying panel (TVP) coefficients and $95 \%$ confidence intervals (dotted lines), calculated using the wild bootstrap method (1000 iterations), are shown. The panel includes Austria, Belgium, Finland, France, Ireland, Italy, the Netherlands, Portugal and Spain. The dependent variable is the 10-year government bond yield spread versus Germany. The set of explanatory variables includes the logarithm of the Chicago Board Options Exchange Volatility Index (vix), the bid-ask spread of 10year government bonds (BA), the logarithm of the Economic Sentiment Index relative to Germany (esi), and the 1 -year ahead expected gross government debt to GDP ratio relative to Germany (ED). The shaded area denotes the period July 2007 - July 2012. 
Figure A5: TVP coefficients - Full panel - Alternative bandwidth correction parameters
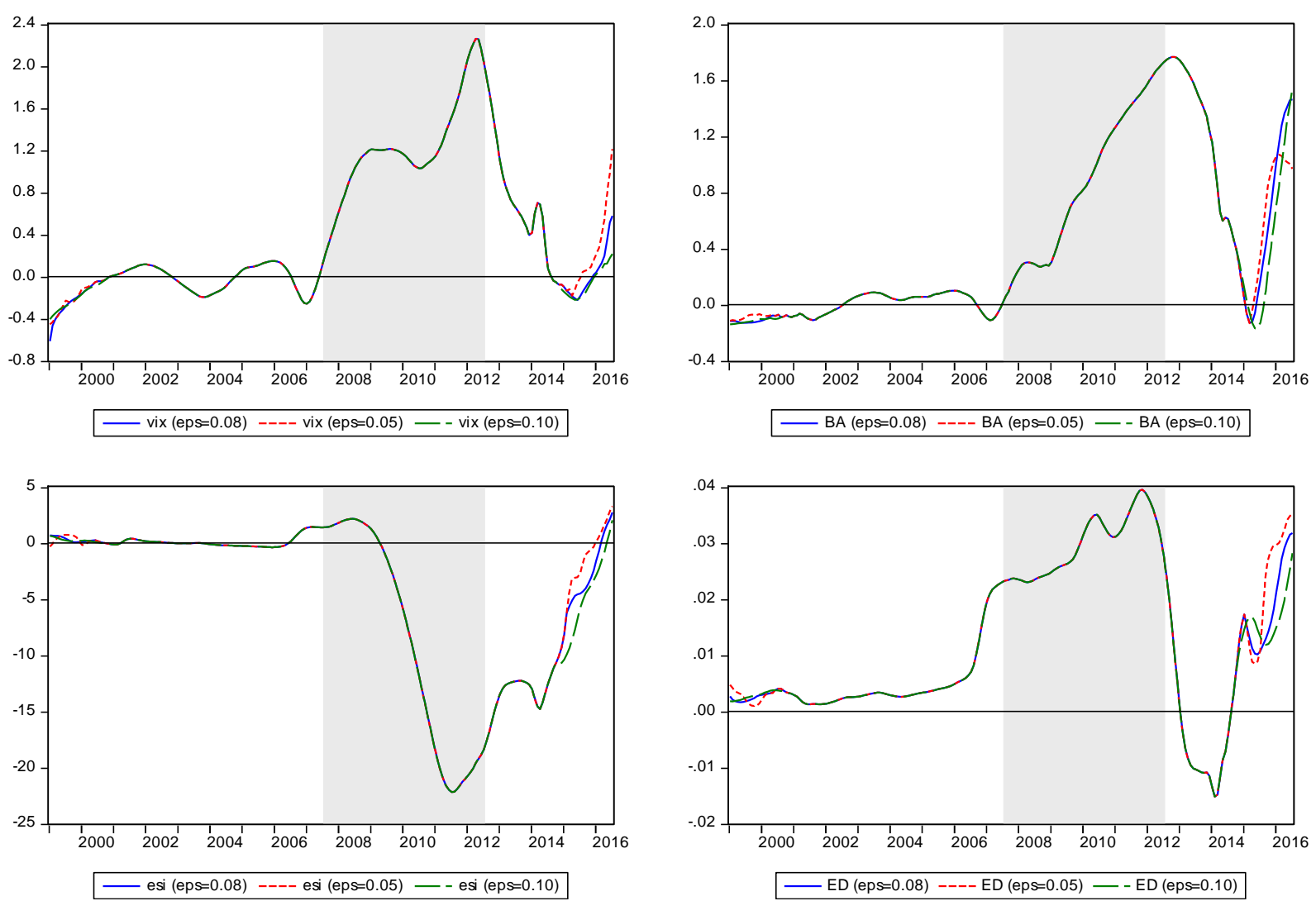

Note: This figure plots non-parametric estimates of Equation (1) over the period January 1999 - July 2016 (211 observations), using three alternative values for the bandwidth correction parameter: $\varepsilon=0.08,0.05$ and 0.10 . In all cases, the bandwidth parameter $(h)$ is set to 0.15 . Time-varying panel (TVP) coefficients and $95 \%$ confidence intervals (dotted lines), calculated using the wild bootstrap method (1000 iterations), are shown. The panel includes Austria, Belgium, Finland, France, Ireland, Italy, the Netherlands, Portugal and Spain. The dependent variable is the 10-year government bond yield spread versus Germany. The set of explanatory variables includes the logarithm of the Chicago Board Options Exchange Volatility Index (vix), the bid-ask spread of 10-year government bonds (BA), the logarithm of the Economic Sentiment Index relative to Germany (esi), and the 1year ahead expected gross government debt to GDP ratio relative to Germany (ED). The shaded area denotes the period July 2007 - July 2012. 
Figure A6: TVP coefficients - Core countries - Using orthogonalized bid-ask spread
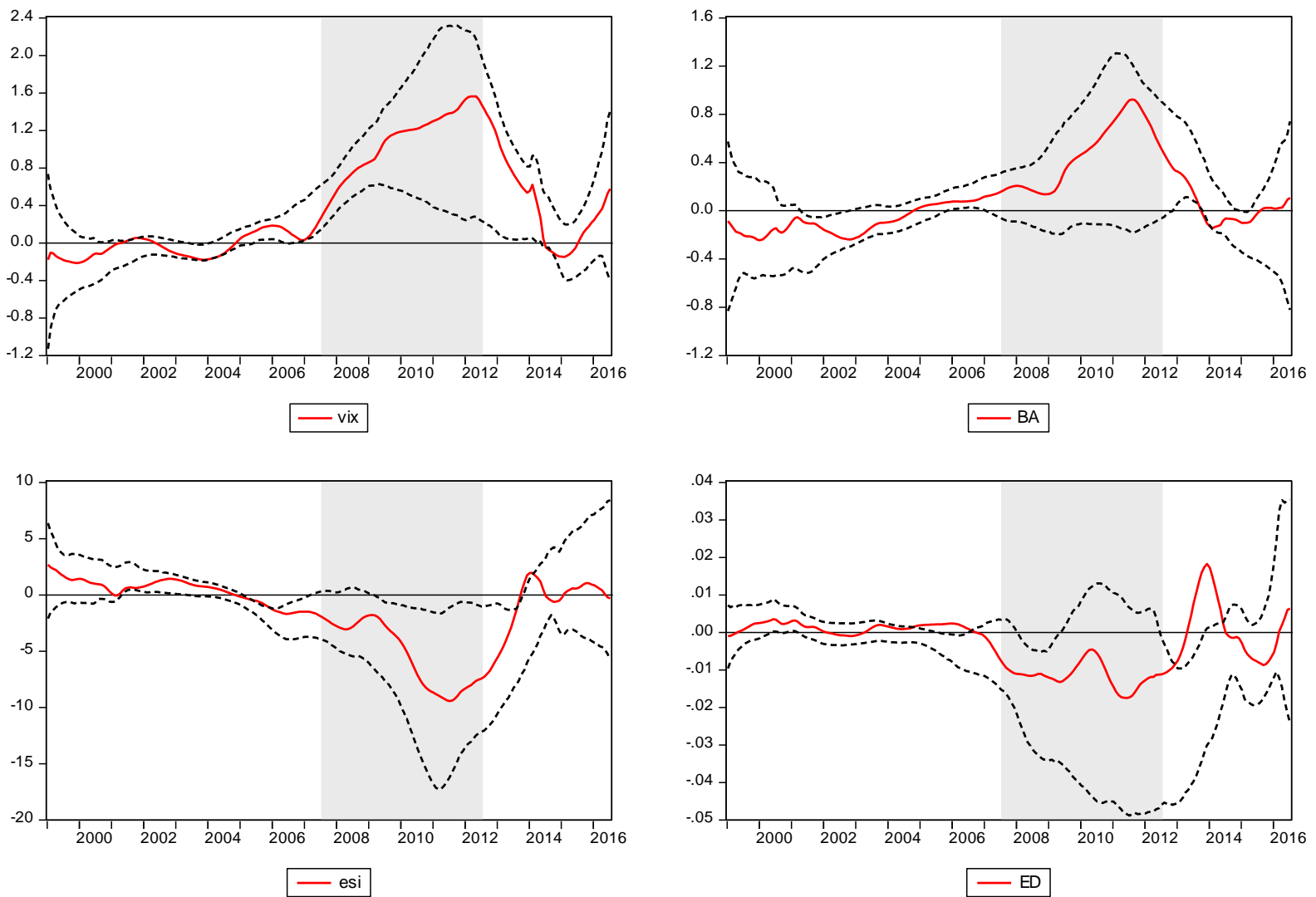

Note: This figure plots non-parametric estimates of Equation (1) over the period January 1999 - July 2016 (211 observations). Time-varying panel (TVP) coefficients and 95\% confidence intervals (dotted lines), calculated using the wild bootstrap method (1000 iterations), are shown. The estimation bandwidth parameter $(h)$ is set to 0.15 and the bandwidth correction parameter $(\varepsilon)$ to 0.08. The panel includes Austria, Belgium, Finland, France and the Netherlands. The dependent variable is the 10-year government bond yield spread versus Germany. The set of explanatory variables includes the logarithm of the Chicago Board Options Exchange Volatility Index (vix), the orthogonalized bid-ask spread of 10-year government bonds (BA), the logarithm of the Economic Sentiment Index relative to Germany (esi), and the 1-year ahead expected gross government debt to GDP ratio relative to Germany (ED). The orthogonalized BA series correspond to the residuals from a fixed effects panel regression of BA on vix, esi and ED. The shaded area denotes the period July 2007 - July 2012. 


\section{Figure A7: TVP coefficients - Periphery countries - Using orthogonalized bid-ask spread}
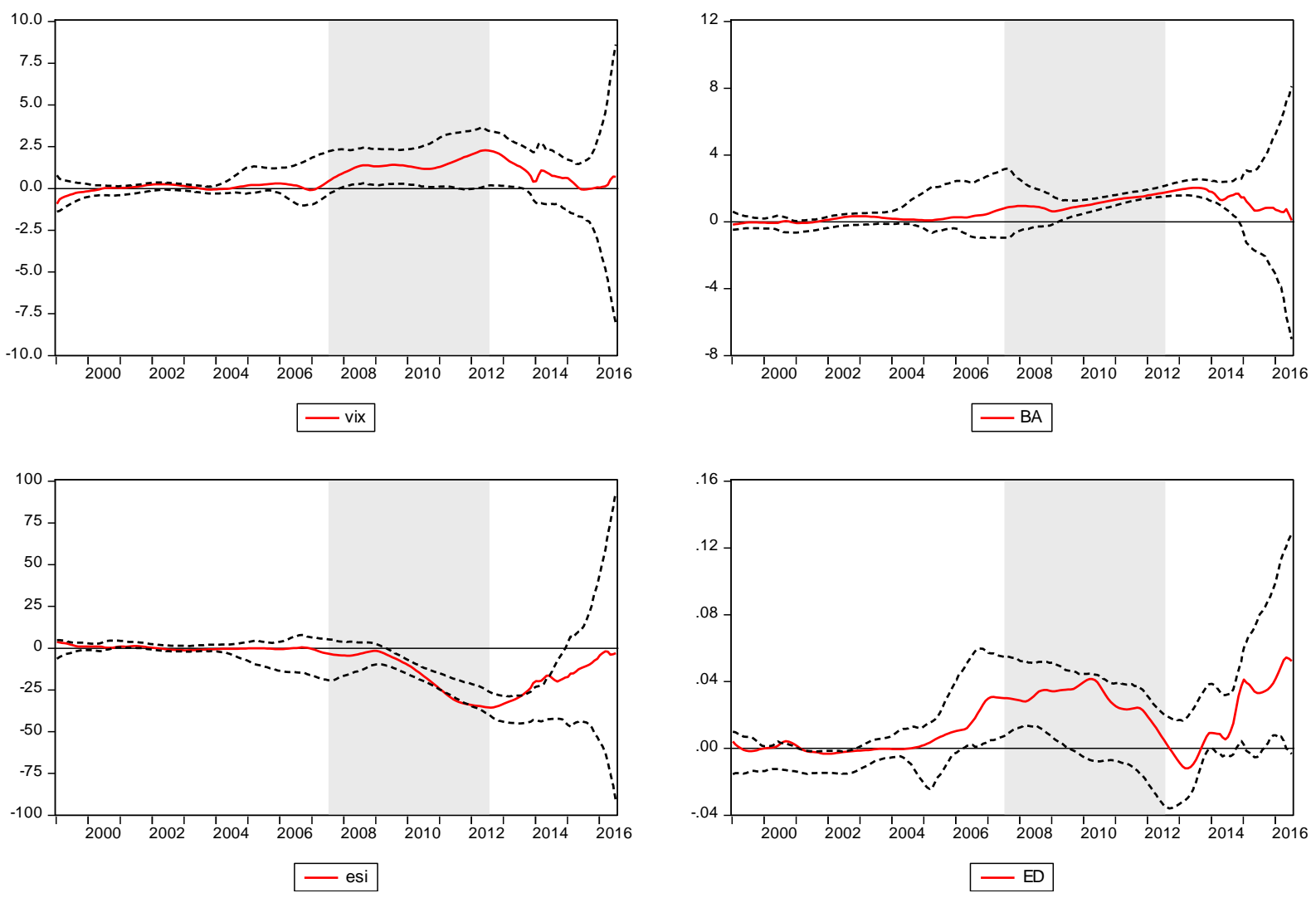

Note: This figure plots non-parametric estimates of Equation (1) over the period January 1999 - July 2016 (211 observations). Time-varying panel (TVP) coefficients and 95\% confidence intervals (dotted lines), calculated using the wild bootstrap method (1000 iterations), are shown. The estimation bandwidth parameter $(h)$ is set to 0.15 and the bandwidth correction parameter $(\varepsilon)$ to 0.08 . The panel includes Ireland, Italy, Portugal and Spain. The dependent variable is the 10-year government bond yield spread versus Germany. The set of explanatory variables includes the logarithm of the Chicago Board Options Exchange Volatility Index (vix), the orthogonalized bid-ask spread of 10-year government bonds (BA), the logarithm of the Economic Sentiment Index relative to Germany (esi), and the 1-year ahead expected gross government debt to GDP ratio relative to Germany (ED). The orthogonalized BA series correspond to the residuals from a fixed effects panel regression of BA on vix, esi and ED. The shaded area denotes the period July 2007 - July 2012. 
Figure A8: TVP coefficients - Full panel - Replacing expected debt with actual debt
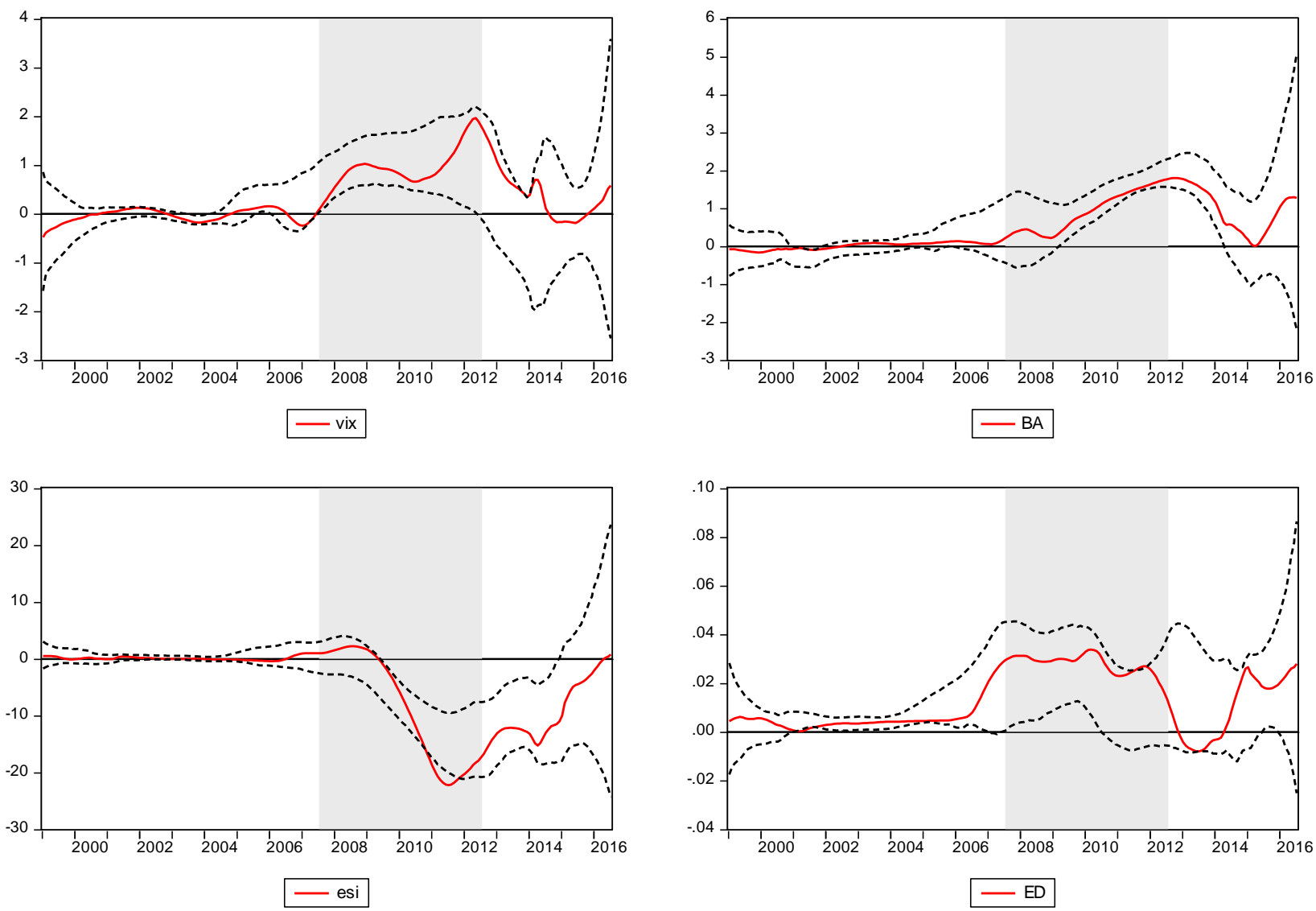

Note: This figure plots non-parametric estimates of Equation (1) over the period January 1999 - July 2016 (211 observations). Time-varying panel (TVP) coefficients and 95\% confidence intervals (dotted lines), calculated using the wild bootstrap method (1000 iterations), are shown. The estimation bandwidth parameter $(h)$ is set to 0.15 and the bandwidth correction parameter $(\varepsilon)$ to 0.08 . The panel includes Austria, Belgium, Finland, France, Ireland, Italy, the Netherlands, Portugal and Spain. The dependent variable is the 10-year government bond yield spread versus Germany. The set of explanatory variables includes the logarithm of the Chicago Board Options Exchange Volatility Index (vix), the bid-ask spread of 10-year government bonds (BA), the logarithm of the Economic Sentiment Index relative to Germany (esi), and the actual gross government debt to GDP ratio relative to Germany (ED). The shaded area denotes the period July 2007 - July 2012. 
Figure A9: TVP coefficients - Non-EMU countries including Switzerland
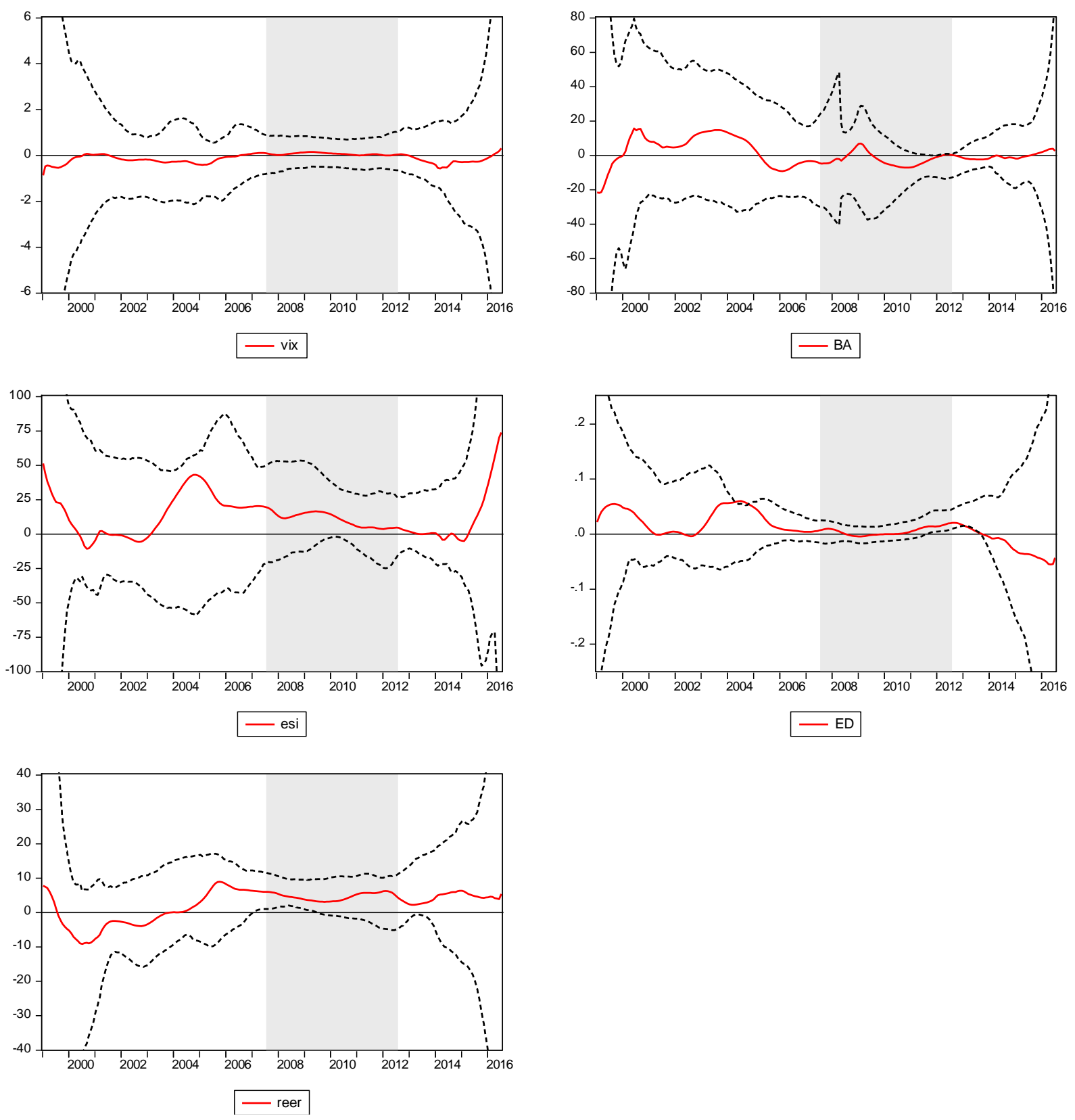

Note: This figure plots non-parametric estimates of Equation (1) over the period January 1999 - July 2016 (211 observations). Time-varying panel (TVP) coefficients and 95\% confidence intervals (dotted lines), calculated using the wild bootstrap method (1000 iterations), are shown. The estimation bandwidth parameter $(h)$ is set to 0.15 and the bandwidth correction parameter $(\varepsilon)$ to 0.08. The panel includes Denmark, Sweden, the United Kingdom and Switzerland. The dependent variable is the 10-year government bond yield spread versus Germany. The set of explanatory variables includes the logarithm of the Chicago Board Options Exchange Volatility Index (vix), the bid-ask spread of 10-year government bonds (BA), the logarithm of the Business Confidence Index relative to Germany (esi), the actual gross government debt to GDP ratio relative to Germany (ED), and the logarithm of the real effective exchange rate (reer). The shaded area denotes the period July 2007 - July 2012. 
Figure A10: TVP coefficients - Non-EMU countries including Switzerland and Norway
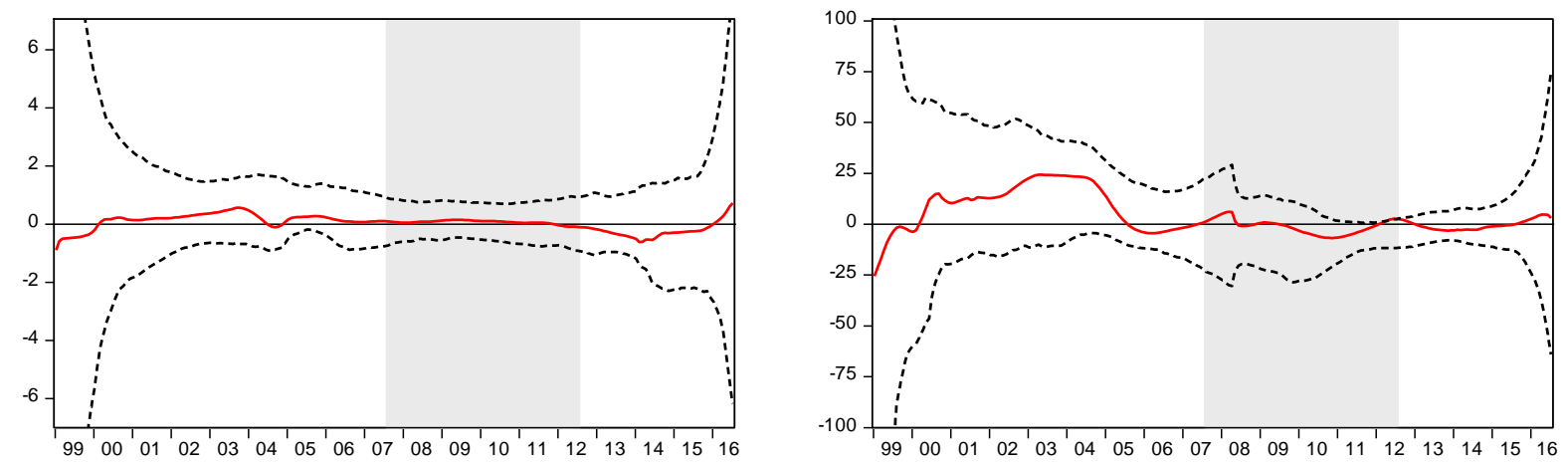

- vix
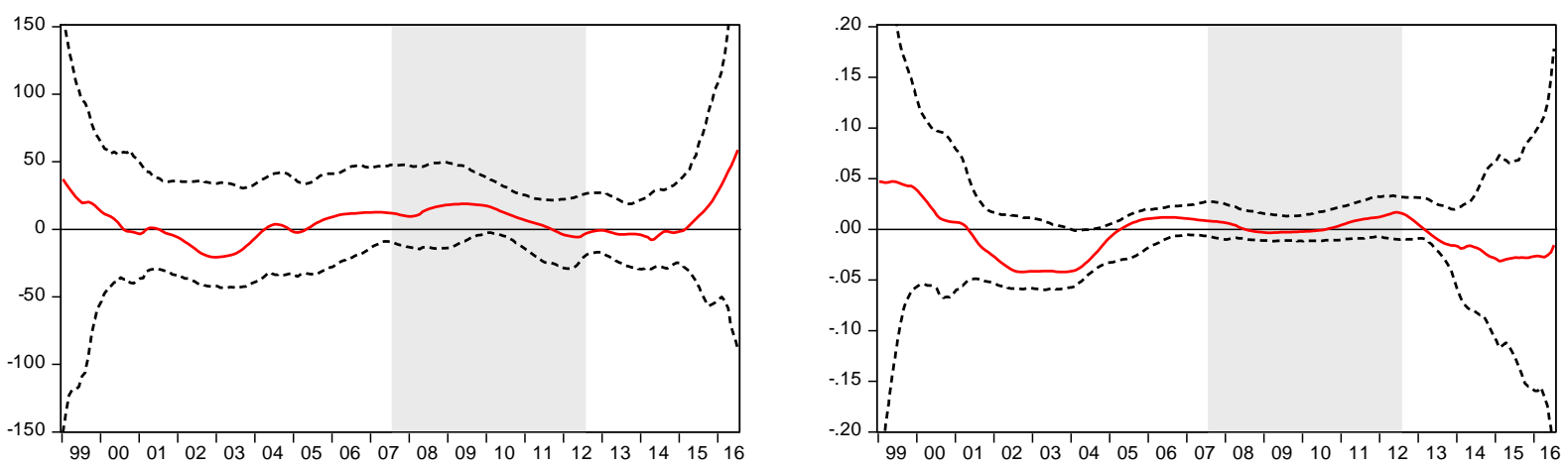

- esi
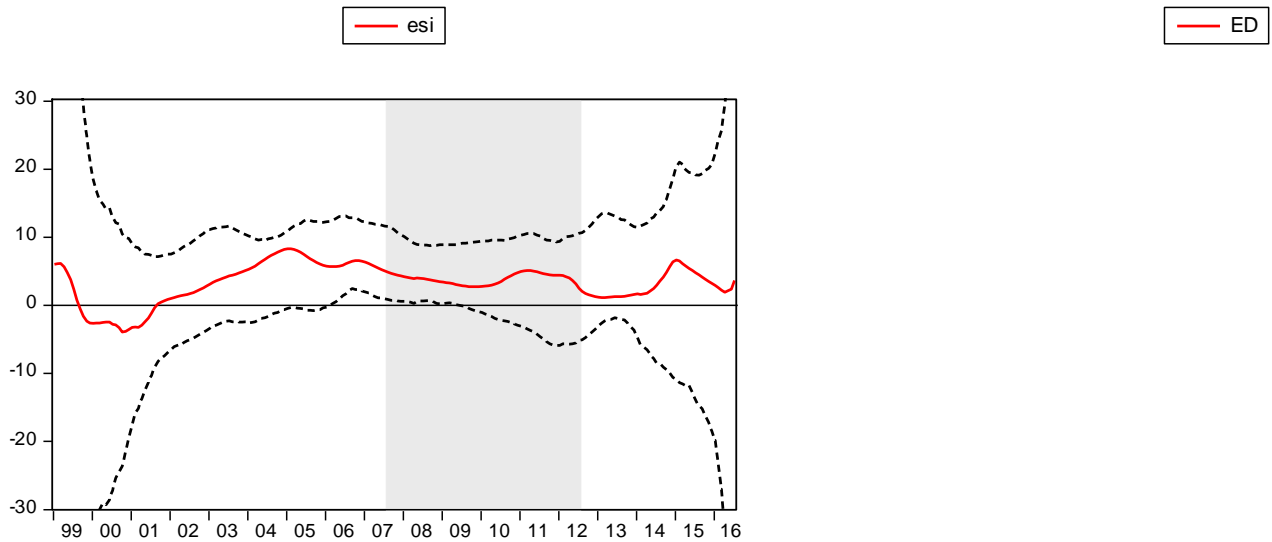

- reer

Note: This figure plots non-parametric estimates of Equation (1) over the period January 1999 - July 2016 (211 observations). Time-varying panel (TVP) coefficients and 95\% confidence intervals (dotted lines), calculated using the wild bootstrap method (1000 iterations), are shown. The estimation bandwidth parameter $(h)$ is set to 0.15 and the bandwidth correction parameter $(\varepsilon)$ to 0.08 . The panel includes Denmark, Sweden, the United Kingdom, Switzerland and Norway. The dependent variable is the 10 -year government bond yield spread versus Germany. The set of explanatory variables includes the logarithm of the Chicago Board Options Exchange Volatility Index (vix), the bid-ask spread of 10-year government bonds (BA), the logarithm of the Business Confidence Index relative to Germany (esi), the actual gross government debt to GDP ratio relative to Germany (ED), and the logarithm of the real effective exchange rate (reer). The shaded area denotes the period July 2007 July 2012. 
Figure A11: First principal component of spreads

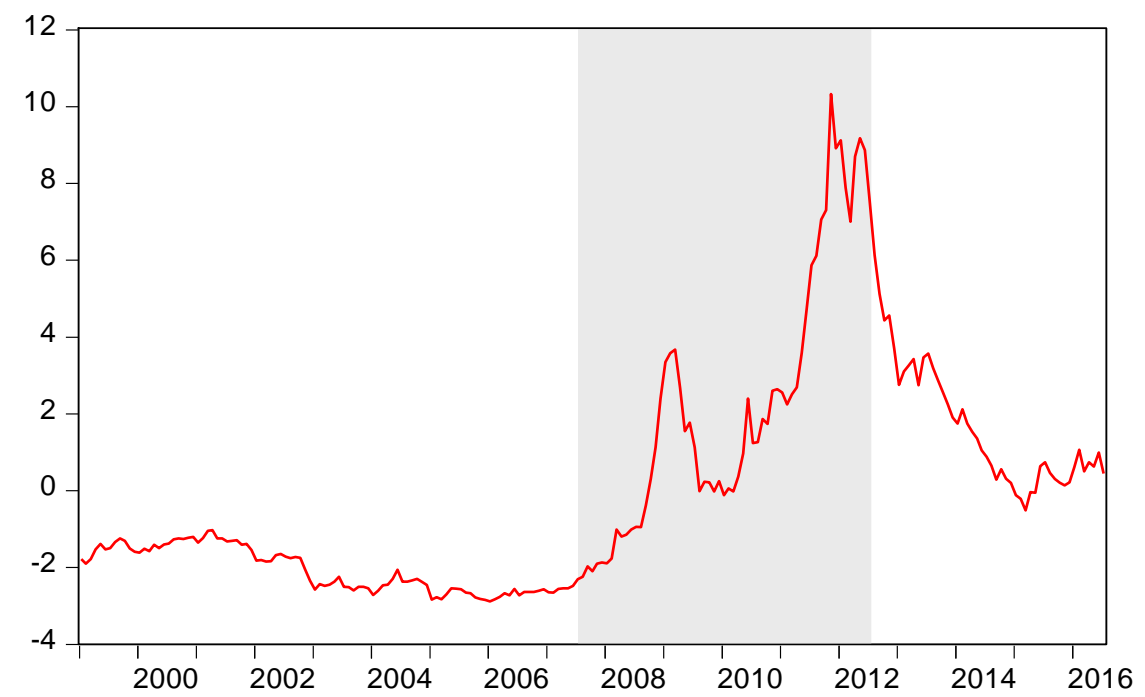

Note: This figure plots the first principal component of spreads, calculated using the full set of countries (including Greece) over the period January 1999 - July 2016 (211 observations). The shaded area denotes the period July 2007 - July 2012.

\section{Figure A12: ECB balance sheet and securities held for monetary policy purposes}

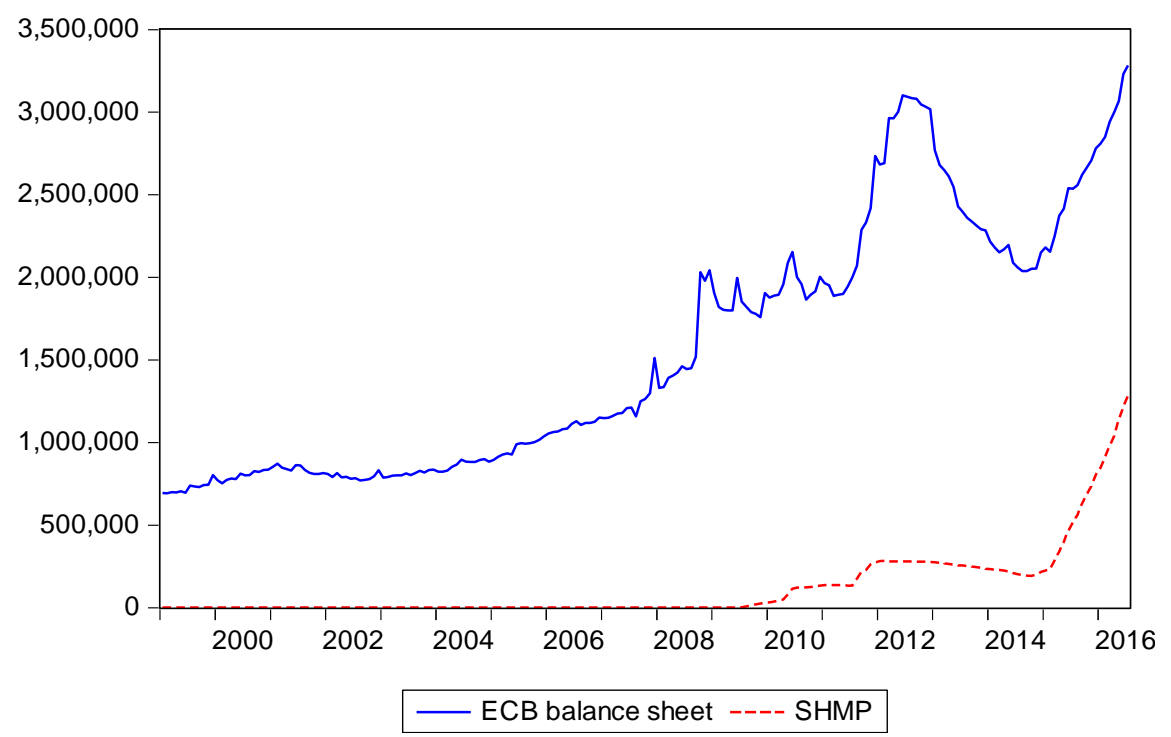

Note: This figure plots the ECB balance sheet size (in millions of euros) over the period January 1999 - July 2016 (211 observations) and the amount of securities held by the ECB for monetary policy purposes (SHMP) over the period July 2009 - July 2016 (85 observations). Source: European Central Bank. 
Table A1: Modelling TVP parameters on ECB policy and bank credit risk - Including Greece

\begin{tabular}{c|c|c|c|c|c|c|c|c}
\hline \hline & \multicolumn{4}{|c|}{ Full panel } & \multicolumn{4}{c}{ Periphery countries } \\
\hline & $\beta_{\mathrm{t}}^{\text {vix }}$ & $\beta_{\mathrm{t}}^{\text {BA }}$ & $\beta_{\mathrm{t}}^{\text {esi }}$ & $\beta_{\mathrm{t}}^{\text {ED }}$ & $\beta_{\mathrm{t}}^{\text {vix }}$ & $\beta_{\mathrm{t}}^{\text {BA }}$ & $\beta_{\mathrm{t}}^{\text {esi }}$ & $\beta_{\mathrm{t}}^{\text {ED }}$ \\
\hline Constant & -0.204 & $1.002^{* * *}$ & -2.516 & $0.040^{* * *}$ & -0.563 & $1.862^{* * *}$ & $9.640^{* * *}$ & $0.064^{* * *}$ \\
& $(0.351)$ & $(0.279)$ & $(3.025)$ & $(0.011)$ & $(0.394)$ & $(0.437)$ & $(3.797)$ & $(0.009)$ \\
\hline $\mathrm{D}_{\mathrm{t}}^{\text {OMT }}$ & -0.376 & $1.337^{* * *}$ & $7.489^{* * *}$ & $-0.066^{* * *}$ & -0.248 & $1.775^{* * *}$ & 7.081 & $-0.083^{* * *}$ \\
& $(0.252)$ & $(0.193)$ & $(2.694)$ & $(0.008)$ & $(0.376)$ & $(0.291)$ & $(4.341)$ & $(0.007)$ \\
\hline$\Delta$ shmp $_{\mathrm{t}-1}$ & 0.016 & $-0.042^{*}$ & $1.580^{* * *}$ & $-0.002^{* *}$ & -0.033 & $-0.069^{* *}$ & $1.686^{* *}$ & $-0.003^{* * *}$ \\
& $(0.031)$ & $(0.026)$ & $(0.589)$ & $(0.001)$ & $(0.061)$ & $(0.031)$ & $(0.809)$ & $(0.001)$ \\
\hline$\Delta \mathrm{MRO}_{\mathrm{t}-1}$ & 0.984 & -0.036 & -10.021 & 0.010 & 1.472 & -0.651 & -17.999 & -0.009 \\
& $(1.000)$ & $(0.617)$ & $(11.230)$ & $(0.032)$ & $(1.370)$ & $(1.019)$ & $(18.810)$ & $(0.030)$ \\
\hline $\mathrm{CDS}_{\mathrm{t}-1}$ & $1.465^{* * *}$ & -0.096 & $-12.34^{* * *}$ & $0.021^{* * *}$ & $2.220^{* * *}$ & $-0.654^{* * *}$ & $-22.56^{* * *}$ & $0.011^{* *}$ \\
& $(0.197)$ & $(0.156)$ & $(1.461)$ & $(0.007)$ & $(0.220)$ & $(0.247)$ & $(2.056)$ & $(0.006)$ \\
\hline \hline Adj R $^{2}$ & 0.692 & 0.749 & 0.623 & 0.837 & 0.616 & 0.783 & 0.615 & 0.854 \\
\hline \hline
\end{tabular}

Note: This table presents OLS estimates with heteroscedasticity and autocorrelation consistent standard errors (in parentheses) of Equation (2) over the period August 2009 - July 2016 (84 observations). The dependent variable is, respectively, the time-varying panel coefficient of Equation (1) associated with the logarithm of the Chicago Board Options Exchange Volatility Index $\left(\beta_{\mathrm{t}}^{\mathrm{vix}}\right)$, the bid-ask spread of 10 -year government bonds $\left(\beta_{\mathrm{t}}^{\mathrm{BA}}\right)$, the logarithm of the Economic Sentiment Index relative to Germany $\left(\beta_{\mathrm{t}}^{\text {esi }}\right)$, and the 1-year ahead expected gross government debt to GDP ratio relative to Germany $\left(\beta_{\mathrm{t}}^{\mathrm{ED}}\right)$. The set of explanatory variables includes a dummy variable that is equal to 1 since August 2012 and 0 otherwise $\left(\mathrm{D}_{\mathrm{t}}{ }^{\mathrm{OMT}}\right)$, the lagged first difference of the logarithm of securities held for monetary policy purposes by the ECB $\left(\Delta \operatorname{shmp}_{\mathrm{t}-1}\right)$, the first difference of the ECB main refinancing operations rate $\left(\triangle \mathrm{MRO}_{\mathrm{t}-1}\right)$, and the lagged European banking sector senior subordination CDS index $\left(\mathrm{CDS}_{\mathrm{t}-1}\right)$. The full panel includes Austria, Belgium, Finland, France, Greece, Ireland, Italy, the Netherlands, Portugal and Spain. The panel of periphery countries includes Greece, Ireland, Italy, Portugal and Spain. *, **, $* * *$ indicate statistical significance at the $10 \%, 5 \%$ and $1 \%$ level, respectively. 
Table A2: Modelling TVP parameters on ECB policy and bank credit risk - Using orthogonalized bid-ask spread

\section{Panel A: Full panel}

\begin{tabular}{|c|c|c|c|c|c|c|c|c|c|c|c|c|}
\hline & \multicolumn{3}{|c|}{$\beta_{\mathrm{t}}^{\mathrm{vix}}$} & \multicolumn{3}{|c|}{$\beta_{\mathrm{t}}^{\mathrm{BA}}$} & \multicolumn{3}{|c|}{$\beta_{\mathrm{t}}^{\mathrm{esi}}$} & \multicolumn{3}{|c|}{$\beta_{\mathrm{t}}^{\mathrm{ED}}$} \\
\hline & (1) & (2) & (3) & (1) & (2) & $(3)$ & (1) & $(2)$ & (3) & (1) & (2) & (3) \\
\hline Constant & $\begin{array}{c}1.925^{* * *} \\
(0.173)\end{array}$ & $\begin{array}{l}1.961^{* * *} \\
(0.173)\end{array}$ & $\begin{array}{c}0.256 \\
(0.249) \\
\end{array}$ & $\begin{array}{c}1.267^{\text {**** }} \\
(0.083)\end{array}$ & $\begin{array}{l}1.302^{* * *} \\
(0.082)\end{array}$ & $\begin{array}{c}0.238 \\
(0.213)\end{array}$ & $\begin{array}{c}-21.175^{* * *} \\
(2.471)\end{array}$ & $\begin{array}{c}-22.150^{* * *} \\
(2.352)\end{array}$ & $\begin{array}{c}-5.720^{* * *} \\
(2.664)\end{array}$ & $\begin{array}{c}0.047^{* * * *} \\
(0.002)\end{array}$ & $\begin{array}{c}0.047^{* * * *} \\
(0.002)\end{array}$ & $\begin{array}{c}0.036^{* * * *} \\
(0.004)\end{array}$ \\
\hline $\mathrm{D}_{\mathrm{t}}^{\mathrm{OMT}}$ & $\begin{array}{c}-1.226^{* * *} \\
(0.277)\end{array}$ & $\begin{array}{c}-1.301^{* * * *} \\
(0.278)\end{array}$ & $\begin{array}{c}-0.651^{* * * *} \\
(0.187)\end{array}$ & $\begin{array}{l}-0.453^{*} \\
(0.258)\end{array}$ & $\begin{array}{c}-0.518^{* *} \\
(0.260)\end{array}$ & $\begin{array}{l}-0.113 \\
(0.212)\end{array}$ & $\begin{array}{l}8.709^{* *} \\
(3.550)\end{array}$ & $\begin{array}{c}9.917^{* * *} \\
(3.430)\end{array}$ & $\begin{array}{c}3.654 \\
(2.270) \\
\end{array}$ & $\begin{array}{c}-0.034^{* * * *} \\
(0.004)\end{array}$ & $\begin{array}{c}-0.035^{* * * *} \\
(0.004)\end{array}$ & $\begin{array}{c}-0.030^{* * * *} \\
(0.004)\end{array}$ \\
\hline$\Delta \operatorname{shmp}_{\mathrm{t}-1}$ & - & $\begin{array}{c}-0.105^{* *} \\
(0.052) \\
\end{array}$ & $\begin{array}{c}0.011 \\
(0.022) \\
\end{array}$ & - & $\begin{array}{c}-0.100^{* *} \\
(0.047)\end{array}$ & $\begin{array}{l}-0.027 \\
(0.031) \\
\end{array}$ & - & $\begin{array}{c}2.797^{* * * *} \\
(0.772) \\
\end{array}$ & $\begin{array}{c}1.675^{* * * *} \\
(0.548)\end{array}$ & - & $\begin{array}{l}-0.001^{* * * *} \\
(0.0003)\end{array}$ & $\begin{array}{c}-0.0006 \\
(0.0004) \\
\end{array}$ \\
\hline$\Delta \mathrm{MRO}_{\mathrm{t}-1}$ & - & $\begin{array}{c}-1.987^{* *} \\
(0.974)\end{array}$ & $\begin{array}{c}0.473 \\
(0.674) \\
\end{array}$ & - & $\begin{array}{c}-1.600^{* *} \\
(0.715)\end{array}$ & $\begin{array}{c}-0.065 \\
(0.809) \\
\end{array}$ & - & $\begin{array}{c}15.311 \\
(11.527)\end{array}$ & $\begin{array}{l}-8.394 \\
(9.646)\end{array}$ & - & $\begin{array}{l}-0.001 \\
(0.018)\end{array}$ & $\begin{array}{c}0.015 \\
(0.011)\end{array}$ \\
\hline $\mathrm{CDS}_{\mathrm{t}-1}$ & - & - & $\begin{array}{c}1.010^{* * * *} \\
(0.134)\end{array}$ & - & - & $\begin{array}{c}0.630^{* * * *} \\
(0.131)\end{array}$ & - & - & $\begin{array}{c}-9.737^{* * * *} \\
(1.364)\end{array}$ & - & - & $\begin{array}{c}0.007^{* * *} \\
(0.002)\end{array}$ \\
\hline Adj $R^{2}$ & 0.419 & 0.439 & 0.801 & 0.087 & 0.107 & 0.338 & 0.192 & 0.250 & 0.561 & 0.700 & 0.696 & 0.725 \\
\hline
\end{tabular}

Panel B: Core countries

\begin{tabular}{|c|c|c|c|c|c|c|c|c|c|c|c|c|}
\hline & \multicolumn{3}{|c|}{$\beta_{\mathrm{t}}^{\mathrm{vix}}$} & \multicolumn{3}{|c|}{$\beta_{\mathrm{t}}^{\mathrm{BA}}$} & \multicolumn{3}{|c|}{$\beta_{\mathrm{t}}^{\mathrm{esi}}$} & \multicolumn{3}{|c|}{$\beta_{\mathrm{t}}^{\mathrm{ED}}$} \\
\hline & (1) & $(2)$ & (3) & (1) & $(2)$ & (3) & (1) & $(2)$ & (3) & (1) & (2) & (3) \\
\hline Constant & $\begin{array}{c}1.321^{* * *} \\
(0.044)\end{array}$ & $\begin{array}{c}1.336^{* * * *} \\
(0.043)\end{array}$ & $\begin{array}{c}0.535^{* * *} \\
(0.178) \\
\end{array}$ & $\begin{array}{c}0.653^{* * *} \\
(0.054)\end{array}$ & $\begin{array}{c}0.670^{* * *} \\
(0.053)\end{array}$ & $\begin{array}{c}0.318^{* * *} \\
(0.060)\end{array}$ & $\begin{array}{c}-7.298^{* * * *} \\
(0.644)\end{array}$ & $\begin{array}{c}-7.553^{* * * *} \\
(0.600) \\
\end{array}$ & $\begin{array}{c}-2.539^{* * *} \\
(1.023)\end{array}$ & $\begin{array}{c}-0.012^{* * * *} \\
(0.001)\end{array}$ & $\begin{array}{c}-0.012^{* * * *} \\
(0.001)\end{array}$ & $\begin{array}{c}-0.007^{* * *} \\
(0.003)\end{array}$ \\
\hline $\mathrm{D}_{\mathrm{t}}^{\mathrm{OMT}}$ & $\begin{array}{c}-0.902^{* * * *} \\
(0.135)\end{array}$ & $\begin{array}{c}-0.932^{* * * *} \\
(0.135)\end{array}$ & $\begin{array}{c}-0.626^{* * * *} \\
(0.122)\end{array}$ & $\begin{array}{c}-0.608^{* * * *} \\
(0.072)\end{array}$ & $\begin{array}{c}-0.625^{* * *} \\
(0.069)\end{array}$ & $\begin{array}{c}-0.491^{\text {**** }}(0.049) \\
\end{array}$ & $\begin{array}{c}6.301^{* * *} \\
(0.970)\end{array}$ & $\begin{array}{c}6.569^{* * *} \\
(0.924) \\
\end{array}$ & $\begin{array}{c}4.658^{* * *} \\
(0.837)\end{array}$ & $\begin{array}{c}0.012^{* * *} \\
(0.003)\end{array}$ & $\begin{array}{c}0.011^{\text {**** }}(0.003) \\
\end{array}$ & $\begin{array}{c}0.010^{* * * *} \\
(0.003)\end{array}$ \\
\hline$\Delta \operatorname{shmp}_{\mathrm{t}-1}$ & - & $\begin{array}{c}-0.044^{* *} \\
(0.017)\end{array}$ & $\begin{array}{c}0.011 \\
(0.012) \\
\end{array}$ & - & $\begin{array}{c}-0.048^{* * * *} \\
(0.011)\end{array}$ & $\begin{array}{c}-0.024^{* * * *} \\
(0.007)\end{array}$ & - & $\begin{array}{c}0.731^{* * *} \\
(0.156)\end{array}$ & $\begin{array}{c}0.388^{* * *} \\
(0.115)\end{array}$ & - & $\begin{array}{c}0.000 \\
(0.0002) \\
\end{array}$ & $\begin{array}{l}-0.0004 \\
(0.0003) \\
\end{array}$ \\
\hline$\Delta \mathrm{MRO}_{\mathrm{t}-1}$ & - & $\begin{array}{c}-0.755 \\
(0.499) \\
\end{array}$ & $\begin{array}{c}0.401 \\
(0.460) \\
\end{array}$ & - & $\begin{array}{c}-0.071 \\
(0.335) \\
\end{array}$ & $\begin{array}{c}0.436^{*} \\
(0.236) \\
\end{array}$ & - & $\begin{array}{c}1.723 \\
(4.010) \\
\end{array}$ & $\begin{array}{l}-5.511^{*} \\
(3.005) \\
\end{array}$ & - & $\begin{array}{c}-0.011 \\
(0.011) \\
\end{array}$ & $\begin{array}{l}-0.018^{*} \\
(0.009) \\
\end{array}$ \\
\hline $\mathrm{CDS}_{\mathrm{t}-1}$ & - & - & $\begin{array}{c}0.475^{* * *} \\
(0.101)\end{array}$ & - & - & $\begin{array}{c}0.208^{* * *} \\
(0.041)\end{array}$ & - & - & $\begin{array}{c}-2.971^{* * *} \\
(0.581)\end{array}$ & - & - & $\begin{array}{l}-0.003 \\
(0.002)\end{array}$ \\
\hline Adj $R^{2}$ & 0.600 & 0.604 & 0.813 & 0.759 & 0.768 & 0.879 & 0.627 & 0.645 & 0.819 & 0.402 & 0.396 & 0.417 \\
\hline
\end{tabular}




\section{Panel C: Periphery countries}

\begin{tabular}{|c|c|c|c|c|c|c|c|c|c|c|c|c|}
\hline & \multicolumn{3}{|c|}{$\beta_{\mathrm{t}}^{\text {vix }}$} & \multicolumn{3}{|c|}{$\overline{\beta_{\mathrm{t}}^{\mathrm{BA}}}$} & \multicolumn{3}{|c|}{$\beta_{\mathrm{t}}^{\mathrm{esi}}$} & \multicolumn{3}{|c|}{$\bar{\beta}_{\mathrm{t}}^{\mathrm{ED}}$} \\
\hline & (1) & (2) & (3) & (1) & (2) & (3) & (1) & (2) & (3) & (1) & $(2)$ & (3) \\
\hline Constant & $\begin{array}{l}1.530^{* * *} \\
(0.121)\end{array}$ & $\begin{array}{l}1.549^{* * *} \\
(0.124)\end{array}$ & $\begin{array}{c}0.255 \\
(0.254)\end{array}$ & $\begin{array}{l}1.261^{* * *} \\
(0.086)\end{array}$ & $\begin{array}{l}1.296^{* * *} \\
(0.082)\end{array}$ & $\begin{array}{c}0.547^{* * *} \\
(0.127)\end{array}$ & $\begin{array}{c}-23.850^{* * *} \\
(3.232)\end{array}$ & $\begin{array}{c}-24.968^{* * *} \\
(3.116)\end{array}$ & $\begin{array}{l}-1.439 \\
(2.457)\end{array}$ & $\begin{array}{c}0.027^{* * *} \\
(0.003)\end{array}$ & $\begin{array}{l}0.026^{* * *} \\
(0.003)\end{array}$ & $\begin{array}{c}0.057^{* * *} \\
(0.005)\end{array}$ \\
\hline $\mathrm{D}_{\mathrm{t}}^{\mathrm{OMT}}$ & $\begin{array}{c}-0.756^{* * *} \\
(0.218)\end{array}$ & $\begin{array}{c}-0.798^{* * *} \\
(0.222)\end{array}$ & $\begin{array}{l}-0.305 \\
(0.188)\end{array}$ & $\begin{array}{c}0.070 \\
(0.174)\end{array}$ & $\begin{array}{c}0.018 \\
(0.173)\end{array}$ & $\begin{array}{l}0.303^{* *} \\
(0.131)\end{array}$ & $\begin{array}{c}4.611 \\
(4.268)\end{array}$ & $\begin{array}{c}6.017 \\
(4.170)\end{array}$ & $\begin{array}{l}-2.952 \\
(2.277)\end{array}$ & $\begin{array}{l}-0.009 \\
(0.007)\end{array}$ & $\begin{array}{l}-0.008 \\
(0.007)\end{array}$ & $\begin{array}{c}-0.019^{* * * *} \\
(0.005)\end{array}$ \\
\hline$\Delta \mathrm{shmp}_{\mathrm{t}-1}$ & - & $\begin{array}{c}-0.053 \\
(0.038)\end{array}$ & $\begin{array}{c}0.035^{*} \\
(0.018)\end{array}$ & - & $\begin{array}{c}-0.010^{* * * *} \\
(0.035)\end{array}$ & $\begin{array}{c}-0.048^{* *} \\
(0.023)\end{array}$ & - & $\begin{array}{c}3.209^{* * *} \\
(0.878)\end{array}$ & $\begin{array}{l}1.601^{* * *} \\
(0.487)\end{array}$ & - & $\begin{array}{l}0.002^{* *} \\
(0.001)\end{array}$ & $\begin{array}{c}0.0002 \\
(0.0008)\end{array}$ \\
\hline$\Delta \mathrm{MRO}_{\mathrm{t}-1}$ & - & $\begin{array}{l}-1.201 \\
(0.817)\end{array}$ & $\begin{array}{c}0.665 \\
(0.595)\end{array}$ & - & $\begin{array}{c}-1.014^{* *} \\
(0.453)\end{array}$ & $\begin{array}{c}0.067 \\
(0.517)\end{array}$ & - & $\begin{array}{c}18.534 \\
(14.082)\end{array}$ & $\begin{array}{c}-15.416 \\
(9.619)\end{array}$ & - & $\begin{array}{c}0.033^{*} \\
(0.017)\end{array}$ & $\begin{array}{l}-0.013 \\
(0.020)\end{array}$ \\
\hline $\mathrm{CDS}_{\mathrm{t}-1}$ & - & - & $\begin{array}{c}0.766^{* * *} \\
(0.133)\end{array}$ & - & - & $\begin{array}{l}0.444^{* * * *} \\
(0.079)\end{array}$ & - & - & $\begin{array}{c}-13.944^{* * *} \\
(1.291)\end{array}$ & - & - & $\begin{array}{c}-0.018^{* * * *} \\
(0.003)\end{array}$ \\
\hline $\operatorname{Adj} R^{2}$ & 0.295 & 0.298 & 0.687 & 0.000 & 0.032 & 0.318 & 0.036 & 0.101 & 0.649 & 0.048 & 0.055 & 0.379 \\
\hline
\end{tabular}

Note: This table presents OLS estimates with heteroscedasticity and autocorrelation consistent standard errors (in parentheses) of Equation (2) over the period August 2009 July 2016 (84 observations). The dependent variable is, respectively, the time-varying panel coefficient of Equation (1) associated with the logarithm of the Chicago Board Options Exchange Volatility Index $\left(\beta_{\mathrm{t}}{ }^{\mathrm{vix}}\right)$, the orthogonalized bid-ask spread of 10-year government bonds $\left(\beta_{\mathrm{t}}{ }^{\mathrm{BA}}\right)$, the logarithm of the Economic Sentiment Index relative to Germany $\left(\beta_{\mathrm{t}}^{\text {esi }}\right)$, and the 1-year ahead expected gross government debt to GDP ratio relative to Germany $\left(\beta_{\mathrm{t}}^{\mathrm{ED}}\right)$. The orthogonalized BA series correspond to the residuals from a fixed effects panel regression of BA on vix, esi and ED. The set of explanatory variables includes a dummy variable that is equal to 1 since August 2012 and 0 otherwise $\left(\mathrm{D}_{\mathrm{t}}{ }^{\mathrm{OMT}}\right)$, the lagged first difference of the logarithm of securities held for monetary policy purposes by the ECB $\left(\Delta\right.$ shmp $\left.\mathrm{t}_{\mathrm{t}-1}\right)$, the first difference of the ECB main refinancing operations rate $\left(\triangle \mathrm{MRO}_{\mathrm{t}-1}\right)$, and the lagged European banking sector senior subordination CDS index $\left(\mathrm{CDS}_{\mathrm{t}-1)}\right)$. The full panel $($ Panel A) includes Austria, Belgium, Finland, France, Ireland, Italy, the Netherlands, Portugal and Spain. The panel of core countries (Panel B) includes Austria, Belgium, Finland, France and the Netherlands. The panel of periphery countries (Panel C) includes Ireland, Italy, Portugal and Spain. *, **, *** indicate statistical significance at the $10 \%, 5 \%$ and $1 \%$ level, respectively. 